\title{
The Professional Development of Primary School Teachers with Leadership Responsibilities in a New Zealand Context
}

\section{MARGARET EMILY HESKETH}

A thesis submitted in partial fulfilment of the requirements for the degree of Master of Education, Victoria University of Wellington 


\begin{abstract}
Middle and senior leaders in primary schools have an important role with significant accountability and responsibility. They are teaching practitioners who have a large influence on the quality of learning that takes place within a school. Middle and senior leaders carry out the majority of the significant conversations about teaching and learning within a school with the teachers they lead. In 2012 the New Zealand Ministry of Education produced a publication reiterating the importance of middle and senior leaders within schools. As part of that publication they identified the need for ongoing professional development and learning for middle and senior leaders to strengthen their effectiveness as leaders. However no suggestions were made in this document as to what this may look like. The purposes of this multiple case study were to explore what professional development and learning were provided to senior and middle leaders primary schools within the greater Wellington area, how effective the principals and senior middle leaders considered the professional development and learning to be, and to identify which factors enabled effective professional development and learning within a school. To answer the research questions data was collected through an online survey, focus groups and individual interviews. The findings indicated that there were two categories of organisation of professional development and learning provided within different schools; unsystematic and systematic. The more effective systematic system involved the identification of the learning needs of the middle and senior leaders through discussion or co-construction of their job descriptions, leading to a mixture of professional development and learning structures that combined sharing, collaboration and reflection to enhance leadership capabilities. In addition regular mentoring allowed for more effective leadership learning. An important factor determining the success of the professional development and learning was the deliberate actions that were carried out by the principal.
\end{abstract}




\section{Acknowledgements}

I would like to acknowledge and thank:

- The New Zealand Ministry of Education for the study award that allowed for the writing of this thesis;

- My supervisor Kate Thornton for her valuable feedback and support;

- My school and principal, for allowing me to pursue this study;

- All the middle and senior leaders and principals who participated in this study;

- Kaye Stannard and Debra Taylor for giving up their valuable time to proofread my thesis. 


\section{Table of contents}

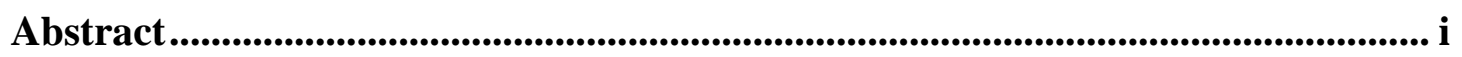

Acknowledgements...................................................................................................

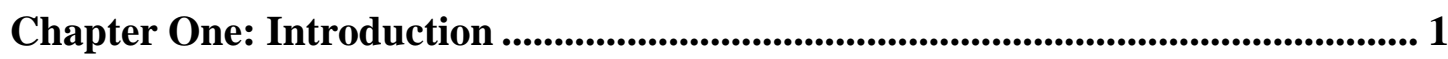

1.1 Overview.....................................................................................................................1

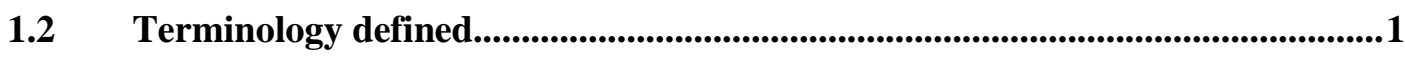

1.1.1 Teachers with leadership responsibilities (TLR) .............................................. 1

1.2.1 Professional development and learning (PDL) .............................................. 1

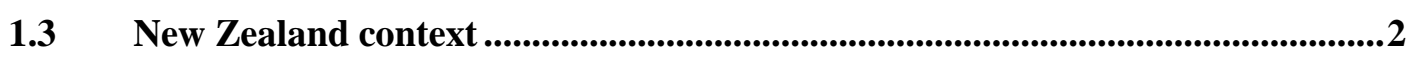

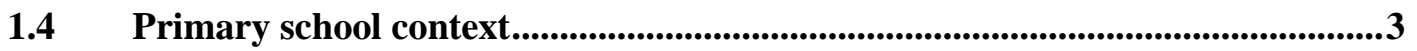

1.5 Significance of study ...........................................................................................................4

1.6 Researcher's perspective .........................................................................................................5

1.7 Research questions ..................................................................................................................5

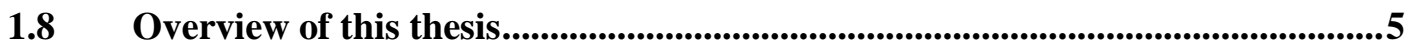

Chapter Two: Review of literature.......................................................................... 7

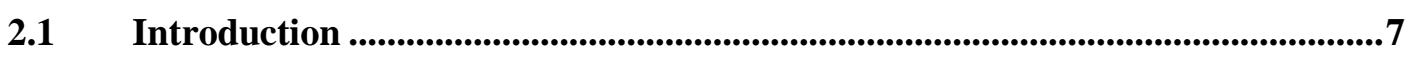

2.2 Types of leadership PDL and their effectiveness ...................................................7

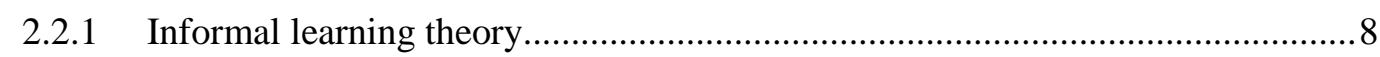

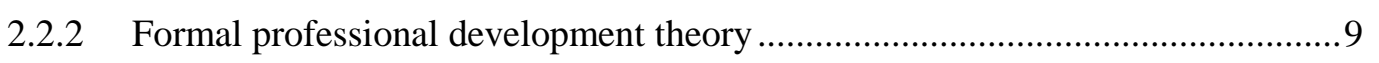

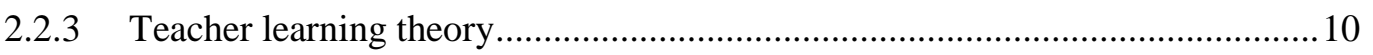

2.2.4 Effectiveness of PDL structures theory ........................................................... 11

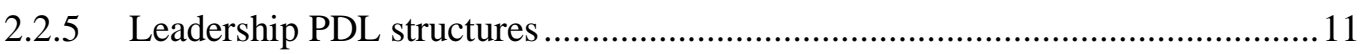

Mentoring and coaching: Formal and informal learning....................................................... 11

Professional learning communities: Deliberative, informal learning ...................................... 13

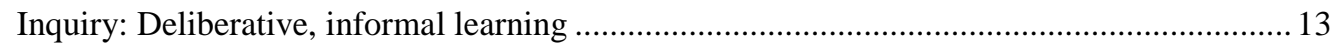

Self-directed learning: Reactive and deliberative, informal learning ...................................... 15

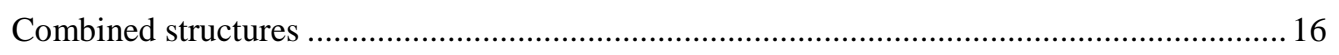

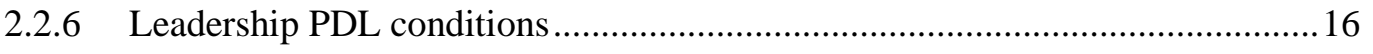

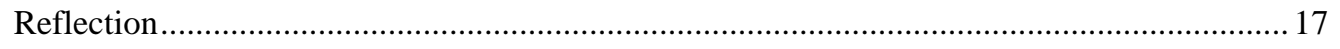

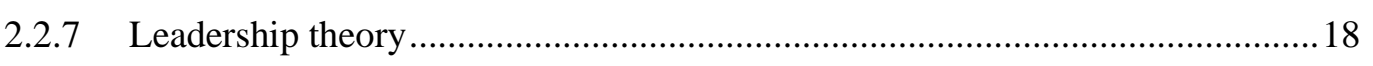

2.2.8 Summary of structures and conditions of leadership PDL ................................ 18

2.3 Issues and challenges for first-time TLRs ...............................................................19

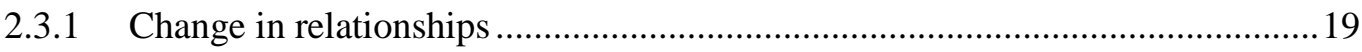

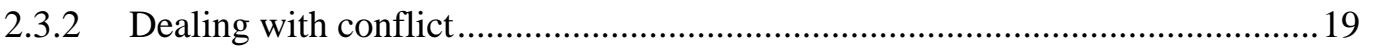

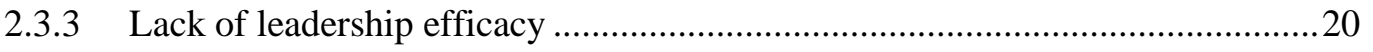


2.3.4 Summary of issues and challenges for first time TLRs.

2.4 Enablers for leadership PDL within a school..................................................21

2.4.1 Contextual factor one: Allocation and structuring of work................................22

2.4.2 Contextual factor two: Encounters and relationships with people at work ........23

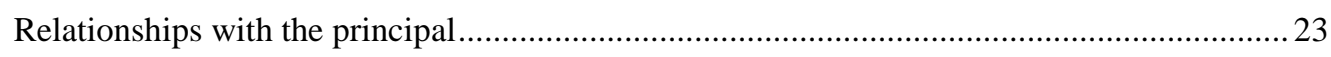

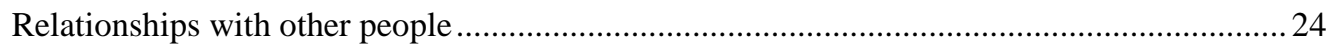

2.4.3 Contextual factor three: Expectations of each person's role, performance and

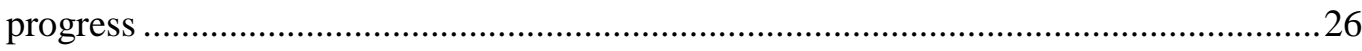

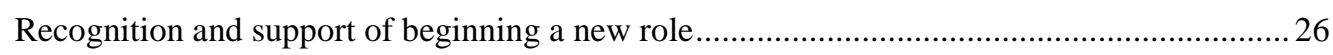

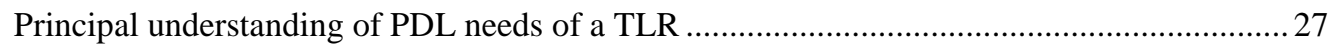

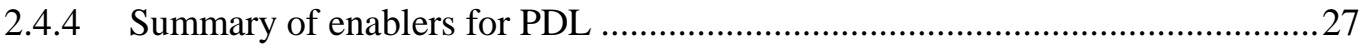

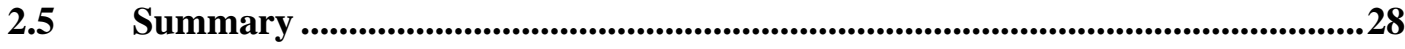

Chapter Three: Methodology and methods............................................................... 29

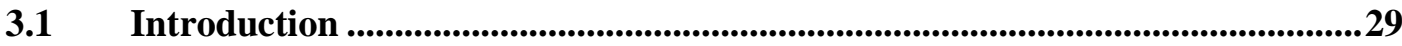

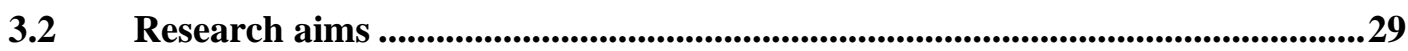

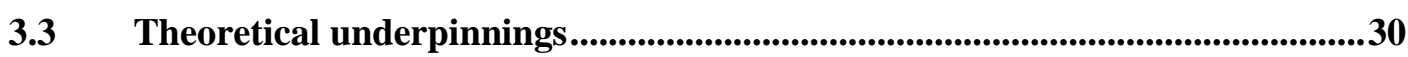

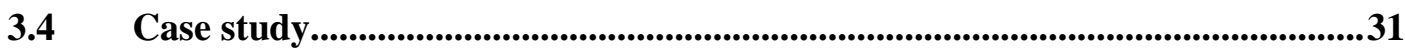

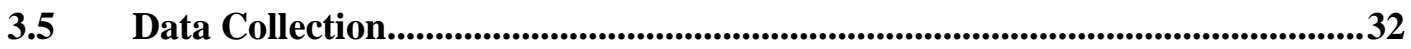

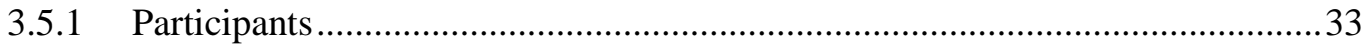

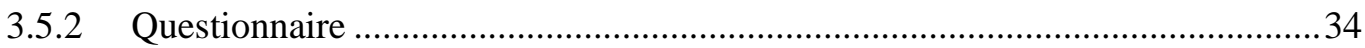

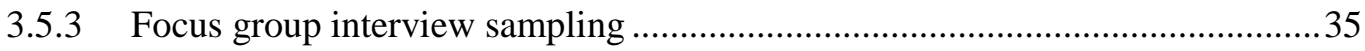

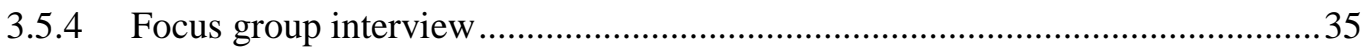

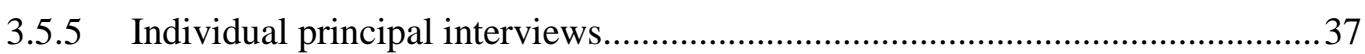

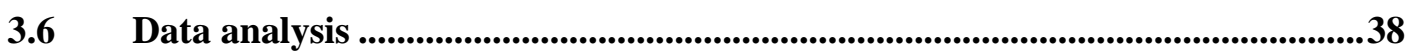

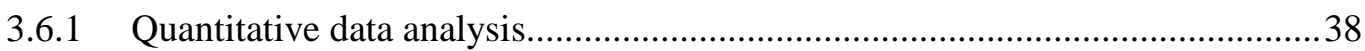

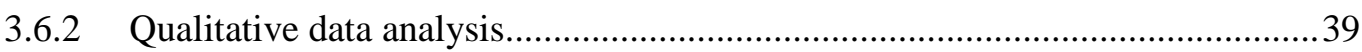

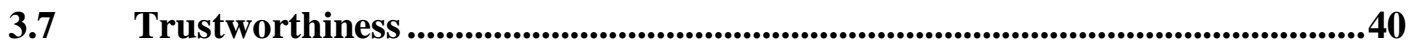

3.8 Ethical considerations ......................................................................................................41

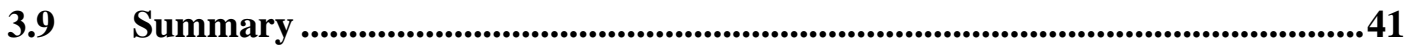

Chapter Four: Questionnaire findings......................................................................... 43

4.1 Introduction .......................................................................................................................43

4.2 Teaching and leadership background..........................................................................44

4.3 Types of leadership PDL ........................................................................................46

4.4 Issues and challenges for first-time TLRs ........................................................48

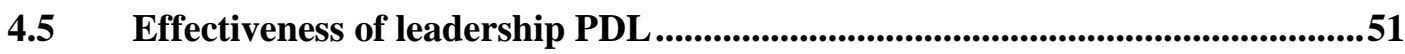

4.6 Enablers for leadership PDL within a school...................................................54 
Chapter Five: Interview findings................................................................................... 58

$5.1 \quad$ Introduction .........................................................................................................................58

$5.2 \quad$ Background details of participants ..................................................................59

$5.3 \quad$ Types of leadership PDL ...............................................................................................60

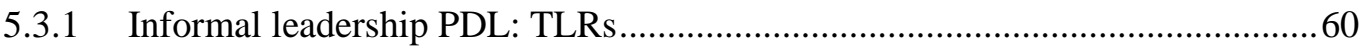

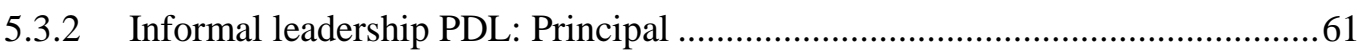

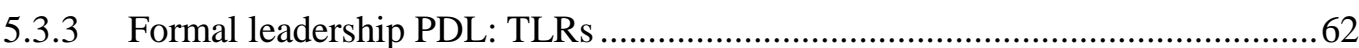

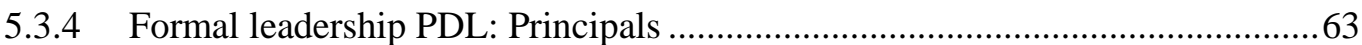

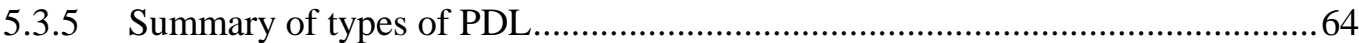

5.4 Issues and challenges for first-time TLRs ....................................................64

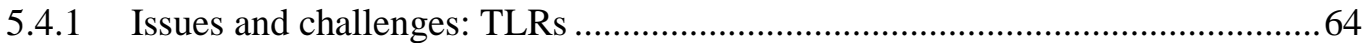

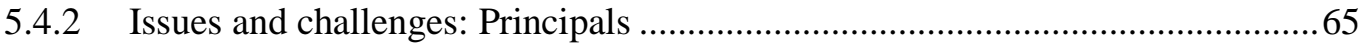

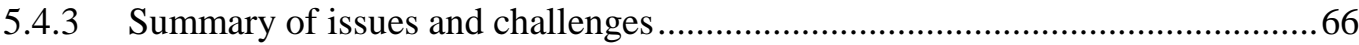

$5.5 \quad$ Effectiveness of leadership PDL .........................................................................66

5.5.1 Effectiveness of leadership PDL: TLRs .........................................................67

5.5.2 Effectiveness of leadership PDL: Principals ....................................................68

5.5.3 Summary of effectiveness of leadership PDL .................................................. 70

5.6 Enablers for leadership PDL within a school.........................................................70

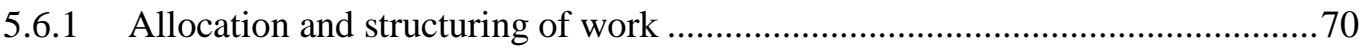

Allocation and structuring of work: TLRs .......................................................................... 70

Allocation and structuring of work: Principals ................................................................... 71

5.6.2 Encounters and relationships with people at work ......................................... 71

Encounters and relationships with people at work: TLRs...................................................... 71

a. Providing on-going PDL in the workplace: Relationships with the principal ................71

b. Providing on-going PDL in the workplace: Relationships with others .......................... 73

Encounters and relationships with people at work: Principals .......................................... 74

a. Providing on-going PDL in the workplace: Relationships with the principal ................ 74

b. Providing on-going PDL in the workplace: Relationships with others ........................ 75

5.6.3 Expectations of each person's role, performance and progress ..........................76

Expectations of each person's role, performance and progress: TLRs ................................ 76

Expectations of each person's role, performance and progress: Principals ............................. 77

5.6.4 Summary of enablers for PDL within a school ................................................ 78

$5.7 \quad$ Summary of interview findings ...................................................................................79 
Chapter Six: Discussion ............................................................................................................ 81

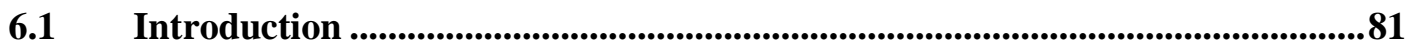

$6.2 \quad$ Justification for framework ......................................................................................81

6.3 Part one: Contextual factors that enable leadership PDL ................................85

6.4 Part two: Annual cycle of PDL for TLRs...............................................................87

6.4.1 Component one: Co-construction or review of job description and PDL

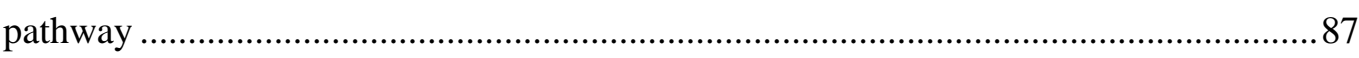

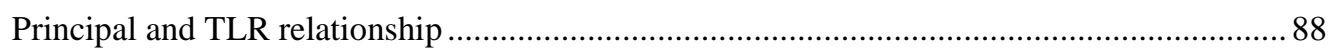

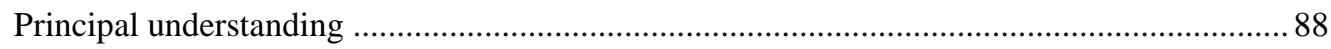

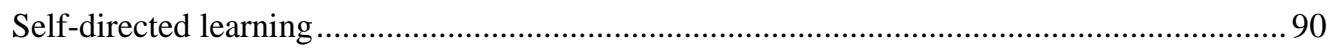

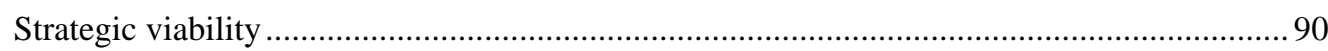

Summary of component one: Co-construction or review of job description and PDL pathway91

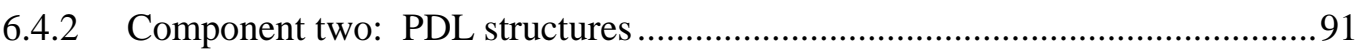

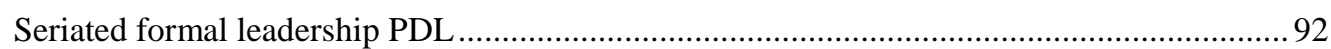

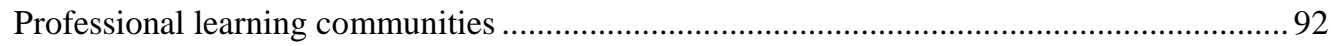

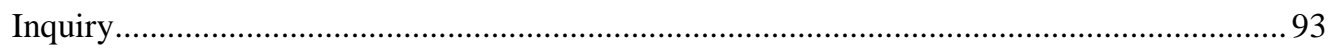

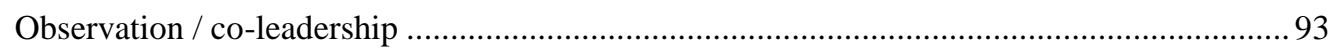

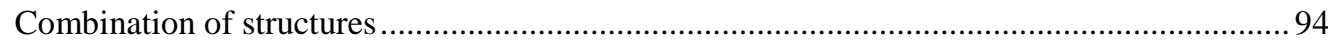

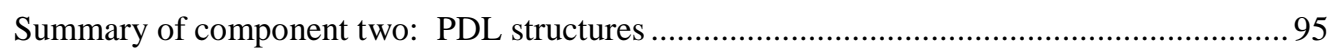

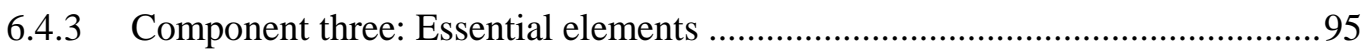

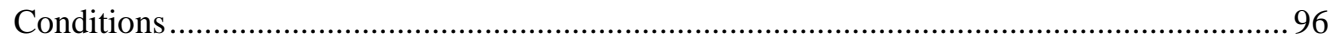

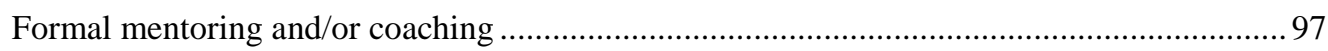

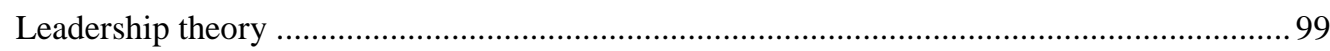

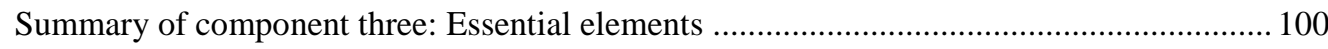

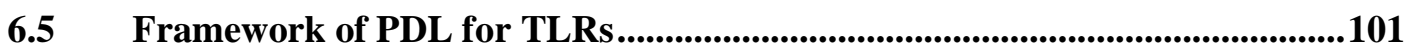

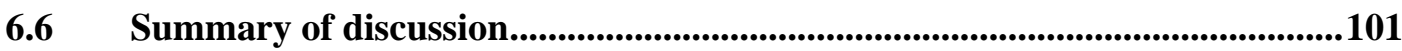

Chapter Seven: Conclusion .................................................................................... 103

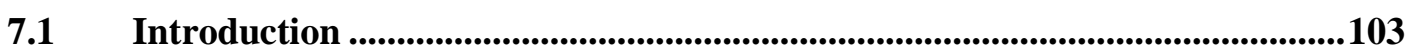

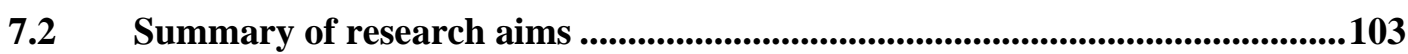

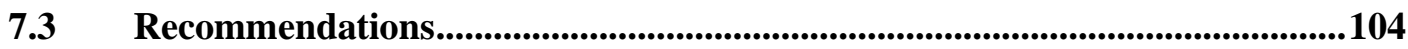

7.3.1 On-going leadership PDL in the workplace ……............................................104

7.3.2 Strategic resourcing of principal's time and expertise ...................................105

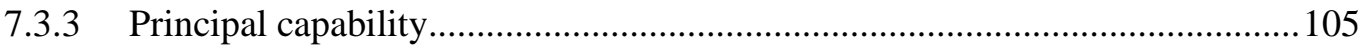

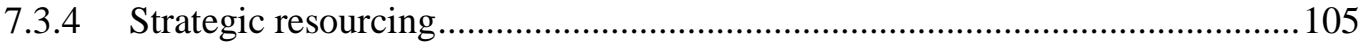

7.4 Limitations of the research ........................................................................................105

7.5 Opportunities for future research ................................................................106

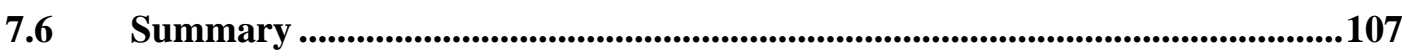


Reference List .............................................................................................................................. 109

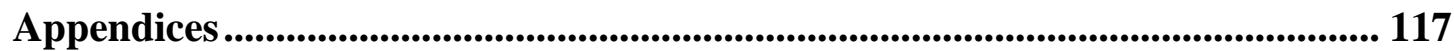

Appendix A...............................................................................................................118

Appendix B ..............................................................................................................................122

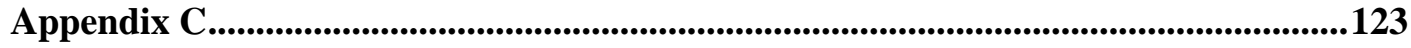

Appendix D.................................................................................................................................124

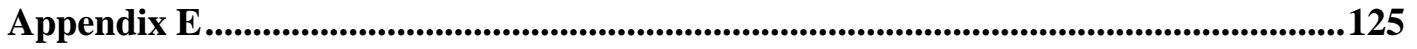

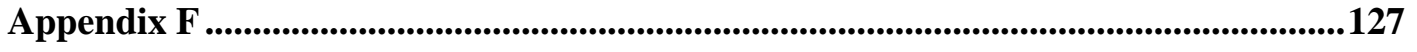

Appendix G ..........................................................................................................128

Appendix H ....................................................................................................................129

Appendix I .........................................................................................................................130

Appendix J ............................................................................................................131

Appendix K ............................................................................................................................132

Appendix L ..................................................................................................................................134

\section{List of tables}

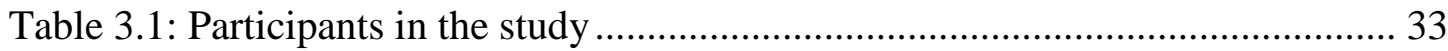

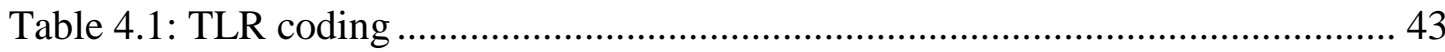

Table 4.2: Teaching and leadership background......................................................... 44

Table 4.3: Teaching and leading context ………………........................................ 45

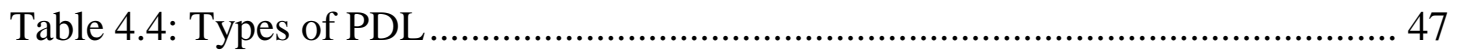

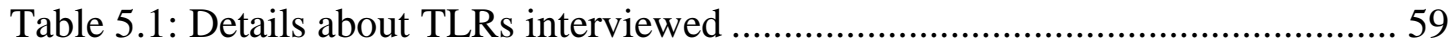

Table 5.2: Details about school principals interviewed ……....................................... 59

Table 6.1: Where contextual factors fit in the PDL framework................................... 86

\section{List of figures}

Figure 2.1: Informal learning continuum ......................................................... 8

Figure 2.2: Turbill's (2002) 'frameworks' model of professional learning (p.69) ....... 10

Figure 2.3: Growth from novice to expert (Edwards et al., 1997, p. 183) ................. 25 
Figure 3.1: Timeline of data collection 33

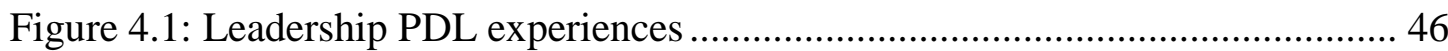

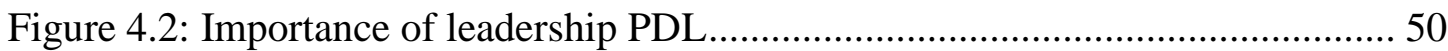

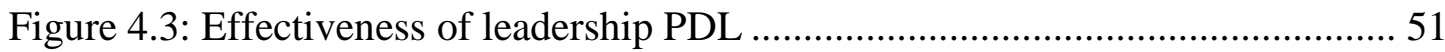

Figure 4.4: School priority for leadership PDL ................................................... 55

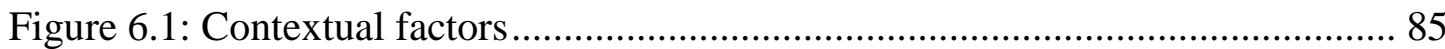

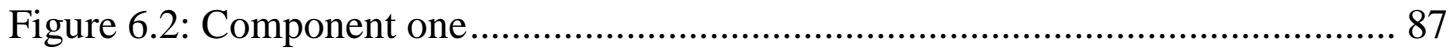

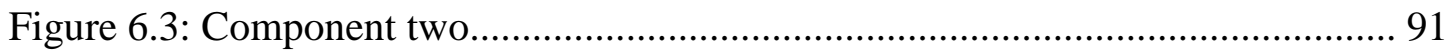

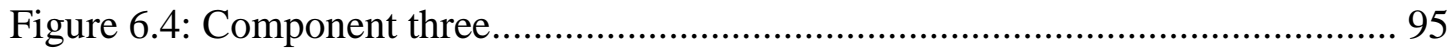

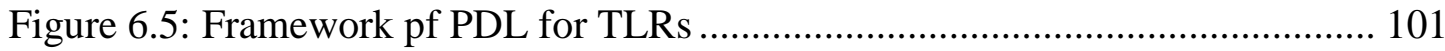




\section{Chapter One: Introduction}

\subsection{Overview}

In 2012 the New Zealand Ministry of Education published Leading from the Middle: Educational Leadership for Middle and Senior Leaders (Ministry of Education, 2012), a document explaining the importance of these leaders within a school context. This publication identified the need for middle and senior leaders to have ongoing professional development and learning but did not provide suggestions of how this could be done. The purpose of this study was to explore how New Zealand state-funded primary schools have been supporting new middle and senior leaders to develop their leadership capacity. The study is set in the greater Wellington region of New Zealand and involves volunteer middle and senior leaders of primary schools.

\subsection{Terminology defined}

This section defines the terms for teachers with leadership responsibilities and professional development and learning that will be referred to throughout this study.

\subsubsection{Teachers with leadership responsibilities (TLR)}

Middle and senior leaders can range from deputy principals and team leaders, to teachers who may lead their school in particular curriculum areas such as mathematics or physical education (Ministry of Education, 2012). The majority of these leaders are also classroom teachers (Ministry of Education, 2012). Middle and senior leaders have many differing titles depending on the school they are in. In overseas literature middle and senior leaders can also be identified using the term teacher leaders. For the purpose of this study they will be referred to as teachers with leadership responsibilities (TLRs).

\subsubsection{Professional development and learning (PDL)}

For the purpose of this study professional development and learning (PDL) is defined as the intricate and ongoing process in which TLRs use, combine and reflect on their own and others', leadership theories, beliefs and practices (Turbill, 2002) to create and apply new knowledge to their own leadership role. 


\subsection{New Zealand context}

The current New Zealand education system requires first and second year teachers to undertake a support and guidance programme (New Zealand Teachers Council, 2010) administered by the school, in which they develop their knowledge, skills and attitudes sufficiently in order to become fully registered teachers. In 2002 the Firsttime Principals Programme (University of Auckland, 2012)was initiated by the Ministry of Education to ensure that all first time principals are provided with the opportunity to strengthen knowledge, skills and capabilities necessary for efficacious leadership of a school (University of Auckland, 2012). There is no mandatory training provided for teachers who move into designated middle or senior leadership roles for the first time, in either primary or secondary schools (Cardno, 2005).

This is not to say that there is no organised PDL offered to TLRs. There are regional courses run by private companies, educational consultants work with leadership teams within schools and a National Aspiring Principals Programme (NAPP) funded by the Ministry of Education exists for TLRs. However TLRs who wish to participate must apply and not all are accepted as spaces are limited. NAPP is largely about preparing leaders for principalship (Ministry of Education, 2013c), therefore it caters more for TLRs who have the competency to move up the leadership ladder. TLRs new to leadership roles generally do not fit into this category.

The importance of compulsory PDL for TLRs cannot be underestimated. In 1989, with the introduction of self-governance of schools, principals became responsible for the day to day management of the school and for being the leader of learning for their students and staff (Cardno, 2005; Harvie, 2009). In order to carry this role out effectively principals needed to move to more distributed leadership (Anderson, Clarke, \& Vidovich, 2009; Cardno, 2005; Deece, 2003). Distributed leadership is described as shared decision making (Blase \& Blase, 1999) and a division of labour and collaborative action (Gronn, 2002) in order to achieve a common vision.

TLRs play a pivotal role in distributed leadership working effectively. They are considered to be highly influential members of staff (Foster, 2010; Harris, Busher, \& Wise, 2001; Patterson \& Patterson, 2004) as they are seen as individuals with credibility and expertise (Patterson \& Patterson, 2004). TLRs have a substantial 
impact on learning by facilitating the majority of the significant conversations about teaching and learning with the teachers they lead. Not only does this have an effect on those teachers but also on the wider school community (Foster, 2010; Patterson \& Patterson, 2004).

An additional impact of distributed leadership on TLRs is that they have increased responsibility and accountability (Cardno, 2005; Harris et al., 2001). Being cognisant of all these factors, formalised PDL for these influential members of staff is imperative (Duignan \& Cannon, 2011; Harris et al., 2001). Fullan (2002) states "we need to design and invest in many opportunities for people to learn to lead" (p. $1)$.

\subsection{Primary school context}

This study is set in the context of New Zealand state funded primary schools. Primary schools cater for students from approximately five years to twelve years old. The generic term of a New Zealand primary school can be divided into three different categories of schools. They are:

- Full primary: students aged approximately between five and twelve;

- Contributing primary: students aged approximately between five and ten;

- Intermediate school: students aged approximately between eleven and twelve.

A New Zealand state funded school receives an operations' grant from the New Zealand government. This grant pays for all costs including staff PDL; it does not include the payment of teachers' salaries or the upkeep of essential infrastructure (Ministry of Education, 2013a).

All New Zealand schools including state funded schools are self-governing; this means having a board of trustees, membership of which is representative of the school community. The school principal is charged with the responsibility of managing the day-to-day operations of the school, teaching and learning programmes and monitoring staff performance (Ministry of Education, 2013b). Teaching and learning within a state funded school is driven by the New Zealand Curriculum (Ministry of Education, 2007) where the aim is for students to become 
"confident, connected, actively involved, lifelong learners" (Ministry of Education, 2007, p. 7).

\subsection{Significance of study}

The Ministry of Education (2012) identified a number of factors that would affect the success of middle and senior leaders; "opportunities to engage in professional development and learning" (Ministry of Education, 2012, p. 8) is one. However there is no mention of what form that PDL may take. From literature reviewed it is clear that effective professional development of middle and senior leaders is in the early stages of being identified and described. Of the national and international research read for the purposes of this study, there does not appear to be a baseline understanding of the appropriate professional development middle and senior leaders need to have and how it might be carried out. There is limited research on this topic in a New Zealand context.

This study may contribute to the body of research about the provision and success of professional development for middle and senior leaders in a New Zealand context. It will provide additional data on the type of PDL that is taking place in New Zealand primary schools for new TLRs and whether that PDL is providing adequate guidance and support.

This study could possibly assist principals in determining what planned PDL they need to be providing for new TLRs they have employed. With the inclusion of the identification of factors enabling PDL in this study the principal can plan PDL that is easily implemented, cost effective and appropriate. An education workforce advisory group (Ministry of Education, 2010) acknowledged that effective leadership can raise the learning outcomes of students within a school. Resources need to be provided for the development of new middle and senior leaders to ensure that they are successful. This study could possibly contribute to considerations regarding government funding, firstly for a nationwide support and guidance programme for new TLRs and secondly, providing schools, within the staffing allowance, to supply appropriate PDL for their new leaders. 


\subsection{Researcher's perspective}

I have been a teacher for over 21 years and have had leadership responsibilities in three of the four jobs that I have had in this time. At present I am a deputy principal with no classroom teaching responsibility at a decile eight school in the northern suburbs of Wellington. I have been in this position for almost ten years.

I recall that when I became a TLR for the first time within a school there was no planned PDL offered nor was there any official guidance provided by my superiors. Although that was some time ago, more recently I observed two newly appointed team leaders in the school in which I presently teach, struggle with their new roles despite the fact that they were attending a highly regarded professional development course for middle and senior leaders. Having completed a professional development paper as part of my study I now recognise that the PDL was helpful but did not provide the adequate on-going support that was needed to assist these new team leaders in becoming competent educational leaders.

\subsection{Research questions}

The main question that frames this research enabling the exploration of this topic is:

How are teachers, who are new to having leadership responsibility in New Zealand primary schools, supported in their role?

The sub-questions that facilitate further guidance are:

- What professional development and learning are new teachers with learning responsibilities offered and/or encouraged to participate in?

- How effective do principals and new teachers with learning responsibilities consider the current professional development and learning of teachers with learning responsibilities?

- What factors enable effective professional development and learning of teachers with learning responsibilities within a school?

\subsection{Overview of this thesis}

This thesis begins with a literature review that explores the PDL strategies used to support TLRs, the effectiveness of the PDL strategies and organisational factors 
within a school that enable effective PDL. Following this the methodology of the research is described and justified. Next the separate findings from data gathered from each of the questionnaire and interview processes is shared. The findings and theory are combined in the discussion to answer the research questions and are presented through a possible PDL framework. Finally the conclusion offers specific recommendations for the PDL of TLRs, explores the limitations of the research and suggests areas of future research. 


\section{Chapter Two: Review of literature}

\subsection{Introduction}

This review sets out to examine literature identifying PDL strategies used to support TLRs, their effectiveness and the organisational factors within a school that enable effective PDL. Since the focus of this research is the professional development of leaders, this review will not explore the concept of leadership. The review focuses mainly on international literature, as there is limited research on middle and senior leadership in a New Zealand educational context.

The literature review is split into three sections. Section one is the identification and classification of the commonly used PDL strategies and their effectiveness. Following that the issues and challenges experienced by first time leaders will be explored. The last section discusses organisational factors that enable the effective PDL of TLRs.

\subsection{Types of leadership PDL and their effectiveness}

A variety of PDL strategies and their effectiveness were identified in the literature and will be discussed in this chapter. Turbill (2002) theorises that for successful teacher learning to take place, planned structures and conditions need to exist to facilitate the integration between the knowledge domains of theory, beliefs and practices. Structures are the components set up to initiate learning and over which both the facilitator of learning and the learner have some control. Conditions are facilitated within a structure to make tacit knowledge explicit and for transformational learning to transpire (Turbill, 2002). For the purpose of this study Turbill's (2002) terms of structures and conditions will be used to categorise PDL strategies throughout the writing.

As a beginning to this section the theories of informal learning, professional development, teacher learning and what is effective PDL are explained. Then follows a description of the most commonly identified PDL structures throughout the literature and their effectiveness. These structures are coaching and mentoring, professional learning communities, inquiry, self-directed learning and combined structures. The three conditions of sharing, collaboration and reflective learning are then explained with a focus on reflection. Finally the place of theory in any type of 
PDL is then discussed.

\subsubsection{Informal learning theory}

Learning is commonly understood as a procedure in which knowledge is obtained. Learning can transpire when current knowledge is applied to a new situation or used in different combinations (Eraut, 2000). Learning is an intricate and ongoing process that never stops, regardless of the experience, position or context a learner is in. The transfer of learning is the process that occurs when an individual takes on new skills, knowledge or behaviour (Hager \& Hodkinson, 2009) and is part of this definition of learning since new knowledge is being developed as part of the whole learning process (Eraut, 2000).

Figure 2.1 shows an informal learning continuum that includes Eraut's Typology of Learning (2004, p. 250), with a continuum below and arrows to indicate where the differing modes of informal learning identified, sit on the continuum.

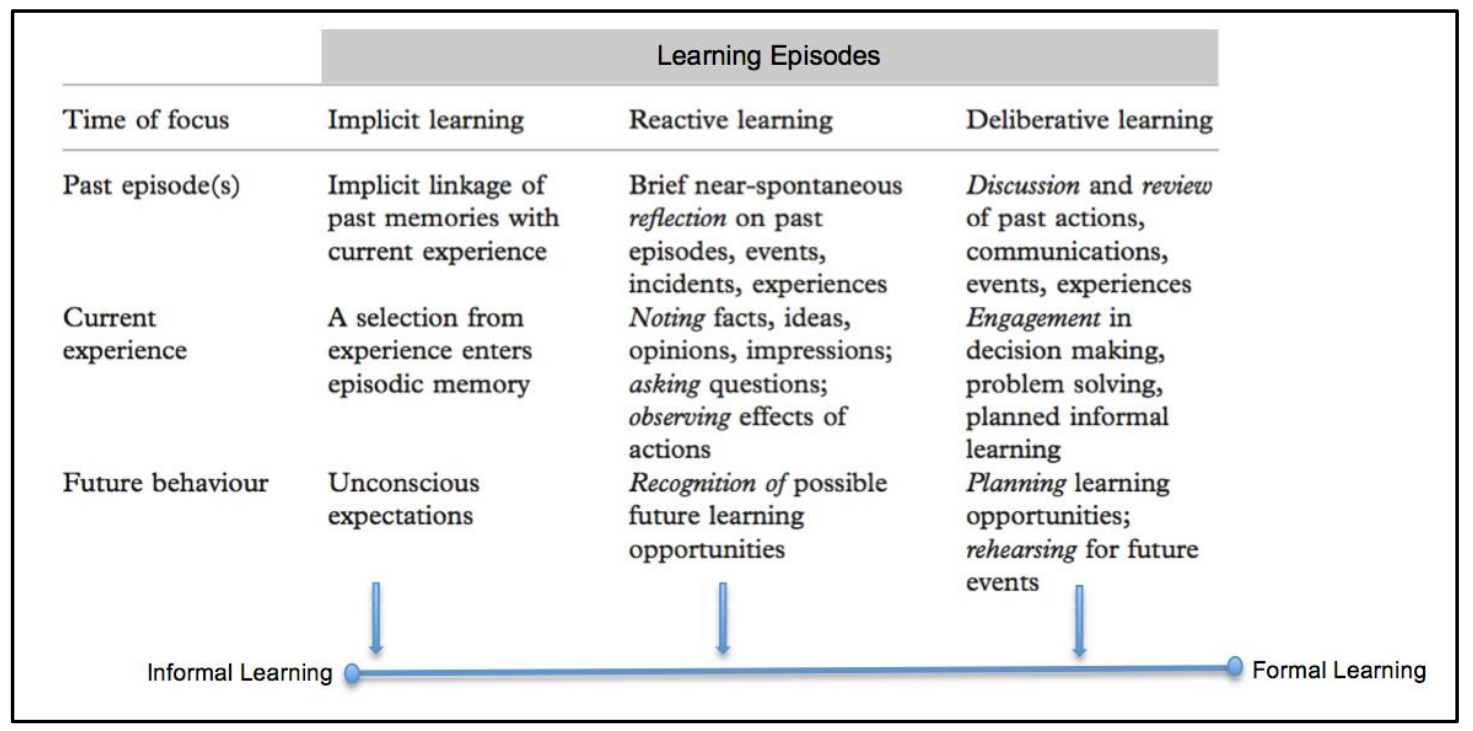

Figure 2.1: Informal learning continuum

The continuum represents a temporal relationship between the experience and the resulting learning episode (Eraut, 2004). Informal learning is seen as mostly implicit, that is, tacit knowledge (Timperley, Wilson, Barrar, \& Fung, 2007) that is acquired without knowing, there has been no conscious effort to learn and the knowledge becomes part of an individual's general capability (Eraut, 2004). Informal learning is also opportunistic and unstructured. 
Eraut (2004) views reactive learning, although intentional, as often happening when there is little time to think whereas deliberative learning has time set aside for it. The context of learning is always in the present whilst the focus can be in the past, present or future. During the planning stage of a deliberative learning episode the future learning opportunities can be both formal and informal.

\subsubsection{Formal professional development theory}

At the right end of Eraut's (2004) continuum formal learning otherwise known as professional development (PD) is found. Eraut (2000) identifies PD has having any one of the following characteristics:

- A prescribed learning framework;

- An organised learning event package;

- $\quad$ Presence of a designated teacher or trainer;

- Award of a qualification credit;

- External specification of outcomes (Eraut, 2000, p. 114).

Effective PD draws on a learner's technical, rational, reflective and academic thinking, and competencies (Cheetham \& Sandberg, 2005) to develop an "understanding of, and in, professional practice" (Dall'Alba \& Sandberg, 2006, p. 401). PD also encourages the growth of attitudes such as flexibility and spontaneity and the habits of analytical, reflective and creative thought to become self-directed and lifelong learners (Cheetham \& Sandberg, 2005).

Duignan (2004) believes PD should deal with unfamiliar problems in unfamiliar contexts. This type of professional development is future oriented, and engages learners in utilising the leadership capabilities to problem-solve through active learning (Bush, 2008; Pont, Nusche, \& Moorman, 2008; Robertson, 2005). This form of PD not only draws on an individual's knowledge, self-beliefs and values but also their creativity and courage. In doing so leaders are taught capabilities in order to manage in situations of "uncertainty, ambiguity and seeming contradiction or paradox" (Duignan, 2004, p. 10). 


\subsubsection{Teacher learning theory}

Turbill (2002) created an adult learning framework as a model of professional learning undertaken by teachers (refer to Figure 2.2). The framework divides a teacher's learning into inside-out and outside-in. Inside-out learning occurs when a teacher's mostly tacit, personal theory that drives their practice is integrated with the personal theory in practice. Teachers reflect on their practice and check whether there is congruence with their personal theory. In doing so the teacher brings the inside, out, by making the tacit, explicit. Outside-in learning traditionally dominates conventional PD with a mixture of theory and practice of others.

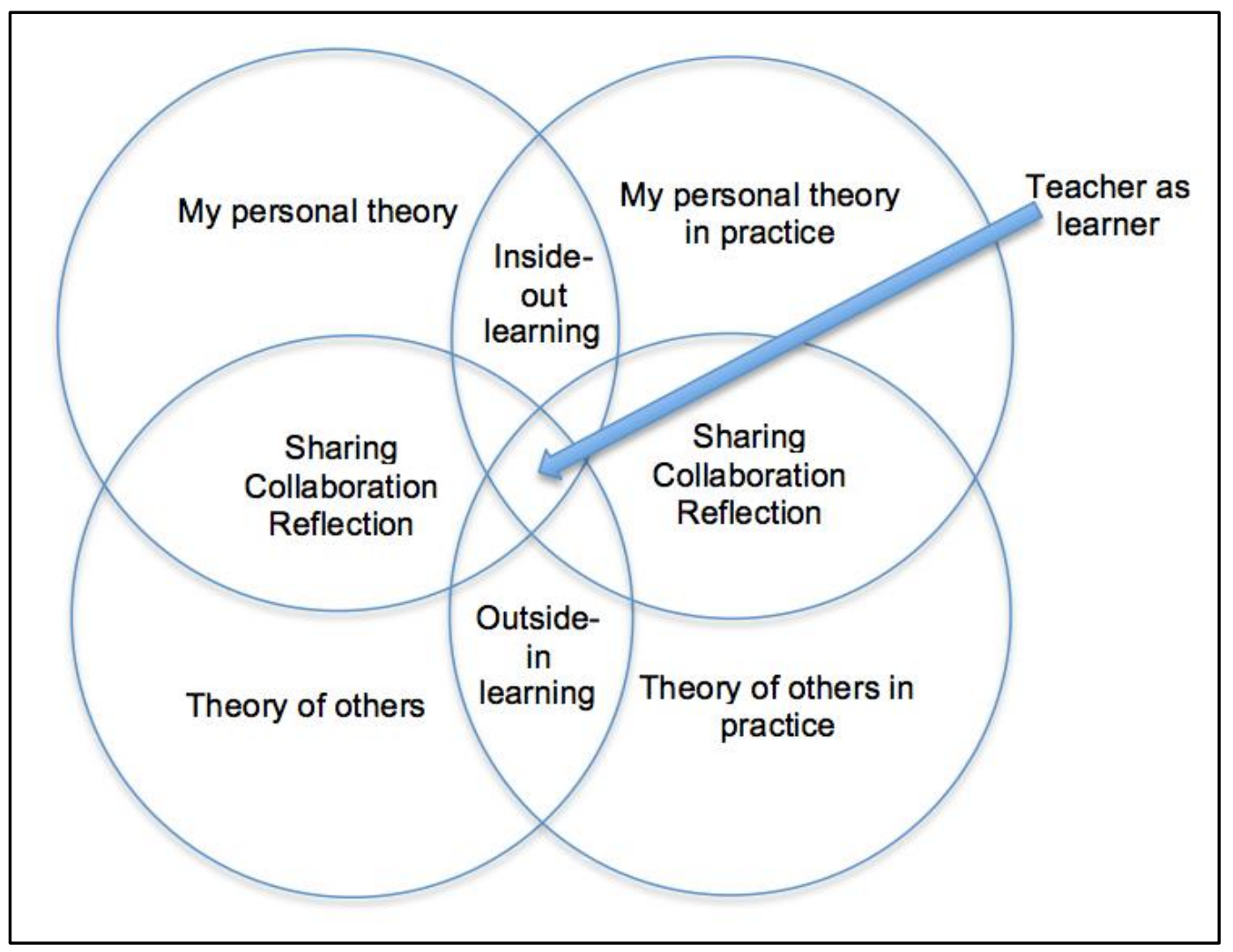

Figure 2.2: Turbill's (2002) 'frameworks' model of professional learning (p.69) 


\subsubsection{Effectiveness of PDL structures theory}

For PDL to be effective it must create opportunities that challenge and extend a TLR's current understanding and practice of leadership (Dall'Alba \& Sandberg, 2006). It should also capture the gap between the knowledge they have and the ability to articulate it as this leads to a stronger efficacy (Clemans, Berry, \& Loughran, 2012). To optimise learning for adults, PDL needs to be active, constructive, self-directed, social, relevant, reflective and enjoyable (Elmuti, 2004; Fransson, Lakerveld, \& Rohtma, 2008; Garrison, 1997; Wlodkowski, 2008). Turbill (2002) suggests that the most effective PDL takes place when inside-out and outsidein learning are combined with collaboration, reflection and sharing and dissonance between the teachers own theories, beliefs and practices and those of others occurs.

\subsubsection{Leadership PDL structures}

There were a number of PDL structures that were most commonly mentioned across the literature. They were mentoring and coaching, professional learning communities, inquiry learning, self-directed learning and the combined use of a number of theses PDL structures. Each structure will be discussed, beginning with identification of the nature of the structure, this will be followed by the learning theory the structure is based on and finally the effectiveness identified in the literature.

\section{Mentoring and coaching: Formal and informal learning}

The two PDL structures that are most commonly mentioned in the literature are formally organised mentoring and coaching (Clemans, Berry, \& Loughran, 2010; Cotter, 2007; Day, 2001; Rhodes \& Brundrett, 2009; Ross et al., 2011). There is much debate about the difference between coaching and mentoring. They have many similar characteristics but serve two different purposes (Brockbank \& McGill, 2006; Pask \& Joy, 2007).

Mentoring is a broad, holistic type of development interaction (D'Abate, Eddy, \& Tannenbaum, 2003) in which psychosocial and career needs (McManus \& Russell, 1997) of the learner are met to support the growth, learning and integration into a particular community (Clutterbuck, 2008; Duncan \& Stock, 2010; McDonald \& Flint, 2011). Coaching, one aspect of mentoring, is a development strategy designed to assist individuals in assessing the present reality and making changes in order to alter 
that reality (Pask \& Joy, 2007). The use of measurable actions as part of coaching allows for observable, improved behavioural change (Day, 2001).

It has been suggested that mentoring is developing a way of being; coaching is a way of doing and they are both necessary tools to be utilised in empowering an individual as they avoid the risk of self-deception that may occur in reflection that occurs within an internal dialogue (Brockbank \& McGill, 2006). Talking with another person can lead to a change in thinking about a situation and actions taken to change it (Brockbank \& McGill, 2006).

Eraut (2004) views mentoring as reactive learning. In her study of the transition of Australian teachers to leaders, McCulla (2011) found informal mentoring with colleagues was highly valued for just-in-time, reactive learning needs and was one structure that aided new leaders in coping with the change in collegial relationships with their staff.

Mentoring and coaching are also deliberative episodes of learning and can be used in tandem in both a formal and informal arrangement (Cotter, 2007). For new school leaders in the United States, Duncan and Stock (2010) found both coaching and mentoring paramount for beginning principals who were at a significant transition point in their career by assisting them in coming to terms with the complexities that are involved in leadership. Mentoring can also provide external pressure that prompts individuals into action (Harris et al., 2001).

Coaching provides a platform for TLRs to identify learning needs and strategise ways to address them (Patti, Holzer, Stern, \& Brackett, 2012) through setting realistic, achievable goals (Henning \& McIver, 2008). In a study on the impact of coaching on teacher leaders in the USA Patti et al. (2012) found improved leadership performance through development and realignment of several leadership behaviours. Accompanying that was an increased self and social awareness. Consequently conflict was managed better and empathy for others was increasingly taken into account when making decisions. 


\section{Professional learning communities: Deliberative, informal learning}

Professional learning communities (PLCs) is another strategy identified across the literature that expedites the alignment of inside-out, outside-in learning and sharing, collaboration and reflection (Earley \& Jones, 2011; Eraut, 2009; Turbill, 2002).

Effective PLCs within and across educational institutions are utilised to keep up with changes and challenges in leadership theories, beliefs and practices (Hipp \& Huffman, 2010). PLCs involve collaborative, critical and reflective discourse concerning the leaders' own theories, beliefs and practices in relation to PDL (Dalton, 2010; Servage, 2008). This type of dialogue elicits critical reflection about work experiences from which individuals will learn if they are prepared to do so (Fenwick \& Tennant, 2004). Furthermore if the discourse within a PLC is effective enough, it can bring about transformative change within the individual (Cotter, 2007; Mezirow, 2003; Ross et al., 2011; Servage, 2008).

Ideally PLCs provide an environment for peer support, mentoring, motivation and resources in a safe and more intimate setting for leaders who are undergoing the same experiences (Clemans et al., 2010; Cotter, 2007; Gilpin-Jackson \& Bushe, 2007). Participants are able to share "frustrations, vulnerabilities and insights" (Clemans et al., 2010, p. 224) and a common language (Gilpin-Jackson \& Bushe, 2007). The social support that is found in a PLC is an important factor in affecting successful transfer of learning into a work place; someone going through the same training provides greater impetus and support (Gilpin-Jackson \& Bushe, 2007).

\section{Inquiry: Deliberative, informal learning}

In the literature reviewed inquiry learning was a recurring structure identified as effective in developing leadership capabilities (Anderson \& Cawsey, 2008; Day, 2001; Earley \& Jones, 2011; Hunzicker, 2012; Ross et al., 2011). Inquiry learning provides an avenue in which leaders question things they are curious about in their practice and assumptions they have (Reid, 2004). Inquiry pushes reflection deeper as it takes the practitioner beyond present understandings and there is a self-generation of relevant knowledge-of-practice (Kiss \& Townsend, 2012; Robertson, 2005; Simkins, 2005) created in the leader's reality and context (Kiss \& Townsend, 2012). 
Inquiry is a systematic, rigorous, targeted critical reflection about professional practice (Kiss \& Townsend, 2012; Reid, 2004; Schulz, 2010) and can be carried out through action research (Cardno \& Piggott-Irvine, 1996; Cotter, 2007; Reid, 2004; Taylor, Goeke, Klein, Onore, \& Geist, 2011) or action learning (Cardno \& PiggottIrvine, 1996; Day, 2001; Robertson, 2005). The difference between the two is that action research makes more deliberate links between theory and practice and findings are shared in written form. Whilst with action learning there is no obligation to share findings and greater emphasis is placed on the learning (Cardno \& Piggott-Irvine, 1996; Robertson, 2005). The purpose of both is to narrow the gap between theory and practice (Cardno \& Piggott-Irvine, 1996).

The acquisition of knowledge that occurs in both types of inquiry is underpinned by personalised, experiential learning (Cardno \& Piggott-Irvine, 1996; Cotter, 2007; Robertson, 2005). That is a cyclic framework consisting of, critical self-assessment of a concrete experience (Cardno \& Piggott-Irvine, 1996; Robertson, 2005), making generalisations or formulating abstract concepts (Cardno \& Piggott-Irvine, 1996), and finally, actively experimenting with those concepts (Cardno \& Piggott-Irvine, 1996; Robertson, 2005).

Whilst critical self-assessment initiates metacognition and a general ability to learn, it may not be entirely accurate or explicit enough to create precise meaning (Garrison, 1997). Throughout the inquiry cycle it is important for the learner to reflect with at least one other person, as the effectiveness of the learning is linked closely to the amount of group and individual reflection that takes place (Day, 2001). Receiving questions and feedback from an outside source needs to occur to monitor and challenge the quality of the learning and to provide alternative perspectives (Garrison, 1997; Reid, 2004; Robertson, 2005; Schulz, 2010).

Bush (2008) states that the most successful leadership learning is derived from structured, reflective inquiry. Through inquiry leaders utilise inside-out learning to construct and apply new knowledge and initiatives (Taylor et al., 2011). With a deeper understanding of leadership comes the ability to more clearly define the complexities of the role resulting in a sense of increased identity and authority (Taylor et al., 2011). 


\section{Self-directed learning: Reactive and deliberative, informal learning}

Self-directed learning is when learners are empowered to make decisions about their learning (Hiemstra, 1999) and this allows the learner to have control of what is to be learnt and how it will be learnt (Garrison, 1997). A sense of control over the learning process enhances motivation and responsibility (Garrison, 1997). Having little or no control over learning tends to result in one not taking responsibility for one's learning and progress is not achieved (Garrison, 1997).

Garrison (1997) believes that self-directed learning might be the sole PDL structure that assists in profound learning as critical cognition is the driving force behind it. However a collaborative environment is a necessity for self-directed learning to optimise the creation of that meaningful knowledge (Garrison, 1997). Within this environment goals and learning activities are co-constructed, with regular opportunities to reflect on thinking with others throughout the process (Garrison, 1997).

Boyer (2004) found that facilitated and carefully monitored self-directed learning allowed aspiring school leaders to develop their own personal learning plan to achieve the desired outcomes. Rather than controlling systems of learning and having to provide all the knowledge, the facilitators were the catalysts for learning and used scaffolding to structure the learning process (Boyer, 2004; Confessore \& Kops, 1998). The learners became active creators of knowledge rather than passive receivers (Boyer, 2004; Taylor et al., 2011). Having the locus of control over content motivates and empowers TLRs as professionals (Taylor et al., 2011). Selfdirected learning can also reignite passions and expertise (Taylor et al., 2011).

In some of the literature reviewed, self-directed learning was identified as a structure used within the PDL for the TLRs (Cotter, 2007). Others studies mentioned the use of inquiry (Hunzicker, 2012; Taylor et al., 2011), which, throughout the inquiry process, is self-directed learning. Although self-directed learning was not identified as a contributing factor to the success of the PDL it can be inferred that it played its part in enhancing the leaders' capabilities. 


\section{Combined structures}

To improve school leadership there needs to be a variety of appropriate and effective training for educational leaders within schools (Pont et al., 2008). PDL that meets diverse needs can be achieved by providing a series and variety of structures that facilitate effective learning over a regularly supported, predetermined timeframe (Belling, James, \& Ladkin, 2004; Bolden, 2007; Bush, 2008).

An active, balanced programme of leadership PDL should comprise of learning activities that are derived from identified learning needs, embedded in real-life contexts, integrate leadership dimensions with theories, beliefs and practices and provide continual opportunities for reflection and evaluation (Anderson \& Cawsey, 2008; Bush, 2008; Robinson, Hohepa, \& Lloyd, 2009; Turbill, 2002). In the literature reviewed there were a significant number that involved a range of structures, on-site and off-site, to facilitate both formal and informal effective leadership learning and met the former criteria (Clemans et al., 2010, 2012; Cotter, 2007; Henning \& McIver, 2008; Hunzicker, 2012; Ross et al., 2011; Taylor et al., 2011).

\subsubsection{Leadership PDL conditions}

Turbill (2002) broadly describes the conditions for learning as sharing, collaboration and reflection that occur in PDL structures. Interactions between structures and conditions develops shared meanings and language, leading to increased trust, and respect for different perspectives and opinions (Turbill, 2002). If structures are organised well then conditions will operate implicitly and transformational learning will occur (Turbill, 2002).

Sharing and collaboration lead to a risk-taking situation where individuals work through confusion and uncertainties by sharing and reflecting on their own opinions with peers (Turbill, 2002). This discourse provides insights into personal learning and thinking (Eraut, 2009; Turbill, 2002). There is no right or wrong way to create conditions for sharing and collaboration as long as structures allow for this to happen (Turbill, 2002). Although sharing and collaboration were not overtly mentioned in the literature they are a byproduct of all the structures previously discussed. 


\section{Reflection}

Unlike sharing and collaboration, which is not mentioned often, the condition of reflection was mentioned frequently in the literature reviewed (Clemans et al., 2010, 2012; Harris et al., 2001; Patti et al., 2012; Robertson, 2005; Ross et al., 2011; Taylor et al., 2011) and permeates all of the structures discussed.

Reflection is professional thinking and is a means to an end (LaBoskey, 2010). Brockbank and McGill (2006) refer to Argyris and Schon's (1996) concept of single loop learning: the learning that involves reflection and immediate improvement but does not uncover the underlying beliefs and values therefore theory and perceptions do not change. Double loop learning involves questioning and challenging the taken-for-granteds (Brockbank \& McGill, 2006, p. 33) of learners, consequently shifting their paradigms. Double loop learning, also known as transformation, occurs through critical reflection.

Mezirow (2003) talks of the exclusive adult learning capacity to become "critically self-reflective" (p. 60) and to make reflective judgments in critical discourse, challenging beliefs, values and taken-for-granteds. Transformation occurs when the learner begins to see a tension between their espoused theories and what they actually do (Robinson, 2011; Timperley et al., 2007). This cognitive dissonance (Timperley et al., 2007) can open the door to innovation and creativity; changes are more likely to ensue in the learner's values and the subsequent actions they carry out (Brockbank \& McGill, 2006; Robertson, 2005).

Reflection on leadership practice can be accomplished through mentoring, coaching, PLCs and individual writing (Clemans et al., 2010, 2012; Harris et al., 2001; Ross et al., 2011). Through reflection leaders begin to recognise their own tacit knowledge and make that tacit knowledge explicit by articulating it (Clemans et al., 2012). Reflection also elicits critical and pragmatic thinking so learners begin to recognise and name contradictions and assumptions in their practice leading to transformational learning and effective practice (Clemans et al., 2010; Harris et al., 2001; Lieberman \& Friedrich, 2010). In their study of teacher leaders in Australia, Clemans et al. (2012) found that TLRs started to position themselves as 'knowers' since they could articulate their knowledge in their written reflections. This heightened their self-efficacy as leaders. 


\subsubsection{Leadership theory}

The inclusion of leadership theory and research in any PDL structure is paramount (Robertson, 2005). Theory and research are powerful tools to explore problems from different perspectives and enable leaders to clarify their own views about organisations and their own leadership (Simkins, 2005). The use of theory provides critical perspectives and theories, beliefs and practice to support and challenge the learner leader. The challenge is required for transformative learning to occur (Robertson, 2005).

The integration of theory with the aforementioned structures and conditions enhances the learner leader's perspectives and understanding about leadership (Cotter, 2007; Henning \& McIver, 2008; Hunzicker, 2012; Ross et al., 2011; Taylor et al., 2011). Clemans et al. (2010) highlighted the use of theory as it enabled new teacher educators in Australia to elucidate the connections between their understanding of pedagogy, (how children learn, required in their roles as classroom teachers) and andragogy, (how adults learn, needed in their new job). Lieberman and Friedrich (2010) also found that "teachers who are well informed about pedagogy, content, and how students and teachers learn... are the best teachers of other teachers" (Lieberman \& Friedrich, 2010, p. 2).

\subsubsection{Summary of structures and conditions of leadership PDL}

The independent PDL structures of PLCs, inquiry and self-directed learning are informal, deliberative learning (Eraut, 2004). The one formal or informal PDL stucture mentioned in the literature was mentoring and coaching. The literature suggests that combining some of these structures is desirable to ensure the mixture of inside-out learning, outside-in learning with the conditions of sharing, collaboration and reflection.

The presence of these conditions in leadership PDL cannot be understated (Turbill, 2002). Duignan (2004) believes "the length of experience is no substitute for depth of experience" (p. 8). PDL needs to involve sharing, collaboration and critical reflexive experiences to build depth of capability in order for TLRs to effectively lead others (Duignan, 2004; Turbill, 2002). The research reviewed previously demonstrates the type of PDL offered to TLRs that does so. 


\subsection{Issues and challenges for first-time TLRs}

When a person begins a new job they generally feel excited and want to be successful. The work they are doing is something they value and feel responsible for therefore they want to be effective (Wlodkowski, 2008). Initially, however, they may find it difficult to do this successfully as they may be lacking in the necessary "knowledge, experiences or expertise" (Anderson \& Cawsey, 2008, p. 71). Consequently it is important for principals to understand "what happens when people are asked to deal with new, emotional or different situations of the kind that emerge in school leadership" (Anderson \& Cawsey, 2008, p. 70).

This section reviews literature that provides a better understanding of what a teacher who has become a leader for the first time is thinking and feeling. In doing so a better understanding of what PDL is required is obtained. The issues and challenges discussed are the change in the relationships with teaching colleagues, dealing with possible conflict as a result of evolving connections and diminishment of selfefficacy.

\subsubsection{Change in relationships}

The factor found in the literature that had the greatest impact was the redefinition of relationships with staff (Anderson et al., 2009; Clemans et al., 2012; Leblanc \& Shelton, 1997). The new leaders were often confronted by the transition to becoming not only a classroom teacher but also leading their colleagues. Consequently professional and personal relationships changed. In their review on literature about teacher leaders in the United States, York-Barr and Duke (2004) found that moving from a social and comfortable relationship to one of "implicit or explicit instructional, professional organisational expectations" (p. 283) created a sense of greater distance or even loss of a specific relationship. Armstrong (2012) found that teachers who became vice principals in Canada had feelings of personal conflict since they were no longer members of the teaching group and this was exacerbated by the changing relationship with the group.

\subsubsection{Dealing with conflict}

New leaders' uncertainty about dealing with conflict in relation to former colleagues may also arise in the capacity as a leader (York-Barr \& Duke, 2004). Harvie (2009) found that New Zealand first-time TLRs' fear of conflict was complicated by the 
desire to be successful leaders. Novice assistant principals from elementary and high schools in the USA felt least prepared for working with people particularly when conflicts arose (Barnett, Shoho, \& Oleszewski, 2012). Meanwhile Armstrong (2012) discovered new leaders experienced instances of bullying and intimidation by experienced teachers. When they tried to cope with these conflicts and subsequent feelings they attempted to return to familiar and safe surroundings but were overtly and covertly discouraged by both teachers and administrators.

\subsubsection{Lack of leadership efficacy}

The third issue experienced by new leaders was the loss of personal efficacy (Bandura, 1997), the self-concept of one's ability to carry out a specific task (Eraut, 2004). While an individual can have all the necessary skills to fulfill a role, he or she may not be able to do so effectively as the cognitive, social, emotional, and behavioural sub-skills are not arranged or structured effectively to serve the purpose (Bandura, 1997). A transition to a new leadership position destabilises the individual both emotionally and socially (Armstrong, 2012) therefore their leadership efficacy is affected.

Clemans et al. (2010) wrote of how the new teacher educators felt 'lost' when they first began their jobs. Firstly they had a sense of fear as they felt they did not have the skills to be teacher educators and the teachers they were educating would find them out. This stemmed from the inability to recognise that the expert teaching strategies they demonstrated in the classroom could be transferred to adult teaching and learning. Meanwhile Armstrong (2012) found that the combined emotional and external socialisation stressors raised doubts in the new vice principals' minds that they were able to do the job despite having specific leadership PDL prior to taking on the new role. Duignan (2004) identifies this concept as capability. Having leadership capability means having the necessary level of skills, knowledge, understandings and competencies to effectively influence the people one works with. Capability depends on the confidence the individual has to apply skills learned, to complex situations rather than just having possession of them (Duignan, 2004).

\subsubsection{Summary of issues and challenges for first time TLRs}

The research reviewed highlights the vulnerability issues that new leaders face when beginning their jobs. (Clemans et al., 2010; Deece, 2003). The issues are changes in 
relationships and possible conflicts that may arise from that change and lack of leadership efficacy. The identification of these issues has implications for the support a principal provides a new leader. Principals cannot take it for granted that a first time TLR will just assume the new role without some difficulties (Clemans et al., 2010).

\subsection{Enablers for leadership PDL within a school}

One of the recurring themes in the literature reviewed was how the value of a culture of learning enhances the PDL of TLRs (Blanchard \& Thacker, 2007; Bush, 2008; Fransson et al., 2008; Rhodes \& Brundrett, 2009; York-Barr \& Duke, 2004). Educational organisations must cope with the reality that change is the constant and keep abreast of the changes in order to best meet the learning needs of their students (Anderson \& Cawsey, 2008; Briggs, 2012b; Duignan \& Cannon, 2011). This can only be achieved through a culture of learning and developing leaders who have the capabilities to meet these demands of constant change (Bush, 2008; Day, 2001; Duignan \& Cannon, 2011; Fullan \& Ballew, 2004; Harris, 2008; Robertson, 2005).

The culture is influenced by the actions of the leader (Blanchard \& Thacker, 2007; Fullan \& Ballew, 2004; Schein, 2004). Leadership action must facilitate a culture that values PDL at all levels (Baecher, 2012; Pont et al., 2008; Schein, 2004). An organisation that values learning is seen as the best and most attractive as they have a reputation for developing people (Fullan, 2011). To do this a leader must purposefully put into place strategies that "energise people to pursue a desired goal" (Fullan, 2011, p. 24). This is achieved through "deliberate practice" (Fullan, 2011, p. 22) relating to the internal operations and tasks that exist in the breadth of a culture (Schein, 2004).

Deliberate practices can be categorised into three contextual factors that enable learning in a workplace: allocation and structuring of work; encounters and relationships with other people; and expectations of each person's role, performance and progress (Eraut, 2004, 2009). The prevalent and positive deliberate practices by principals that influence the PDL of TLRs are the focus for the rest of this section. Each practice is classified under the different contextual factors (Eraut, 2004, 2009). 


\subsubsection{Contextual factor one: Allocation and structuring of work}

Eraut (2009) believes that the deliberate practice of strategic resourcing is an act of allocation and structuring of work. Strategic resourcing is a leadership dimension that influences the calibre of teaching and student learning outcomes within a school (Robinson et al., 2009). Strategic resourcing involves principals determining how resources can be procured and distributed to best meet the pedagogical needs of the school (Barnett et al., 2012; Belling et al., 2004; Pont et al., 2008; Robinson et al., 2009). Limited professional development opportunities (Anderson \& Cawsey, 2008; Anderson et al., 2009; Rhodes \& Brundrett, 2009), workload (Deece, 2003; Rhodes \& Brundrett, 2009) and time constraints (Belling et al., 2004; Leithwood, 2003) have been identified as barriers affecting the PDL of TLRs. Strategic resourcing of both time and money allocated specifically to PDL of TLRs can overcome some of the issues.

The importance of providing intentional and appropriate PDL for TLRs has been emphasized in the literature (Armstrong, 2012; Barnett et al., 2012; Gilpin-Jackson \& Bushe, 2007; Leithwood, 2003; Pont et al., 2008). This will take both time and money. In their study of how organizational culture affected work based learning of Scottish workers Ahlgren and Tett (2010) identified that in cultures where learning was not valued, learning opportunities were mostly unplanned, implicit or reactive informal, on-the-job experiences.

Describing how the conceptual understandings of the leadership styles of Australian TLRs were developed, Deece (2003) found that leadership capabilities were mainly obtained through the same structures as Ahlgren and Tett (2010) described above, quite randomly and left very much to chance. Due to the lack of allocated PDL TLRs were unable to articulate the reasons behind their practice (Deece, 2003). Without organised PDL the leaders were unable to reflect on their effectiveness, as they were ignorant of what they didn't know. They could not therefore be critical and reflective learners.

There is agreement in the literature that the purposeful investment and arrangement of PDL influences and motivates the individuals or groups involved. There is increased volition (Garrison, 1997; Wlodkowski, 2008) to participate if the learners feel as if they are worth investing in (Ahlgren \& Tett, 2010; Gilpin-Jackson \& Bushe, 
2007). Learning leads to other learning (Eraut, 2004): hence the need to strategically plan and resource for it.

As the primary facilitator of a TLR's learning, a principal needs to take into account other pressures such as workload and to set up different work structures to alleviate that burden, such as release time for leaders (Harvie, 2009; Turbill, 2002). Providing release time for leaders frees up the vital time for learning (Barnett, 2012) when TLRs can try new things out and reflect on them (Clemans et al., 2010; Cotter, 2007; Gilpin-Jackson \& Bushe, 2007; Turbill, 2002).

\subsubsection{Contextual factor two: Encounters and relationships with people at work}

Ongoing support and developmental opportunities for TLRs within the workplace are required to strengthen their leadership capabilities (Anderson \& Cawsey, 2008; Barnett et al., 2012; Eraut, 2004). This can be achieved through two particular ways, relationships with the principal and relationships with others.

\section{Relationships with the principal}

Principals can assist TLRs in developing leadership capabilities through organising and supporting targeted, job embedded PDL (Barnett et al., 2012). This can be achieved by co-constructing the PDL programme with the TLRs (Ahlgren \& Tett, 2010; Bush, 2008; Garrison, 1997; London \& Noe, 1997), providing on-going advice and guidance (Deece, 2003; Fransson et al., 2008; Harvie, 2009; Leithwood, 2003) and organising support systems within the school (Barnett et al., 2012; Breakspear, 2010; Gilpin-Jackson \& Bushe, 2007; Rhodes \& Brundrett, 2009; Simkins, 2005). This last practice will be discussed under relationships with others.

In a study about the amount of support principals provided for teacher leaders in elementary schools in the USA, Mangin (2007) found that the "effectiveness of teaching leadership roles is dependent in part on support received from principals" (p. 320). Cameron and Dingle (2006) found that a number of New Zealand teachers reported irregular PDL and support in new leadership roles and a few teachers reported no help was available.

Creating a purposeful and coherent PDL plan that is co-constructed between the 
principal and the TLR provides TLRs with the opportunity for self-directed learning (Ahlgren \& Tett, 2010; Confessore \& Kops, 1998; Gilpin-Jackson \& Bushe, 2007). Self-directed learning maximises self-determination (Belling et al., 2004) and increases empowerment and motivation (Cyboran, 2005; Vardi, 2000). New leaders who see themselves as making their own choices and taking consequent actions vigorously and positively adapt to their new position and feel psychologically empowered to carry out tasks (Cyboran, 2005; Vardi, 2000).

Creating an organised relationship between the principal and the TLR that can provide on-going feedback, support and monitoring of learning during regularly scheduled chats (Eraut, 2004) is another deliberate practice that enables successful PDL. It is particularly important that assessment of learning is carried out regularly during these chats to ensure accuracy of PDL and pinpoint learning needs (Cheetham \& Sandberg, 2005; Dall'Alba \& Sandberg, 2006; Day, 2001; Robertson, 2005). The principal could assume the role of mentor and/or coach for the TLR (Briggs, 2012a; Harvie, 2009).

\section{Relationships with other people}

To support ongoing leadership PDL a principal can organise opportunities for TLRs to observe and/or co-lead with more experienced leaders (Bush, 2008; Earley \& Jones, 2011; Eraut, 2009). A component of scaffolding new learning is providing good role models to observe and work with (Anderson \& Cawsey, 2008). These role models are normally more experienced and can come from within the school or be in another school (Barnett et al., 2012; Rhodes \& Brundrett, 2009).

Part of this modelling can come from a shared leadership model where a more experienced leader and the new TLR are can co-lead a certain area of responsibility (Barnett et al., 2012; Leithwood, 2003). Working alongside colleagues leads to the learning of new practices and perspectives and the less experienced leaders gain some sense of the other's tacit knowledge (Ahlgren \& Tett, 2010).

A mentoring/coaching relationship can also be established between a more experienced leader and the TLR rather than with the principal. Edwards, Butler, Hill, and Russell (1997) believe that an individual who is at the competent stage (Dreyfus, 
2004) of skill levels within a role (refer to Figure 2.3) is the most appropriate to be a mentor for novices and advanced beginners.

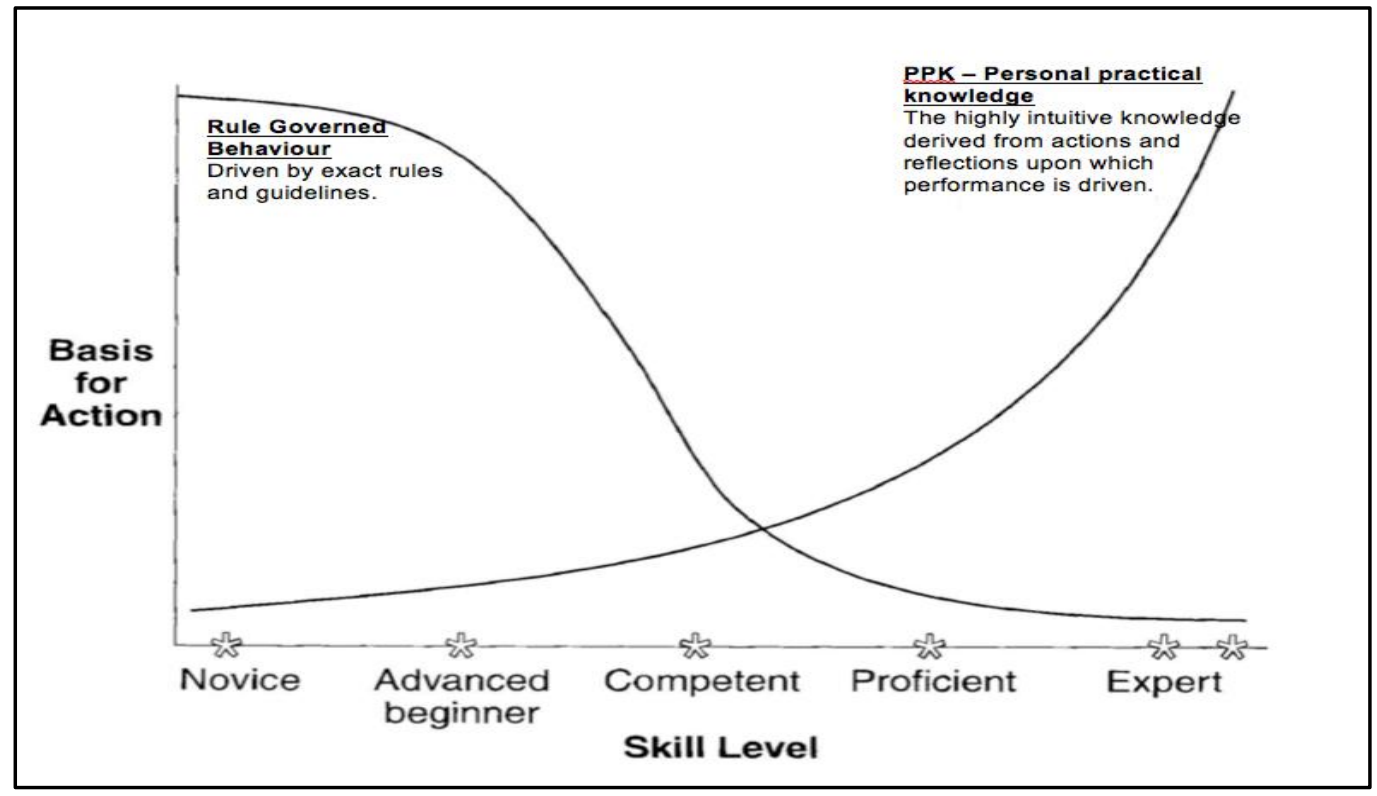

Figure 2.3: Growth from novice to expert (Edwards et al., 1997, p. 183)

Expert leaders, such as principals, utilise highly tacit and contextual personal practical knowledge to determine actions (Dreyfus, 2004; Edwards et al., 1997). They are driven by their own-context specific rules derived from manipulation of the deeply embedded, original rules to deal with different situations (Dreyfus, 2004; Edwards et al., 1997). Experts cannot generally remember or articulate those original rules that guide a novice (Dreyfus, 2004; Edwards et al., 1997). Consequently expert leaders may make poor mentors for first-time TLRs.

Meanwhile, competent leaders are efficient and organised in their roles but still draw on the structures and rules they relied upon when they were novices, to analyse and solve an issue (Dreyfus, 2004; Edwards et al., 1997). Competent individuals are able to provide clear steps and guidance for novice leaders as they can still distinctly articulate their analysis and plans in relation to the rule-governed behaviour which novices rely upon. When studying the effectiveness of mentoring programmes for provisionally registered teachers (PRTs) in New Zealand, Patterson (2013) found that some PRTs would prefer to have a mentor who had recently been through the process of becoming a registered teacher, as there was greater empathy and understanding. 
Lastly, allowing chances for TLRs to undertake the same PDL with other leaders provides motivation, peer support and a shared understanding and language (GilpinJackson \& Bushe, 2007). Briggs (2012b) and Gilpin-Jackson and Bushe (2007) suggest involvement of superiors in the same PD. This allows for greater facilitation and engagement with the learning for the TLRs (Gilpin-Jackson \& Bushe, 2007).

\subsubsection{Contextual factor three: Expectations of each person's role, performance and progress}

Throughout the literature reviewed, two distinct aspects of the contextual factor of expectations of each person's role, performance and progress that affect PDL within the workplace were identified. They were the recognition and support of beginning a new role and the understanding by the principal of the PDL needs of a TLR.

\section{Recognition and support of beginning a new role}

With support during a job transition, leaders begin a new job feeling enabled to perform effectively from the start (Vardi, 2000). "Rule governed behaviour" (Edwards et al., 1997, p. 183) directs an individual just starting out in a new position. Just like an individual learning to drive a car for the first time (Dreyfus, 2004) a novice leader needs to learn what is expected of them. They require exact rules for deciding what actions to take (Dreyfus, 2004), as they are unsure of what to do and where to start. Providing clear expectations from the start of what is expected in the leadership role in the form of a job description (Armstrong, 2012; Baecher, 2012; Belling et al., 2004; Eraut, 2009) gives a novice leader a commencement point and direction (Dreyfus, 2004).

Studies show that beginning TLRs did not understand the job expectations because role definitions were not provided (Barnett et al., 2012; Leithwood, 2003). Eraut (2004) also found the communication about job expectations for the teachers was very weak. This lack of direction may be derived from principals' not fully appreciating a TLRs job. Mangin (2007) findings showed a correlation between principals' knowledge of the teacher leaders roles with the amount of support the principals gave. It is important that principals understand the role of TLRs and all that is involved, including the issues and challenges they have and not just take for granted that TLRs will just assume their roles without problems (Briggs, 2012a; Clemans et al., 2010; Deece, 2003; Eraut, 2009). 


\section{Principal understanding of PDL needs of a TLR}

Principals need to ensure that they have sound understanding of the PDL needs of TLRs. Assumptions made by principals about teachers who move to a leadership position have been widely discussed in the literature (Baecher, 2012; Clarke, 2008; Patti et al., 2012; Pont et al., 2008). Teachers who seem natural at leading may have actually learnt those qualities somewhere in their past (Avolio, 2005) and whilst leadership may be natural for some people, most need PDL in order to become effective leaders (Patti et al., 2012). As Pont et al. (2008) suggests "traits in and of themselves do not produce leadership practice until they are combined with knowledge and competence and used to enact the particular performances of leadership practice" (p. 11).

Principals have a major responsibility for increasing positive teacher leadership. Unfortunately most principals are not taught how to do this (Childs-Bowen, Moller, \& Scrivner, 2000). Harvie (2009) found that the experienced New Zealand principals interviewed were unable to articulate their understanding of the development of leadership or the importance of it. Cardno (2005) believes that "unless leaders fully understand leadership development and have the skills to develop the leaders, they will not be effective in fulfilling this important role" (Cardno, 2005, p. 102). It is necessary for principals to be able to identify and understand the teaching and learning processes required for the PDL of TLR (Belling et al., 2004).

\subsubsection{Summary of enablers for PDL}

In summary the literature suggests principals are the leading learners in a school environment. They need to have a vision for leadership development and bring that vision to fruition through deliberate practices. The professional development of TLRs cannot be haphazard and informal. There must be a well thought out, practical plan with attention paid to supporting the learning through the contextual factors of allocation and structuring of work, encounters and relationships with people at work and clear expectations of each person's role, performance and progress. 


\subsection{Summary}

In this chapter the review of literature has firstly categorised existing types of PDL for TLRs and their effectiveness was identified and discussed. The different strategies mentioned were the structures of coaching and mentoring, professional learning communities, inquiry, self-directed learning and how a mixture of these can be combined to strengthen the development process and subsequently improve leadership capability. The power of infiltrating any PDL structure with the conditions of sharing, collaboration and reflection was then discussed. Finally the place of research and theory and the need for it to permeate all of these structures was explored. Next the issues and challenges of leaders new to a leadership position were outlined: the redefinition of the relationships with teaching colleagues conflict that may arise with the changing roles and the diminishing of leadership efficacy.

Finally, the recurring contextual factors of allocation and structuring of work, encounters and relationships with people at work and clear expectations of each person's role, performance and progress that enable effective PDL for TLRs were described. These factors were classified through deliberate practices that principals could carry out to enhance the PDL. Throughout the chapter adult learning theory has been included to support the findings and theory put forward from the research about PDL of TLRs. 


\section{; Chapter Three: Methodology and methods}

\subsection{Introduction}

An effective way of capturing a comprehensive snapshot of how teachers who are new to having leadership responsibilities in New Zealand primary schools are being supported in their roles is using a multiple case study as part of a mixed method research approach. To reach a wide-ranging and trustworthy answer to any research question it is necessary to select a suitable methodology. The level of the design quality found in the methodology contributes to the trustworthiness of the findings and inferences of a mixed-method study (Bush, 2007; Dellinger \& Leech, 2007; Teddlie \& Tashakkori, 2009).

This chapter firstly revisits the research aims then explains the paradigmatic choice of the mixed method approach and justifies the use of a multiple case study. The process of selection of participants is then shared. The rationale for and explanation of the data gathering procedures of a questionnaire, focus group interviews and individual interviews follow. After that are the descriptions of how both quantitative and qualitative data were analysed. Finally the issues concerning trustworthiness and ethics in this study are discussed.

\subsection{Research aims}

The purpose of this study was to explore the strategies carried out in New Zealand primary schools to support teachers who are new to a leadership role within the school. The main question that frames the methodology of this research is:

How are teachers, who are new to having leadership responsibility in New Zealand primary schools, supported in their role?

The sub-questions that facilitate further guidance are:

- What professional development and learning are new TLRs offered and/or encouraged to participate in?

- How effective do principals and TLRs consider the current PDL of TLRs?

- What factors enable effective PDL for TLRs within a school? 


\subsection{Theoretical underpinnings}

This research is approached through the interpretivist paradigm. Also known as constructivism (Creswell, 2012; Teddlie \& Tashakkori, 2009), the interpretivist paradigm assumes that there are many different social realities of a phenomenon (Creswell \& Clark Plano, 2011; Haverkamp \& Young, 2007). The understanding of that phenomenon is established through an individual's subjective interpretation of it (Creswell \& Clark Plano, 2011; Haverkamp \& Young, 2007; Mack, 2010; Merriam $\&$ Associates, 2002). Their views are influenced by "social interactions with others and their own personal histories" (Creswell \& Clark Plano, 2011, p. 40). The researcher must seek "to understand reality from the point of view of the other" (Creswell \& Clark Plano, 2011, p. 40) at one point in time, in a specific context (Burnett, 2012).

In this study it was important to capture the reality of the strategies utilised in different schools through the gathering of qualitative data since PDL of TLRs varies from school to school and there is no national, mandatory approach. Merriam and Associates (2002) believe that qualitative research can give a more comprehensive picture of the status of the PDL occurring as it can take into account the differences in participants, context and methodologies.

Whilst qualitative research is the predominant approach there was also some quantitative data gathered. Therefore a mixed method research approach was used. Tashakkori and Creswell (2007) broadly define mixed methods "as research in which the investigator collects and analyses data, integrates the findings, and draws inferences using both qualitative and quantitative approaches or methods in a single study" (p. 4). The reasons for using a mixed method approach in this study were to utilise both the quantitative and qualitative results in order to triangulate the data to ensure increased trustworthiness (Bryman, 2006; Greene, Caracelli, \& Graham, 1989) and to achieve greater completeness: a more thorough description and account of the phenomenon of PLD for TLRs (Bryman, 2006; Tashakkori \& Teddlie, 2008). A secondary reason for combining quantitative and qualitative methods was to obtain a suitable sample of participants from the quantitative stage to be used in the proceeding qualitative phase (Bryman, 2006; Creswell \& Clark Plano, 2011). 
The reason for collecting quantitative data was to create "an accurate description or picture of the status or characteristics of the situation or phenomenon" (Johnson \& Christensen, 2012a, p. 366). Johnson and Christensen (2012a) promote the use of descriptive research by educators to learn about "attitudes, opinions... and demographics" (p. 366) of the individuals they are studying. The qualitative data gathered allowed for a fairly accurate picture of the TLRs ' contexts, attributes and opinions.

\subsection{Case study}

A case study was used within the overarching interpretivist paradigm and the mixed methods approach. A case study is the in-depth description of how one or more cases, bounded and integrated systems, address a research issue (Creswell \& Clark Plano, 2011; Johnson \& Christensen, 2012a; Merriam \& Associates, 2002) subsequently providing a rich, holistic and contextual insight into a phenomenon (Johnson \& Christensen, 2012a; Merriam, 1988; Yin, 2003).

Merriam (1988) identified four factors to consider when determining whether a case study is the appropriate method to use. The first is the nature of research questions, Yin (2003) stated that a case study is a suitable approach when a how or why question is asked about a contemporary issue, within a real-life context. The research question is how are teachers, who are new to having leadership responsibility in New Zealand primary schools, supported in their role? This leads on to the second factor identified by Merriam (1988), the amount of control. She also states that a case study offers a means to investigate complex social units that contain many variables that have equal importance in understanding phenomenon. Yin (2003) points out that in a case study the researcher has little or no control. The social unit in this research was New Zealand primary schools which contain a plethora of variables that the researcher has no control over. Therefore the choice of case study was a suitable one.

A third element is whether a bounded system, or a case, can be identified (Merriam, 1988). A case can be a number of things; an object or unit with a clear identity or entities that are less well defined such as an event, activities or programmes (Johnson \& Christensen, 2012a; Yin, 2003). Within a programme the implementation process is studied. For this study, a case could be identified: the 
programme of professional development and learning of first time TLRs in different New Zealand primary schools.

The final deciding factor is the desired end product of the study (Creswell, Hanson, Clark Plano, \& Morales, 2007; Merriam, 1988). Merriam (1988) states "researchers are interested in insight, discovery and interpretation rather than hypothesis testing" (Merriam, 1988, p. 10). A case study inquiry relies on multiple sources of evidence, with a need to converge data in a triangulating fashion (Yin, 2003) in order to understand the meaning of an experience through multiple realities (Johnson \& Christensen, 2012a; Merriam, 1988). The decision was made for the study to be a multiple or collective case study (Creswell et al., 2007; Johnson \& Christensen, 2012a; Yin, 2003). This allowed for selection of one case but in a variety of different contexts (Yin, 2003).

A variety of Wellington primary schools provide multiple contexts to gather data concerning the case of PDL for TLRs. The use of a multiple case approach permitted for multiple sources of evidence and greater insights into understanding the type of PDL that is offered to first time TLRs. Yin (2003) states that a case study of a programme may reveal variations in it and depends on the perspectives of different actors. Through the multiple case study of different primary schools a variety of perspectives on this case were obtained.

\subsection{Data Collection}

Merriam and Associates (2002) states that "data collection is determined by research questions" (p. 12) and a researcher needs to select the methods or methods that will yield the best information to answer the questions. Onwuegbuzie, Dickinson, Leech, and Zoran (2009) and Creswell (2012) suggest multiple methods and data sources should be utilised for a case study as this provides triangulation of the data. Not only does using a number of methods increase the trustworthiness of the research (Merriam \& Associates, 2002) but also allows for the researcher to better understand their chosen phenomenon and answer the research question (Merriam \& Associates, 2002). In this multiple case study data was collected through the use of a questionnaire, followed by concurrent focus group interviews with volunteer TLRs and individual interviews with volunteer principals of the schools where TLRs were from. 
Figure 3.1 illustrates the timeline of the data collection process.

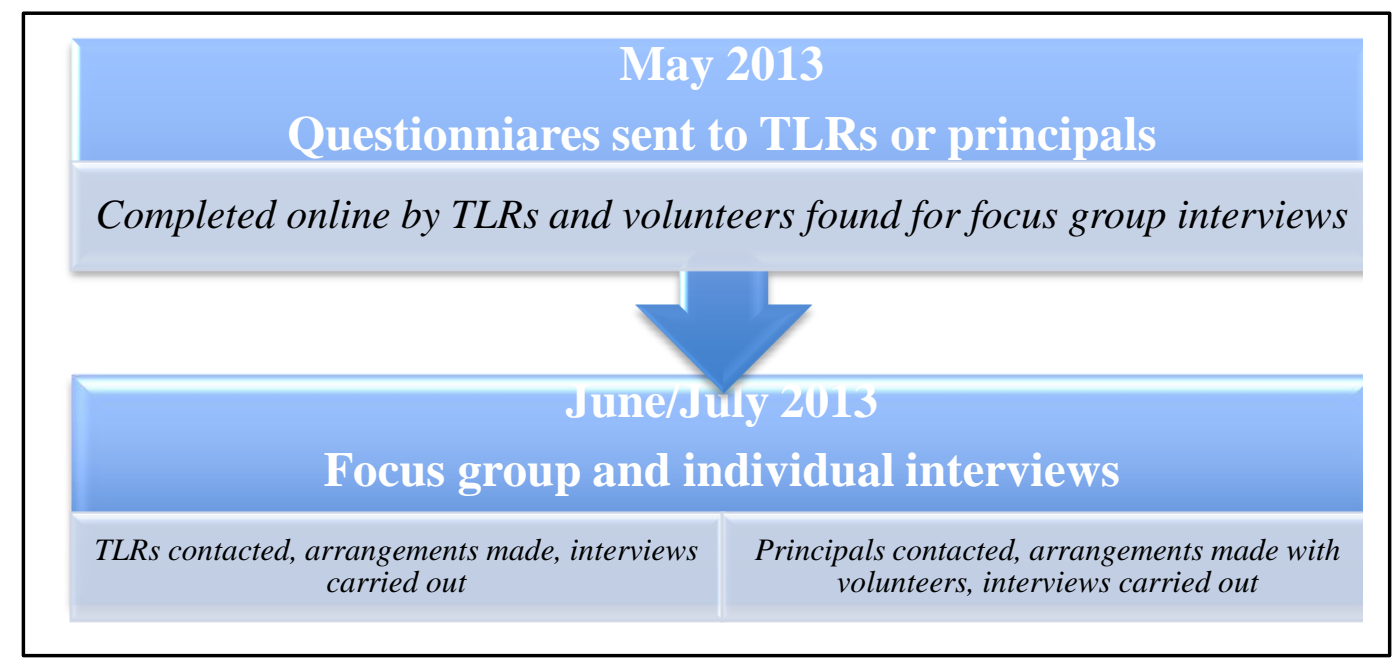

Figure 3.1: Timeline of data collection

\subsubsection{Participants}

The overall sampling used in this study was purposive or criterion-based selection (Creswell, 2012; Johnson \& Christensen, 2012a) in which the characteristics of a population are determined, appropriate individuals are located, contacted and asked to participate (Johnson \& Christensen, 2012a). Table 3.1 shows the type and description of each sample group.

Table 3.1: Participants in the study

\begin{tabular}{|c|c|c|c|}
\hline $\begin{array}{l}\text { Sample } \\
\text { Group }\end{array}$ & $\begin{array}{l}\text { Type of } \\
\text { sample }\end{array}$ & $\begin{array}{l}\text { Description of } \\
\text { sample }\end{array}$ & Additional notes \\
\hline Schools & Purposive & $\begin{array}{l}\text { - All primary and } \\
\text { intermediate schools in } \\
\text { greater Wellington area } \\
\text { - Student roll larger } \\
\text { than } 150 \\
\end{array}$ & $\begin{array}{l}\text { - List of schools compiled } \\
\text { from Wikipedia (2013) and } \\
\text { Ministry of Education (2013d) } \\
\text { website }\end{array}$ \\
\hline Questionnaire & Purposive & $\begin{array}{l}\text { - Teachers holding a } \\
\text { designated TLR } \\
\text { position } \\
\text { - Clearly identified on } \\
\text { school website as a } \\
\text { TLR }\end{array}$ & $\begin{array}{l}\text { - Principals contacted if no } \\
\text { information about TLRs on } \\
\text { school website and asked to } \\
\text { forward e-mail to TLRs } \\
\text { - } 194 \text { TLRs directly contacted } \\
\text { (see Appendix E for e-mail) } \\
\text { - } 86 \text { principals e-mailed (see } \\
\text { Appendix F for e-mail) }\end{array}$ \\
\hline Focus Groups & Convenience & $\begin{array}{l}\text { Individuals volunteered } \\
\text { from questionnaire }\end{array}$ & $\begin{array}{l}\text { - (See Appendices G,H and } \mathrm{J} \\
\text { for e-mails) }\end{array}$ \\
\hline Principals & Convenience & $\begin{array}{l}\text { Principals of teachers } \\
\text { volunteering for focus } \\
\text { groups were invited to } \\
\text { participate }\end{array}$ & - (See Appendix K for e-mail) \\
\hline
\end{tabular}




\subsubsection{Questionnaire}

The quantitative component of the study was the questionnaire. Johnson and Christensen (2012a) describe the purpose of a questionnaire as accessing and understanding some of the variables within the research questions through the participants' responses. Questionnaires are a standardised method of collecting data for both large and small groups (Basit, 2010; Johnson \& Christensen, 2012a). Through the use of a mixed method questionnaire, quantitative and qualitative data can be gathered about exact information required by the researcher and also elicit attitudes about aspects of a phenomenon (Johnson \& Christensen, 2012b). Pragmatically, questionnaires have a quick turnaround and are inexpensive to administer.

The questionnaire was created and administered using the on-line survey tool Qualtrics. The rationale of the questionnaire was to gather initial data about:

- The school context of the TLRs;

- The type of PDL that the TLRs had participated in;

- TLRs thoughts about the efficiency of the PDL and;

- TLRs opinions on the place of PDL for TLRs.

The questionnaire consisted of a mixture of open and closed questions using exhaustive response categories, numerical rating scales and checklists (Johnson \& Christensen, 2012a) The questionnaire was piloted on two leadership colleagues who had the same characteristics as those who were invited to participate (Johnson \& Christensen, 2012a). In doing so some areas of confusion were exposed (Johnson $\&$ Christensen, 2012a) and questions were modified to address them (See Appendix A for questionnaire).

Since TLRs are very busy people and their time is precious, it was important to keep the questionnaire relevant, comprehensible and able to be completed within a short period of time. This also helped to ensure that more people responded (Basit, 2010; Johnson \& Christensen, 2012a). Another strategy to enhance the success of a questionnaire was to show empathy toward the participants through the questions and to "think like" (Johnson \& Christensen, 2012a, p. 165) them by writing 
questions that they would understand. This was easily achieved due to the researcher's career background.

TLRs who chose to participate accessed the questionnaire through a link included on the information e-mail they received inviting them to participate. The mean time for completing the questionnaire was 11 minutes.

\subsubsection{Focus group interview sampling}

A decision was necessary as to whether individual and/or focus group interviews were held. Onwuegbuzie et al. (2009) suggest that a focus group requires between six to twelve participants to obtain sufficient diversity. However the numbers cannot be any larger than that as an environment may occur where the members do not feel safe in sharing their thoughts (Onwuegbuzie et al., 2009). It was planned that if six or more teachers indicated that they would participate in a focus group then only focus groups interviews would be carried out. Teachers who specified preference for an individual interview would be e-mailed and thanked for their willingness to participate and given the option to either join in a focus group interview or not have

an interview at all. The number of focus group interviews held depended upon the numbers of volunteers there were with a maximum of three focus groups as this was manageable and Vaughn, Schumm, and Sinagub (1996) suggest a focus group should be replicated at least once.

\subsubsection{Focus group interview}

Questionnaires have a limited ability to create a full picture of the participants or the contextual factors that influence the degree of effect of the professional development (Conger, 1998). Rubin and Rubin (2005) consider that interviews provide an opportunity for researchers to better understand an individual's experience and reality of a phenomenon, whilst Merriam (1988) and Silverman (2006) assert that interviews are useful when a researcher cannot directly observe the phenomenon. Within a focus group interview the researcher is able to gain multiple views and realities of the phenomenon (Johnson \& Christensen, 2012a). Interviews also allow for more in-depth discussion and deeper probing (Johnson \& Christensen, 2012a; Vaughn et al., 1996) about issues and themes that arise from a questionnaire. 
Focus group interviews are economical and a fast and efficient way to gather meaningful data from many participants (Vaughn et al., 1996). With the socially oriented environment that is present in a focus group interview, a sense of belonging is engendered. Consequently there is a greater sense of cohesiveness and participants feel safer in sharing their ideas and opinions (Onwuegbuzie et al., 2009; Vaughn et al., 1996). The interaction that comes with multiple members within a focus group creates a better chance of significant and more spontaneous responses being shared (Onwuegbuzie et al., 2009; Vaughn et al., 1996). Finally, interviews gather evidence that is more accurate and valid than other methods of data collection (Merriam, 1988; Vaughn et al., 1996). The purposes of the focus group interviews in this study were to generate discussion about the type of PDL that has the most impact upon the participants' efficacy as leaders, find out what other strategies they considered would be useful, and what had been the enablers and barriers during the PDL.

The interviews took a semi-structured approach (Bush, 2007) where there were planned questions as well as probes and prompts. A list of questions to initiate discussion was derived from Harvie (2009) and questions that arose from themes identified in the questionnaire were used alongside supplementary probing questions (Rubin \& Rubin, 2005) in order to clarify responses and gain a deeper understanding (See Appendix B for interview questions). The continuous use of the probing questions ensured that answers given were comprehensive enough to allow for more comprehensive transcripts (Kvale, 2007). Kvale (2007) espouses that interviews should not follow content, but rest on the judgment of the interviewer. It is important for the interviewer to be an active listener, as they need to respond appropriately to what is being said in order to glean as much useful information from the interview as possible (Kvale, 2007).

It is also helpful for the interviewer to know the main themes of the research in order to ask appropriate probing second questions (Kvale, 2007; Rubin \& Rubin, 2005). To steer this type of interview guide approach (Johnson \& Christensen, 2012a) a sheet drawing on Kvale (2007) was created to refer to. The sheet had the planned questions on it, as well as the research question, with lines indicating how the interview questions were linked with the respective research questions. Prompts for 
second questions were also included (See Appendix $\mathrm{C}$ for guide sheet). At times wording of the questions was changed slightly so that the participants understood clearly the questions, which is characteristic of an interview guide approach (Johnson \& Christensen, 2012a).

Eleven TLRs volunteered and opted for the focus group interviews. Two focus groups were planned. The demographic variable of years of leadership experience (Breen, 2006) was used to form the groups as this was convenient and it allowed for the members of each group to have had similar experiences of leadership (Breen, 2006). Once details had been finalised for each focus group some individuals were unable to attend on the specific day and others were unable to turn up on the day, as they were unwell. Therefore, on the days of each focus group, the new TLRs had four members and the experienced TLRs had three. These were both insufficient numbers to allow for diversity within the groups (Onwuegbuzie et al., 2009). However Krueger (1994) advocates the use of "mini-focus groups" (Onwuegbuzie et al., 2009, p. 17) with three to four members when specialised knowledge and/or experience is being discussed. This was evident in the groups as the conversations were fluid with valuable information being discussed and gathered.

In order to gather as much first-hand data as possible about the phenomenon from TLRs, individual interviews were held for the four TLRs who had missed the focus group interviews. Three of these were carried out face-to-face with one held as a phone interview. The same approach to questioning was used for these interviews. The focus group interviews were 60 minutes and 90 minutes respectively while the individual interviews lasted between 30 minutes to 90 minutes. All interviews were recorded using the I-phone application of Supernote and were then transcribed for analysis. Transcripts of audio data provided an "excellent record of "naturally occurring' interaction" (Silverman, 2006, p. 20).

\subsubsection{Individual principal interviews}

School principals of the teachers who were involved in the focus group or individual interviews were invited to participate in an individual interview. This enabled the interviewer to obtain a deeper understanding of the reasons for the type of PDL for TLRs that the school has chosen to undertake, the impact that the PDL has had on 
the TLR and provides an opportunity to identify the barriers and enablers from the school management view point.

Four out of a possible ten principals volunteered to participate in an individual interview. As with the focus group questions the interview questions were adapted from Harvie (2009) and included an additional question after questionnaire data analysis (see Appendix D for interview questions). The principal interviews were undertaken with the same semi-structured approach as the focus groups. The interviews were recorded using the I-phone application of Supernote and were then transcribed for analysis. The interviews lasted between 45 to 60 minutes.

\subsection{Data analysis}

The qualitative and quantitative data sets were analysed separately. Creswell and Clark Plano (2011) suggest that analytical approaches used should be most appropriate for the respective components and then a decision needs to be made as to when the data will be incorporated. For the purpose of this study the findings were kept separate and then integrated in the discussion chapter.

\subsubsection{Quantitative data analysis}

In the questionnaire there were 15 quantitative and four qualitative questions. A descriptive analysis (Basit, 2010; Johnson \& Christensen, 2012a) of the quantitative data was used. For small-scale research such as a Masters' thesis descriptive analysis is appropriate to use (Basit, 2010) in order to identify trends (Creswell, 2012). Descriptive statistics include graphs, measures of general tendencies, variability and distribution (Basit, 2010; Creswell, 2012; Johnson \& Christensen, 2012a). Analysing these elements allows researchers to explore data by summarising, describing and presenting without making inferences or predictions (Basit, 2010; Creswell, 2012; Johnson \& Christensen, 2012a).

Qualtrics provided facility to reduce the raw data down to frequency tables, graphs and the descriptive statistics of mean, range, variance and standard deviation. Subsequent analysis was made of the questions that were presented in the questionnaire. 


\subsubsection{Qualitative data analysis}

There is no one, unique way to analyse qualitative data (Creswell, 2012; Merriam, 1988). Both Creswell (2012) and Merriam and Associates (2002) see analysis as being inductive. Inductive analysis was used to analyse the qualitative data from both the questionnaire and interviews in this study. Leech and Onwuegbuzie (2008) suggest a similar approach but use a different name, constant comparison analysis (CCA). The primary purpose of inductive analysis or CCA is to allow findings to rise from the data and to build a subsequent model of theory about the phenomenon (Leech \& Onwuegbuzie, 2008; Thomas, 2006). Inductive analysis not only enables researchers to describe the planned effects of a programme but the unplanned and unanticipated outcomes as well (Thomas, 2006). The process of inductive analysis or CCA is moving from detailed data to general code and themes (Creswell, 2012; Leech \& Onwuegbuzie, 2008; Merriam \& Associates, 2002; Thomas, 2006).

To analyse the raw, qualitative data of the questionnaire it was downloaded from Qualtrics and recordings of all interviews were transcribed as mentioned earlier. Although the analysis of the questionnaire data and interview data were done separately and subsequent to each other the same process was used for both. Johnson and Christensen (2012a) name the first step as open coding where data is read thoroughly, to provide a general sense of the data (Creswell, 2012). Anecdotal notes were added at this time that highlighted pertinent phrases, ideas and concepts (Creswell, 2012; Thomas, 2006). Once this was achieved open coding followed by assigning a word or phrase that accurately described the essence of the data (Creswell, 2012; Leech \& Onwuegbuzie, 2008; Thomas, 2006). Quotations from the transcripts that were seen as valuable illustrations of the code, and could be used in the results to add realism (Creswell, 2012) were highlighted at the same time.

Following that, axial coding (Johnson \& Christensen, 2012a; Leech \& Onwuegbuzie, 2008) took place; codes were categorised into themes by putting similar codes together to form major ideas that arose from across the data (Creswell, 2012; Thomas, 2006). From the axial coding of data collected from TLRs, four themes in relation to PDL were identified: effectiveness, conditions, type and content. A fifth additional theme was identified, the experiences of a new leader. The same themes were identified from the principals' interview data with two additional themes being 
added, challenges for leaders and principal's expectations. Yin (2003) says that in a case study the analysis should always address the most significant aspects of the data and avoid the lesser issues. Therefore, during analysis, careful decisions were made to omit some of the data in the axial coding.

Finally, selective coding (Johnson \& Christensen, 2012a; Leech \& Onwuegbuzie, 2008) was done where the themes were aggregated together in relation to the research questions in order to write the findings (Creswell, 2012; Thomas, 2006). Throughout the analysis it was important to be mindful that the codes and themes were created from multiple interpretations and influenced by the researcher's assumptions and experiences (Thomas, 2006). Meeting with a research supervisor allowed for the checking of bias (Merriam, 1988) and clarifying analysis in order to ensure accuracy and fairness.

\subsection{Trustworthiness}

To strengthen the trustworthiness of this study, respondent triangulation (Bush, 2007; Teddlie \& Tashakkori, 2009) was used where the same questions were asked of different participants (Bush, 2007). Bush (2007) suggests that triangulation provides a comparison of sources to determine accuracy of information by crosschecking the data, and is a useful strategy in case studies to improve trustworthiness (Bush, 2007; Johnson \& Christensen, 2012a; Teddlie \& Tashakkori, 2009).

Another strategy utilised to increase trustworthiness was to discuss parts of the data analysis with a research supervisor, as a "disinterested peer" (Tashakkori \& Teddlie, 2008, p. 109), in order to ensure that it was accurate and fair. All interview participants were sent a transcript of the interview they were involved in and were asked them to check the transcripts for accuracy (Bush, 2007). This improved the interpretive validity of the study by ensuring accurate portrayal of contributions (Bush, 2007; Johnson \& Christensen, 2012a).

A final element that has helped increase the trustworthiness of this study was researcher knowledge and understanding of the culture and contexts that the TLRs and principals are involved in due to personal educational experience. "Knowing thy participants" (Teddlie \& Tashakkori, 2009, p. 289) is a golden rule for making 
accurate inferences in human research (Teddlie \& Tashakkori, 2009).

\subsection{Ethical considerations}

Johnson and Christensen (2012a) says "ethics are the principles and guidelines that help us uphold the things we value" (p. 99). Educational research involves working with people. The treatment of these people is the highest priority for a researcher (Johnson \& Christensen, 2012a). It is important for a researcher to behave ethically in order to protect those individuals' integrity (McCormack et al., 2012) and right to privacy. The treatment of these individuals is the most important and fundamental issue that researchers confront (Johnson \& Christensen, 2012a).

Initially ethics approval was sought and granted from the Victoria University of Wellington Human Ethics Committee following the guidelines as set out in the Human Ethics Policy (Victoria University of Wellington, 2007). Informed consent was sought from participants after a clear explanation of the research purpose and process and assurances of confidentiality (Johnson \& Christensen, 2012a) (See Appendices I and L for consent forms).

To reinforce confidentiality (Breen, 2006) interviewees were reminded that the reporting would be transcribed and pseudonyms would be used in all stages of the research to ensure anonymity. Focus group members were asked to refrain from discussing the content of the interview with others and to respect the rights of each of the members to remain anonymous (Vaughn et al., 1996). The transcribing and handling of data was done entirely by the researcher and was shared only with her supervisor. Electronic data was stored with only password access.

\subsection{Summary}

A well-documented methodology can increase trustworthiness within any type of research (Bush, 2007; Dellinger \& Leech, 2007; Teddlie \& Tashakkori, 2009). This chapter has explained why the choice of mixed methods matches the purpose of this study and how the use of multiple case studies addresses the research questions (Teddlie \& Tashakkori, 2009). To ensure analytical adequacy, thorough yet succinct reasons for, and descriptions of, quantitative and qualitative data analysis has been provided (Teddlie \& Tashakkori, 2009). Finally the notions of trustworthiness and ethical considerations are clarified by describing how the design procedures were 
implemented, with the necessary care, to effect an accurate and well considered description of the phenomenon of professional development and learning for new teachers with leadership responsibilities research (Teddlie \& Tashakkori, 2009). 


\section{Chapter Four: Questionnaire findings}

\subsection{Introduction}

This chapter presents the findings from the online questionnaire completed by TLRs in the Wellington area. The questionnaire had both quantitative and qualitative components. The quantitative data, gathered as a result of the questionnaire, provided teaching and leadership backgrounds of the participants. The qualitative data gathered opinions and allowed for TLRs to comment on their PDL experiences.

The online survey tool Qualtrics through which the questionnaire was administered was used to reduce the data to frequencies, percentages and means. The data from the closed questions has been organised to compare first time and more experienced leaders. The purpose of this comparison was to investigate how teaching and leadership histories and opinions varied between the two groups.

Data from the qualitative questions has been grouped according to the research questions and will be reported as such. Firstly the teaching and leadership background and context of the participants will be presented. Secondly results on the type of PDL the participants have experienced will be reported on. The issues and challenges that the participants experienced as first time leaders will follow. Next the PDL that the participants found effective will be discussed and lastly the identified enablers for PDL will be examined.

Although Qualtrics records show that 42 surveys were completed only 36 individuals answered the questions. Of those 36, 15 were first-time leaders and 21 were more experienced leaders. For the purpose of identifying the type of TLR quoted in this chapter and the discussion the following codes will be used as shown in Table 4.1.

Table 4.1: TLR coding

\begin{tabular}{|l|l|l|l|}
\hline First category & Code & Second category & Code \\
\hline First-time leader & FTL & Syndicate/Team leader & TL \\
\hline Experienced leader & EL & Associate/Assistant/Deputy principal & AP/DP \\
\hline & & Pedagogical leader of a curriculum area & CL \\
\hline & & $\begin{array}{l}\text { Specific / Designated whole-school } \\
\text { responsibility }\end{array}$ & WSR \\
\hline
\end{tabular}




\subsection{Teaching and leadership background}

The teaching and leadership background of participants were similar within the respective groups of first-time leaders and more experienced leaders but varied between the two groups. Table 4.2 shows the duration of teaching and leadership experience of all participants as fully registered teachers (FRTs).

\section{Table 4.2: Teaching and leadership background}

\begin{tabular}{|c|l|c|c|c|}
\hline Question & Category & FTLs & ELs & Total \\
\hline \multirow{4}{*}{$\begin{array}{c}\text { How many years have you been } \\
\text { teaching as a fully registered } \\
\text { teacher? }\end{array}$} & Under 1 year & 2 & 0 & 2 \\
\cline { 2 - 5 } & $1-4$ years & 2 & 0 & 2 \\
\cline { 2 - 5 } & $5-10$ years & 4 & 3 & 7 \\
\cline { 2 - 5 } & $11-15$ years & 5 & 4 & 9 \\
\cline { 2 - 5 } & $15-20$ years & 0 & 9 & 9 \\
\cline { 2 - 5 } & $20+$ years & 2 & 5 & 7 \\
\hline \multirow{4}{*}{$\begin{array}{c}\text { How many years have you been } \\
\text { teaching at your present school? }\end{array}$} & Under 1 year & 0 & 1 & 1 \\
\cline { 2 - 5 } & $1-4$ years & 5 & 9 & 14 \\
\cline { 2 - 5 } & $5-10$ years & 7 & 7 & 14 \\
\cline { 2 - 5 } & $11-15$ years & 2 & 3 & 5 \\
\cline { 2 - 5 } & $15-20$ years & 1 & 1 & 2 \\
\cline { 2 - 5 } & $20+$ years & 0 & 0 & 0 \\
\hline \multirow{2}{*}{$\begin{array}{c}\text { How many years have you been in } \\
\text { your present role of a teacher with } \\
\text { leadership responsibilities? }\end{array}$} & Under 1 year & 7 & 4 & 11 \\
\cline { 2 - 5 } & $1-2$ years & 5 & 3 & 8 \\
\cline { 2 - 5 } & $3-4$ years & 2 & 7 & 9 \\
\cline { 2 - 5 } & $5+$ years & 1 & 7 & 8 \\
\hline
\end{tabular}

In each category the numbers of leaders vary between the first time leaders and experienced leaders. Many of the new leaders had been FRTs for 5 to 15 years. A similar number of experienced leaders had been FRTs for 15 years or more. It is notable that two of the first time leaders had been FRTs for less than a year whilst two other first-time leaders are at the opposite end of the scale with 20 plus years as FRTs.

A greater number of new leaders had been at their present school for a longer period of time than the majority of experienced leaders. Three of the new leaders have been at the present school longer than 11 years. Conversely the majority of the same new leaders had been in the leadership role less than two years whereas a large proportion of the experienced leaders had been in their present leadership role for over three years. 
Table 4.3 presents the teaching and leading context of participating TLRs.

Table 4.3: Teaching and leading context

\begin{tabular}{|c|c|c|c|c|}
\hline Question & Category & FTLs & ELs & Total \\
\hline \multirow{4}{*}{$\begin{array}{l}\text { How many staff do you } \\
\text { regularly work/interact with } \\
\text { as their leader? }\end{array}$} & Syndicate / Team Leader & 8 & 7 & 15 \\
\hline & $\begin{array}{l}\text { Associate / Assistant / Deputy } \\
\text { Principal }\end{array}$ & 4 & 11 & 15 \\
\hline & $\begin{array}{l}\text { Pedagogical leader of a curriculum } \\
\text { area }\end{array}$ & 1 & 3 & 4 \\
\hline & $\begin{array}{l}\text { Specific / Designated whole-school } \\
\text { responsibility }\end{array}$ & 2 & 0 & 2 \\
\hline \multirow{6}{*}{$\begin{array}{l}\text { How many staff do you } \\
\text { regularly work / interact with } \\
\text { as their leader? }\end{array}$} & $1-2$ staff members & 2 & 0 & 2 \\
\hline & $3-4$ staff members & 5 & 5 & 10 \\
\hline & 5 - 6 staff members & 3 & 4 & 7 \\
\hline & $7-8$ staff members & 3 & 1 & 4 \\
\hline & $9-10$ staff members & 0 & 1 & 1 \\
\hline & 10+ Staff members & 2 & 10 & 12 \\
\hline
\end{tabular}

The main role for just over half of new leaders is as a team leader as shown in Table 4.3. In comparison, almost the same numbers of experienced leaders are assistant, associate or deputy principals (AP/DP). Four new leaders are also in an AP/DP role. The largest group of new leaders regularly interact with three to four staff members in their capacity as a leader, with the next biggest group working with between five to eight staff members. Two of the new leaders work with over ten staff members in their role as a curriculum leader. Higher numbers of experienced leaders tend towards working with greater numbers of teachers with almost half interacting with over ten staff members in their role as a leader. 


\subsection{Types of leadership PDL}

The trend of similar data within the separate cohorts of lesser and more experienced leaders, with some variance between the two groups as reported in teaching and leading backgrounds continued for the types of PDL. Figure 4.1 shows responses of participants when asked if they had had PDL in their present leadership role. Close to a half of the new leaders agreed that they had with a third disagreeing. Conversely a majority of the experienced leaders agreed or strongly agreed with the question.

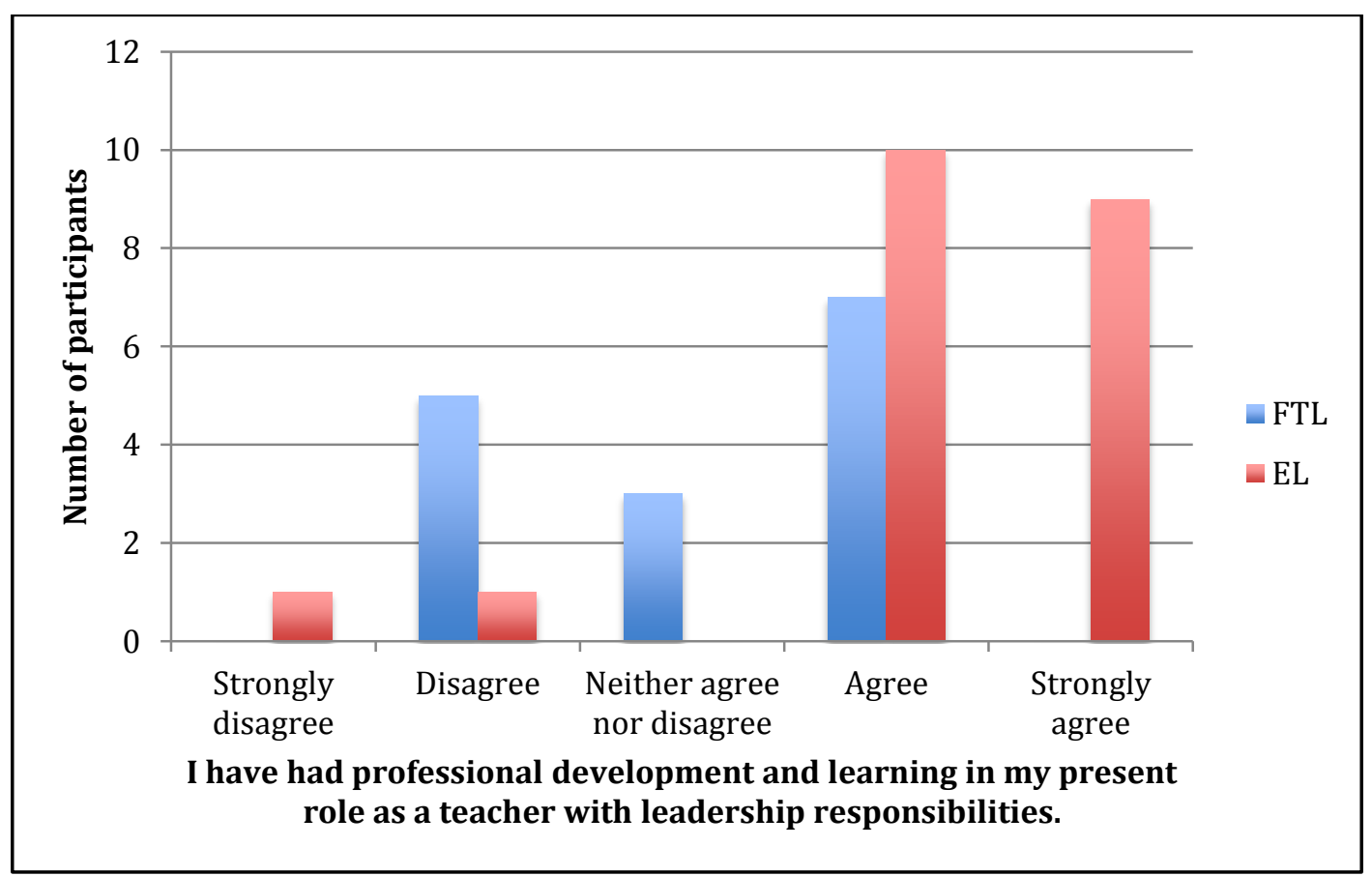

Figure 4.1: Leadership PDL experiences

Asked to comment on the questions of PDL provided in their present leadership role, one first-time leader with 20 plus years as a FRT remarked that they had not received any leadership PDL. A first time leader who had been in a AP/DP role between three to four years commented that although they were receiving PDL now, they had not received anything in the first year of leadership. Another new leader responsible for $\mathrm{ICT}^{1}$ within the school received content support from the previous leader but as of May 2013, when this questionnaire was administered, the leader had not received any organised leadership PDL.

\footnotetext{
${ }^{1}$ ICT - Information communications technologies
} 
Two other leaders identified informal mentoring relationships with fellow staff and teaching colleagues in the wider educational environment as the leadership PDL that they have received. Meanwhile one other felt that self-directed learning was the PDL he/she had received thus far.

Two leaders mentioned that the schools they had organised formal PDL for TLRs within their schools. Similarly two others identified that as part of whole school development of curriculum and pedagogical practices they have been developing leadership skills.

Table 4.4 displays the types of leadership PDL in which participants indicated they had participated. To classify the responses gathered, Eraut's (2004) categories of formal and informal learning conditions were used. It was difficult to determine whether the mentoring and coaching mentioned by the participants was formal or informal learning as Eraut (2004) classifies formal learning as having the presence of a designated teacher or trainer.

Table 4.4: Types of PDL

\begin{tabular}{|c|c|c|c|c|}
\hline Question & Category & FTLs & ELs & Total \\
\hline \multirow{14}{*}{$\begin{array}{l}\text { What professional } \\
\text { development and } \\
\text { learning modes for } \\
\text { leadership and } \\
\text { management have } \\
\text { you participated in? }\end{array}$} & \multicolumn{4}{|l|}{ Formal learning } \\
\hline & A one off, off site, leadership course & 3 & 9 & 12 \\
\hline & A seriated, off site, leadership course & 1 & 11 & 12 \\
\hline & $\begin{array}{c}\text { As part of an in-school curriculum development run by } \\
\text { an outside agency }\end{array}$ & 5 & 14 & 19 \\
\hline & Post - graduate study & 2 & 5 & 7 \\
\hline & Leadership conference & 3 & 13 & 16 \\
\hline & \multicolumn{4}{|c|}{ Formal and/or informal learning } \\
\hline & Mentoring & 7 & 9 & 16 \\
\hline & Coaching & 4 & 9 & 13 \\
\hline & \multicolumn{4}{|l|}{ Informal learning } \\
\hline & Action / Inquiry research & 3 & 4 & 7 \\
\hline & Shadowing another leader & 2 & 3 & 5 \\
\hline & Leadership cluster groups & 3 & 10 & 13 \\
\hline & Other & 3 & 5 & 8 \\
\hline
\end{tabular}

In many instances participants mentioned the use of mentoring relationships that concerned reactive or deliberative informal learning rather than pre-determined, organised mentoring. Therefore, unless the nature of the relationship was clearly specified both mentoring and coaching will be placed in a formal and/or informal 
learning situation.

Table 4.4 shows that half of the first time leaders have had some form of mentoring as part of leadership PDL. Slightly less of the experienced teachers have also participated in a mentoring relationship. With the exception of formal PDL as part of an in-school curriculum development run by an outside agency, close to one fifth of the new leaders have participated in some style of formal or informal leadership PDL. One new leader has also participated in a formal learning, seriated, on site, leadership course. Another first time leader did not select any types of PDL they identified that they had had no form of PDL to assist in developing their leadership role.

Meanwhile close to two thirds of the experienced leaders have had formal leadership PDL through in-school curriculum development run by an outside agency and/or leadership conferences. Close to 50 percent participated in informal learning leadership cluster groups such as quality learning circles, mathematics lead teacher cluster groups, and assistant principal, associate principal, deputy principal clusters. A number of the experienced leaders have attended NAPP, formal PDL in a seriated, offsite, leadership course that involves components of mentoring, inquiry research and cluster groups.

\subsection{Issues and challenges for first-time TLRs}

When asked what the issues and challenges were starting out as a leader for the first time very similar responses were made by all TLRs regardless of level of experience. Three main areas identified from responses made were: familiarisation with the new role, change in relationships and demanding workload.

The leaders expressed the frustration of not knowing what was expected of them as a leader or inconsistent expectations from their superiors. One participant spoke of moving straight from the provisionally registered teacher position into a team leader position and not really knowing what to do. For other leaders there was the demand to not only familiarise oneself with the new role but also a new school. They suggest that having some guidelines such as a job description would have been useful as the following comments show: 
Lack of role description and having to feel around in the dark a bit (FTL, $A P / D P)$

In my role as a maths curriculum leader I find it frustrating not to have a clear description of my responsibilities (EL, TL).

Poorly defined chains of responsibility, inconsistent expectations from principal and deputy principal (FTL, TL).

The change in relationships with other staff members and how to deal with this was another issue identified by the leaders when becoming a first-time leader. One leader commented on how it was sometimes uncomfortable at the beginning of their new leadership role as they had been part of that same team for a few years beforehand. Another leader struggled with being a young leader of older staff.

As part of these changing relationships and a new leadership role many of the participants encountered issues they had not had to deal with before such as poorly performing teachers, managing different adult personalities and leading change. Consequently, in light of altering relationships, the leaders experienced feelings of frustration, apprehension and conflict with staff who were described as passive resistors, consistently negative and demonstrated non-professional behavior towards their colleagues. This led to another challenge for the new leaders; having to carry out the necessary difficult conversations to address these difficulties. Two participants wrote about the interpersonal relationships with the staff when becoming a TLR:

Dealing with staff has been the biggest challenge...the passive resistor who appears to be 'on board' with the PD the school is undertaking but actually isn't (EL, AP/DP).

Dealing with push back behaviour, others who come across as consistently negative (FTL, AP/DP).

Finally, time and workload management was regarded as challenge by many of the leaders when starting out as a new leader. For many it is seen as an ongoing issue. The participants felt that there are many demands required of them and not enough 
time to fit it all in. One new leader getting used to her numerous roles within a school wrote:

The first few weeks of term I felt as though I was running from meeting to class to meeting to duty...if I got 10 minutes to sit down on the day to have a bite to eat I felt lucky! (FTL, TL).

Linked with the time and workload issue is the tension that many of the leaders felt between teaching and leading. Some likened it to a juggling act between the two, and as teachers and leaders with integrity, they felt torn between their responsibilities to the students in the class as well as to the teachers that they lead and to the school in general. One teacher expressed the concern that workload and lack of time were diminishing the opportunity to be an educational leader:

Balancing the needs of the children in your class with the responsibilities of leading a syndicate, being available to support syndicate members and meeting school expectations/targets (EL, TL).

Another said:

If leadership is only concerned with the daily management tasks, it can feel quite draining and overwhelming - there is always so much to do (FTL, TL).

Figure 4.2 illustrates how important a vast majority of the leaders participating in this questionnaire felt about the need for leadership PDL for TL

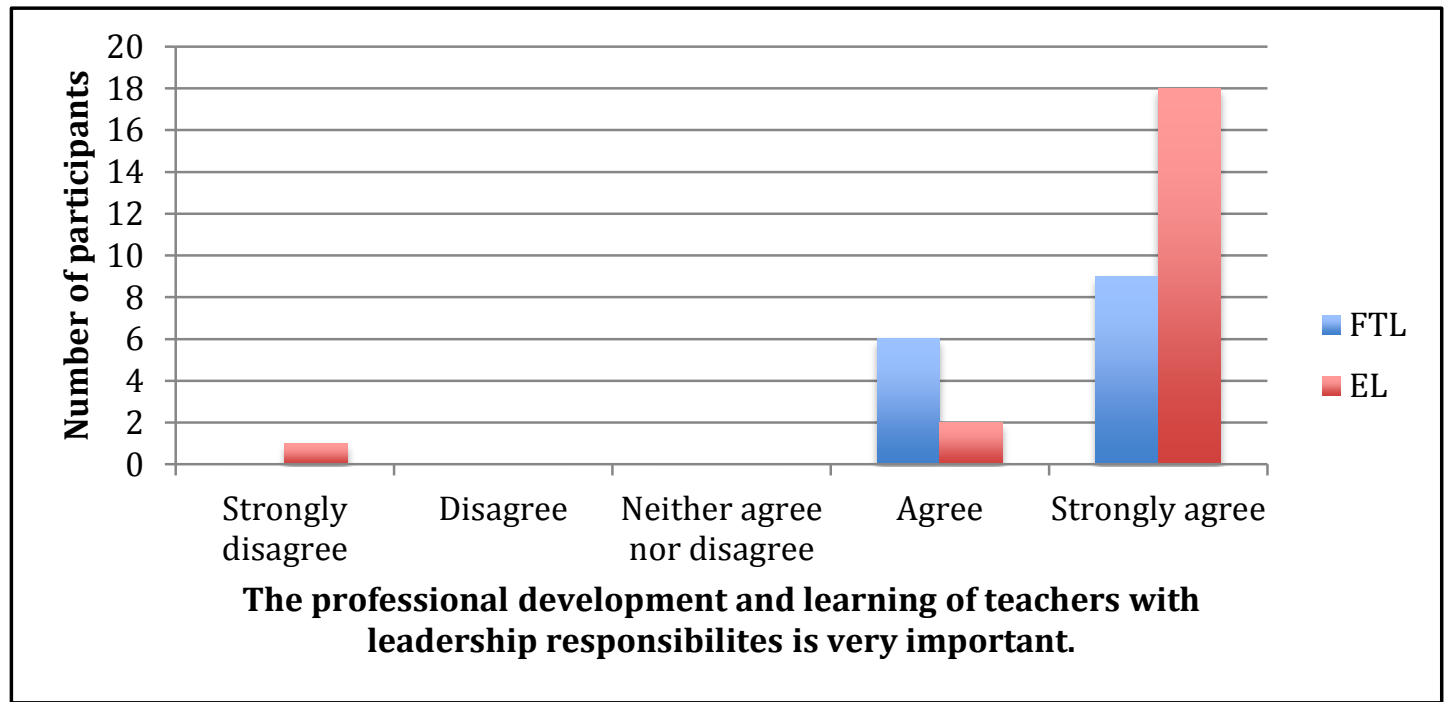

Figure 4.2: Importance of leadership PDL 
The optional comments support these strong opinions and submissions and illustrate the issues and challenges a new leader faces:

Leading other teachers is quite a different role to teaching a class so it is important that middle leaders are supported. It is a big job to juggle classroom teaching alongside the additional responsibilities so that is something else leaders need support in negotiating (FTL, TL).

This should be provided to anyone in a leadership role for the first time how to work with others and how to present to others (FTL, AP/DP).

\subsection{Effectiveness of leadership PDL}

The opinions on whether the leadership PDL experienced had enhanced leadership capabilities varied greatly between first time and experienced TLRs as seen in Figure 4.3 below.

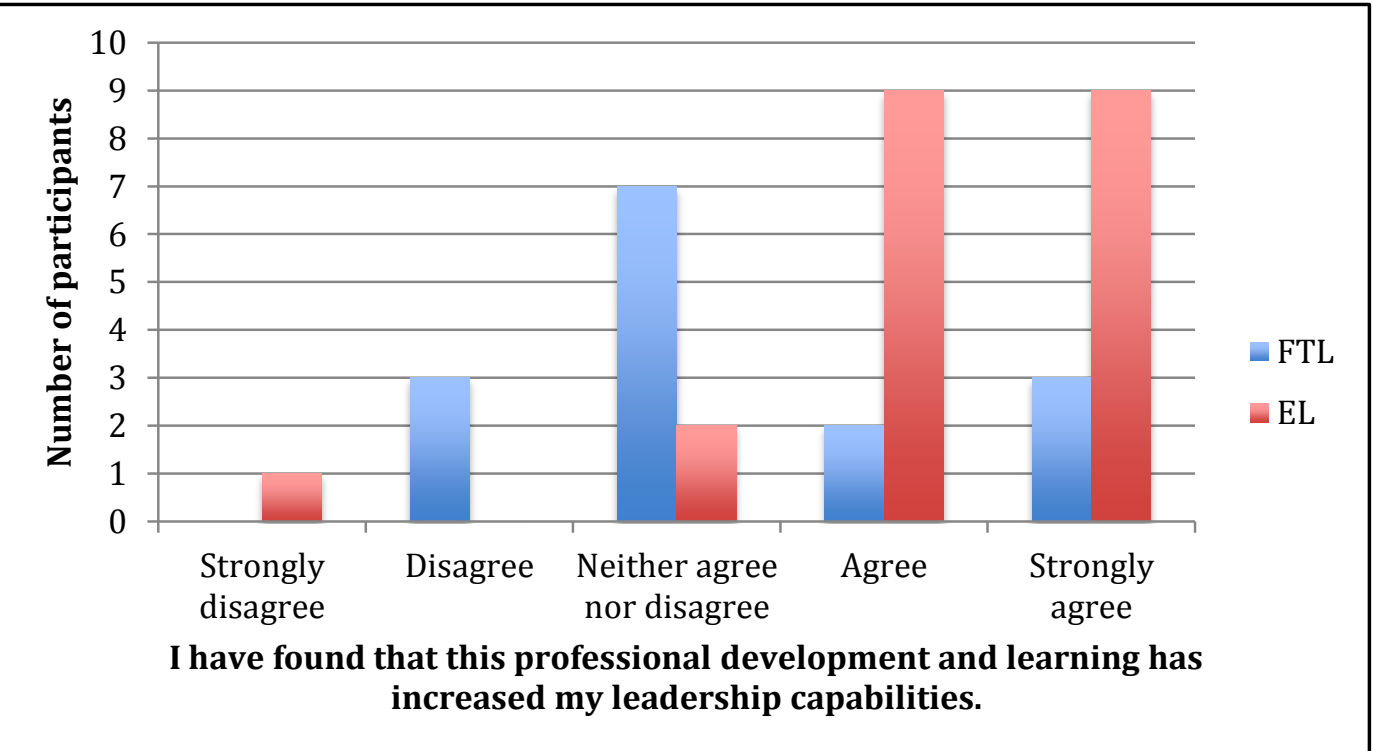

Figure 4.3: Effectiveness of leadership PDL

Almost half of new leaders neither disagreed nor agreed with the statement suggesting that the leadership PDL has had no or little impact. One comment made by a new leader was that the PDL undertaken was related to a curriculum and not specific to leadership itself. An experienced leader echoed this suggestion by saying that the PDL received allowed for a strong educational base but not necessarily a leadership base. Another new leader felt that formal coaching had improved her 
team leader management skills but otherwise her learning was derived from trial and error.

On the other hand most of the experienced leaders felt that PDL had some degree of impact. The use of an outside facilitator working within the school as part of the development in a curriculum area had encouraged one leader to:

Be more discerning in the way I support teachers and to be prepared to challenge them in trying new ideas and pedagogy.

The linking of theory and practice was identified as an effective PDL strategy, as was the content of a middle management course being adapted to the needs of the attendees. When asked to identify what PDL had helped the leaders overcome the issues and challenges identified earlier, a variety of formal PDL was named as well as a few informal strategies.

A recurring formal learning situation was the attendance of seriated, off-site, combined structures courses such as NAPP. These courses offered mentoring and coaching as a component alongside inquiry in self-directed learning. A small number of participants indicated that they had attended NAPP with one commenting:

Learning about my strengths and weaknesses, developing strategies to prioritise, developing my skill set so I am actually leading rather than managing (EL, AP/DP).

Related to this was the use of on-site leadership PDL facilitated by an outside agency; these also included components of formalised coaching and mentoring. Stand-alone, ongoing mentoring and/or coaching provided by an outside agency was also seen as effective. As one participant wrote:

The school invested in an outside provider to come and coach/mentor middle management, being able to talk about and role-play different situations (dealing with difficult people) was useful (EL, TL).

Similarly, two off-site, one-off formal courses run by outside development agencies for specific leadership practices such as conducting open to learning conversations and coaching and mentoring were mentioned on a number of occasions as 
empowering the first-time leaders to overcome some of the issues faced.

The use of informal mentoring relationships was frequently mentioned. Many participants mentioned informal conversations with leadership colleagues and principals as one of the most helpful forms of PDL to address the reactive and deliberative learning that was occurring for them. A first-time TLR commented:

Informal conversations with other management members and staff have been the most helpful as it provides a forum to share ideas/problems and be helped through feedback from them (FTL, TL).

Another informal relationship that was seen as useful was the opportunity to converse with other leaders about their experiences in PLCs. The reading of theory and research was acknowledged by a few teachers as aiding their leadership capabilities. This informal self-directed learning challenged the leaders thinking, clarified vision and actions.

Recognizing other successes that they have had as a result of leadership PDL and a sense of increased self-efficacy and capability was commented on. A repeated theme was one of satisfaction from the leaders about the positive professional growth they have observed in their teachers' practice and attitude and improved achievement by the students as a result of some change that they had lead. In their comments the leaders demonstrate an increased competency in the ability to lead change through the empowerment of others. An experienced leader commented on the successes they have felt and observed as a result of leadership PDL:

Improved school-wide systems and achievement...seeing teachers performing better and seeking to do better. Changed attitudes in the school, leading to better performance (EL, AP/DP).

Some of the leaders commented on an improvement in particular knowledge, skills and understanding. These include enabling others through coaching, improved observation skills and conducting more effective communication with the people they work with. Others wrote about their self-discovery as leaders and consequent increased self-efficacy. After attending the Emerging Leaders' Summit run by Core Education, a New Zealand educational professional development provider, one 
leader found that he/she was:

Coming to the realisation that I am a leader and the reason I like to lead (EL, $T L)$.

For another leader attending a different leadership course has provided greater selfconfidence and self-efficacy:

The leadership course in particular has helped me to view myself as a leader and I am clear about what role the leader entails and learning about leadership studies provided me with some tools and a more detached perspective that helps to reflect on how things are going (FTL, TL).

A perception of enjoyment and fulfillment comes through the comments made by leaders. The ability to help and motivate others and create a culture of learning permeates the responses, as does the undeclared awareness that they are capable leaders and they are making a difference.

\subsection{Enablers for leadership PDL within a school}

The enablers that were reported in the survey have been classified using Eraut's $(2004,2009)$ three contextual factors that affect learning in a workplace: allocation and structuring of work; encounters and relationships with other people; and expectations of each person's role, performance and progress as discussed in section 2.4 of the literature review. 
Firstly, the participants' thoughts on the priority that PDL for TLRs is given within their schools are displayed in Figure 4.4. The priority given to PDL for TLRs influences the enablers that arise under each of Eraut's $(2004,2009)$ contextual factors of allocation and structuring of work, encounters and relationships with people at work and, expectations of each person's role, performance and progress.

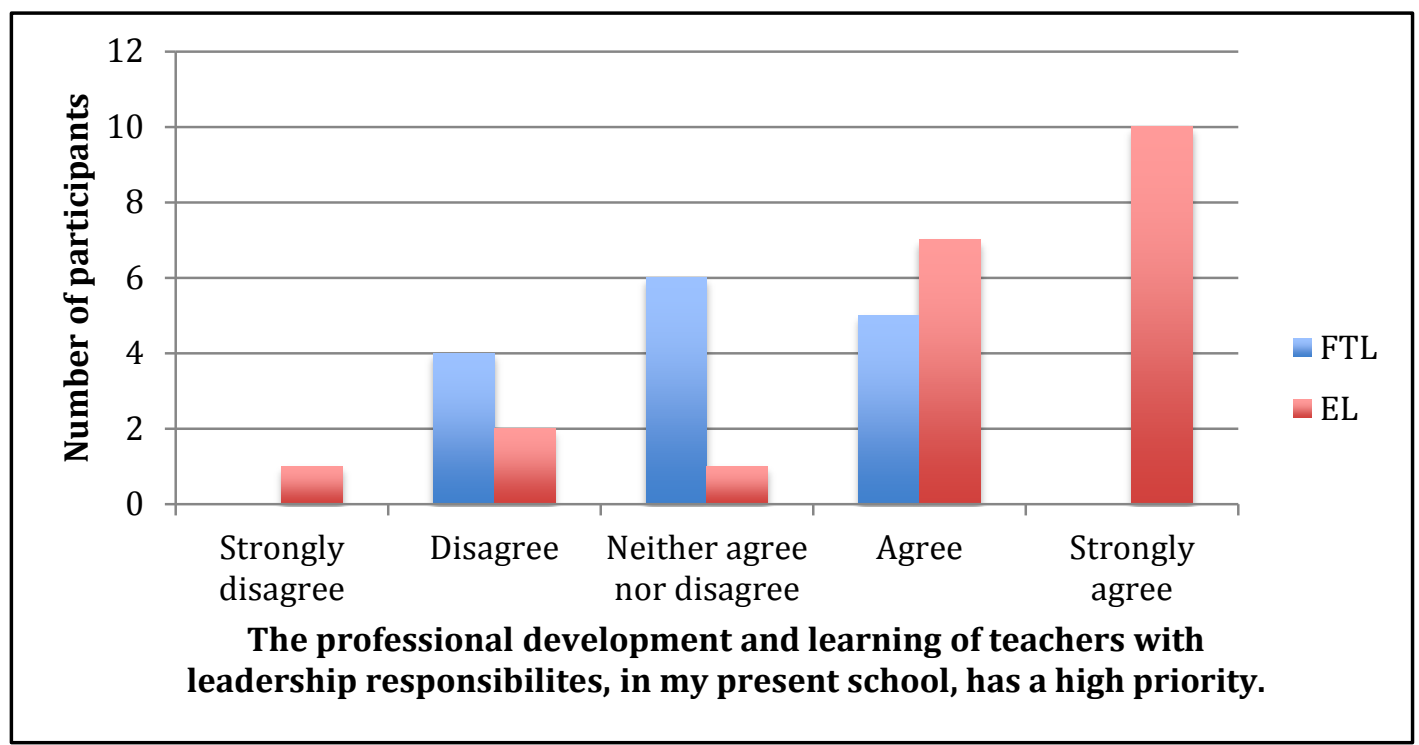

Figure 4.4: School priority for leadership PDL

Although one third of the new leaders agreed that leadership PDL was a priority in their school, just over two thirds either disagreed or neither agreed or disagreed. In contrast, the experienced leaders' views were quite different with just under two thirds indicating that leadership PDL was a priority within their school.

From the data compiled it is clear that a number of principals strategically allocate resources for the PDL of TLRs. Half of the experienced leaders had attended a seriated, offsite leadership course involving allocation of money and time for the attendance of these. Other schools had resourced ongoing onsite leadership PDL support from outside agencies. One leader in response to the priority placed on PDL for TLRs wrote:

This is a driver for us that we identify best practice and share the responsibility of $P D(E L, A P / D P)$.

Although a large number of experienced leaders had received organised PDL, there were a number of new leaders who have not been given the same opportunity. One TLR responded that the PDL is only provided for the AP and DP but not for other 
TLRs in the school.

In the area of encounters and relationships with other people, a very common enabler mentioned is the support from teaching colleagues and the principal. However for many the type of support was not articulated. Some leaders brought up the use of colleagues from leadership teams and the principal as informal mentors. This type of relationship enables both reactive and deliberative learning to take place and is used when required rather than being a predetermined mentoring relationship.

Another use of deliberate practice carried out by some principals is the use of relationships with others involving the leaders in ongoing PDL structures such as organised formal learning, on-site, mentoring and coaching with outside agencies, memberships of regularly meeting non-formal learning PLCs and visits to other schools.

It was difficult to ascertain from the data gathered what deliberate practices principals took as part of Eraut's $(2004,2009)$ third factor, expectations of each person's role and progress.

\subsection{Summary}

Over half the first-time TLRs indicated that they had received or participated in either informal or formal PDL. The structures that were mentioned most often were informal mentoring with a principal or colleagues, and self-directed learning and formal PDL leadership with an outside facilitator. It is noteworthy that one third of first-time TLRs had not received any leadership PDL.

The three main issues the new TLRs identified were not knowing the expectations of the role, workload, and the changing relationships with work colleagues possibly leading to difficult conversations.

A number of PDL structures were identified as developing leadership competency and helped address the issue of changing relationships and possible difficult conversations. Informal mentoring, PLCs, the reading of leadership theory and formal leadership PDL with an outside agent were all identified as structures that had assisted TLRs in developing leadership competency. It is significant that almost one half of new TLRs neither agreed nor disagreed with the statement that PDL had 
increased their leadership capabilities.

The majority of TLRs indicated that they had received some type of PDL therefore the inference can be made that money and time were allocated to allow the PDL to take place. The consistent reference to the support from colleagues and principals demonstrates that relationships are being used within the school to enable PDL. 


\section{Chapter Five: Interview findings}

\subsection{Introduction}

This chapter presents the qualitative findings from the focus group and individual interviews of TLRs and principals in the Wellington area. Firstly the background data of the TLRs and principals interviewed is presented. The interview responses are then be reported on according to the research questions:

- What professional development and learning are new TLRs offered and/or encouraged to participate in?

- How effective do principals and TLRs consider the current PDL of TLRs?

- What factors enable effective PDL for TLRs within a school?

Each section will present the findings from the TLR interviews and individual principal interviews separately. The discussion will begin with identifying the types of leadership PDL experienced and facilitated. Next the issues, challenges and experiences that new leaders have are looked at. The effectiveness of the leadership PDL is then reported on. Finally the enablers for PDL are shared. 


\subsection{Background details of participants}

Table 5.1 shows the background details of the interviewed TLRs. The table illustrates the personal experience of each interviewee and context of the school they are presently working in. As mentioned in section 3.9 pseudonyms have been used for all interviewees to ensure that they cannot be identified.

Table 5.1: Details about TLRs interviewed

\begin{tabular}{|c|c|c|c|c|}
\hline TLR & $\begin{array}{c}\text { Main leadership } \\
\text { role }\end{array}$ & $\begin{array}{l}\text { Number of years } \\
\text { in present position }\end{array}$ & $\begin{array}{l}\text { Years of } \\
\text { teaching }\end{array}$ & $\begin{array}{c}\text { Classroom } \\
\text { Teacher }\end{array}$ \\
\hline \multicolumn{5}{|c|}{ Focus Group One - First time TLRs } \\
\hline Alex (A) & Team Leader & $>1$ & 6 & Yes \\
\hline Bronwyn (B) & Team Leader & $>1$ & 7 & Yes \\
\hline Frances $(\mathrm{F})$ & Team Leader & $>1^{2}$ & 10 & Yes \\
\hline Mary (M) & ICT Leader & $>1$ & 2 & Yes \\
\hline \multicolumn{5}{|c|}{ Focus Group Two - Experienced TLRs } \\
\hline Diana (D) & Deputy Principal & 2 & $20+$ & Yes \\
\hline Clare $(\mathrm{C})$ & Deputy Principal & 5 & $20+$ & Yes \\
\hline Tom $(\mathrm{T})$ & Deputy Principal & $>1$ & 11 & Yes \\
\hline \multicolumn{5}{|c|}{ Individual interviews (Experienced TLRs) } \\
\hline Emily (E) & Team Leader & 3 & 11 & Yes \\
\hline Lisa $(\mathrm{L})$ & Assistant Principal & 4 & $20+$ & No \\
\hline Rachel (R) & Team Leader & $>1$ & 9 & Yes \\
\hline
\end{tabular}

Table 5.2 shows the background context of the four principals interviewed. The final column indicates the relationship between the principal and the TLRs.

Table 5.2: Details about school principals interviewed

\begin{tabular}{|l|c|c|c|}
\hline \multicolumn{1}{|c|}{ Principal } & $\begin{array}{c}\text { School } \\
\text { roll }\end{array}$ & $\begin{array}{c}\text { Number of years } \\
\text { in present position }\end{array}$ & Principal to: \\
\hline Helen $(\mathrm{H})$ & 284 & 10 & Alex and Mary \\
\hline Julia $(\mathrm{J})$ & 222 & 1 & Rachel \\
\hline Graham $(\mathrm{G})$ & 210 & 11 & Emily \\
\hline Sophie $(\mathrm{S})$ & 362 & 4 & Lisa \\
\hline
\end{tabular}

\footnotetext{
${ }^{2}$ Frances has had other leadership positions when teaching overseas but this is her first time as a team leader and first time as a TLR in a New Zealand context.
} 
The initial found in the parentheses beside each name in Tables 5.1 and 5.2 will be included with any quotes contained throughout the findings and discussion for identification purposes.

\subsection{Types of leadership PDL}

The types of leadership PDL have been classified into informal and formal for both TLRs and principals in line with Eraut's (2004) learning continuum. The majority of both informal and formal PDL structures identified by TLRs and principals were the same; therefore the content for the TLR and principal sections are similar.

Firstly the informal PDL structures of incidental mentoring, leadership meetings and regular participation in PLCs are discussed in the respective sections. Discourse on two extra informal learning occasions, self-directed learning as part of on-the-job experience and reflexive practice is found in the TLR learning section. Secondly the acknowledged formal PDL structures of seriated off-site courses, ongoing outside agency-lead curriculum specific PDL within schools, and formally organised mentoring are presented.

\subsubsection{Informal leadership PDL: TLRs}

The use of an informal mentor within a school was commonly mentioned, as learning was normally incidental and reactive in response to a pressing issue. Mentors were principals and/or leadership colleagues. TLRs identified the regular leadership team meetings as a forum for mentoring where implicit, reactive and deliberative learning occurred:

Just using Sophie as a mentor really...the conversations we have, the difficulties that I have not knowing quite what to say and how to say it... as things crop...she's really receptive to just five minutes here and there $(L)$.

Those conversations that you have with the other members of the senior management definitely help because they either reassure you that you're doing the right thing or they give you advice on how you could go about it (A).

The more experienced leaders identified the use of PLCs in various forms as a useful informal structure for deliberative learning to refine leadership capabilities. These 
ranged from deputy principal quality-learning circles to curriculum-based, offsite leadership clusters to online forums. Some were established from formal PDL as in Tom's situation:

It was the networks that were created and those connections, I mean, from there it developed into a whole lot of online learning $(T)$

Many of the TLRs talked in some way about the implicit and reactive learning that occurred when carrying out a leadership task. Self-directed learning took place as they tackled a job that they were unfamiliar with such as running staff meetings as part of whole school PDL:

I do think we learn from things that have happened or things that didn't go so well. I won't do that again or I'll do this differently or work out a way so that it's not going to happen (D).

I think I've run a successful staff meeting...I just did it off my own steam really. It seemed to work $(M)$.

The final type of informal learning is the PDL condition of reflection. Lisa found keeping a reflective journal on coaching conversations particularly useful when first developing her coaching skills. While others learnt different things from reflection:

One thing I've had to teach myself or reflect on is that I don't have to fix everything for everybody $(B)$.

\subsubsection{Informal leadership PDL: Principal}

The informal PDL principals described was a mixture of incidental opportunities and organised events for learning and in line with the informal structure the TLRs spoke of.

The incidental, mentoring discussions where reactive and deliberative learning occur were seen by principals as being a good opportunity for leaders to seek advice and support. Principals felt that it was important to always be available for these informal learning chats:

Allowing for those times where they can sound off or ask advice or seek 
clarification. So providing those opportunities within the school $(G)$.

A further chance for informal learning, implicit, reactive and deliberative was the regular leadership meetings. Within those meetings there was an opening for leaders to support each other, learn from one another and provide feedback. Julia saw leadership team meetings as a perfect opportunity for all the leaders to reflect on the coaching skills they were all learning to improve and to deliberately scaffold the learning for her leaders on how to be educational leaders rather than managers:

When people are first trying new stuff, you actually do have to hand-hold a little bit $(J)$.

Finally the attendance of PLCs by TLRs is another area of informal learning that was identified by both Alan and Sophie. Alan's DP attends a DP cluster whilst Sophie's three senior leaders attend leadership PLCs outside of the school:

They come back absolutely buzzed...there's a real focus around thinking deeply about what's presented, it's huge; it's been really powerful (S).

\subsubsection{Formal leadership PDL: TLRs}

A small number of commonly identified, formally organised PDL structures including seriated, off-site, leadership specific courses were mentioned. All members of the experienced focus group had attended NAPP, which combined a number of different PDL structures within it, including a self-directed leadership inquiry set in their own context. At the time of the interviews Emily was just completing a six-month, full-time, off-site leadership PDL course. Alex and Mary were just beginning an offsite leadership course that included investigating some leadership theory and skills as well as being coached to try out some of the skills. Both Emily and Tom spoke of the usefulness of the PDL:

I think from the beginning, that first lecturer made it really relevant for me, it's really interesting $(E)$.

NAPP won in a way because it did have the in-school inquiry and it did apply our learning out of the school into the school so that put it into some context $(T)$. 
Ongoing, in-school, curriculum specific PDL that included leadership PDL was another common structure. This type of development and learning often involved the whole leadership team. As part of this PDL leaders shadowed facilitators and were mentored in developing skills such as carrying out observations and following up with open-to-learning conversations. Rachel mentioned a similar type of ongoing, on-site leadership PDL that was not embedded in a specific curriculum area.

Finally, organised mentoring with more experienced school leaders was a formal structure that both Rachel and Frances had as they were new to their leadership roles. Although these were official arrangements many of the interactions have been incidental and more informal with both TLRs finding the relationships very supportive and helpful.

\subsubsection{Formal leadership PDL: Principals}

Some principals reported the use of off-site or on-site seriated leadership courses. Sophie and her whole senior leadership team attended off-site seriated courses each year to meet the identified learning needs of the leadership team. Julia organised a 4-month long, on-site leadership PDL with an outside agent focused on developing the coaching skills of her leadership team.

Graham and Sophie spoke of prearranged, regular mentoring meetings with leaders in their schools. Graham met with team leaders to discuss their work. Sophie held a scheduled meeting each term with all curriculum leaders to reflect on and plan actions:

They're talking about where they've got to, so that we are all hearing... they all come together and share their job descriptions so there's a little bit of accountability, a little bit of support happening $(S)$.

Lastly, Julia has utilised the expertise of an outside agent to model for and mentor the literacy leader. Also, as part of the coaching development for all the leaders in her school, Julia has taken on the formal role of coach for her team leaders in routinely arranged meetings. 


\subsubsection{Summary of types of PDL}

There is a little variation in the types of formal and informal leadership PDL identified by both groups. Incidental mentoring and leadership meetings were informal learning occasions identified by both groups. Self-directed learning as part of on-the-job experience and reflexive practice were two extra informal learning structures described by the TLRs. The three common structures of formal leadership PDL were, seriated off-site courses, ongoing outside-agency led curriculum specific PDL within schools and formally organised mentoring. Structures named are similar between different schools but there is some discrepancy between the amounts of premeditated, sequential PDL for TLRs between schools.

\subsection{Issues and challenges for first-time TLRs}

This section will illustrate issues and challenges identified by interview participants. It will show how both TLRs and principals identify the same issues and challenges, changing relationships, dealing with different personalities, lack of self-efficacy, and the issue of time with the subsequent tension between teaching and leading.

\subsubsection{Issues and challenges: TLRs}

Coping with the change in relationships with teaching colleagues and dealing with the diverse personalities were the two most prevalent challenges identified by the focus group of new TLRs. Coupled with these issues was the lack of leadership selfefficacy expressed, leading to some self-doubt and uncertainty:

I was nervous about whether I was going to do a good job, whether my team was going to respect me, whether we were going to achieve what we set out to achieve $(A)$

One of my concerns was knowing that a couple of people in the team were notorious, for want of a better word, potentially difficult to deal with and to lead... I guess apprehension is probably the best word, if an issue arose would I be able to handle it and how would I do it? (B)

Lack of time was a challenge identified by most first-time TLRs. They found themselves dealing with the added pressure of the leadership role on top of their already very busy, classroom teaching responsibilities. For new TLRs, with a 
school-wide curriculum responsibility, there is also the desire for time to strengthen knowledge and skills in that curriculum area:

I'll have two days out for management a term and then normally one or two literacy days as well and then I've got my classroom release...every week or two I've got a day out which does affect my classroom teaching $(F)$.

I think my main issues and challenges have been upskilling myself in terms of ICT and I guess it's just another time thing as well...just staying a couple of steps ahead $(M)$.

Even an experienced leader has faced similar issues and challenges when beginning a new job:

For me, there's always an element of self-doubt...things were so different from where I'd been and some really strong personalities...it took about 18 months to feel comfortable in that school $(L)$.

\subsubsection{Issues and challenges: Principals}

When principals were asked what they considered to be the challenges for first-time leaders the main theme that emerged was relationships, dealing with changing ones and different personalities when you begin to lead a team of either familiar or new staff:

Sometimes working with your peers is really hard, they're colleagues, you know...you're their friend but now you're their leader (S)

That management of those different temperaments that you work with is sometimes that thing that gets really good, organised, efficient and administratively talented people unstuck $(G)$.

Sophie and Julia suggested that the lack of self-efficacy of first-time TLRs means that they may struggle with carrying out their role, as they are determined to be effective leaders but are unsure of what is expected of them and how they should be doing it:

Knowing how much you can do, and how much you need to check up to make 
sure you are doing it right is often at the front of the mind as well (S).

It's the confidence in knowing they can do it. The need to be feeling like they're doing everything right, all of the time $(J)$.

With changing relationships, different personalities and the responsibility of ensuring quality teaching and learning, conflict may arise between a new leader and one of their team members. Both Julia and Helen viewed having difficult conversations as a challenge for new leaders:

If you're a classroom teacher who's picked up a SENCO ${ }^{3}$ role and you need to talk to a teacher about what's happening for a special needs child and the teacher's not quite on board, they're thrown into that kind of thing $(J)$

They are really difficult and to come out at it with both sides with a bit of pride and you can't force the other person to actually be self-aware to see what's happening. (H)

Most principals identified the tension between teaching and leadership that first time TLRs experience. With increasing workload new leaders are torn between the demands of providing a quality-teaching programme within the classroom and being an effective leader.

\subsubsection{Summary of issues and challenges}

Although coming from different perspectives the principals and TLRs acknowledged the same issues and challenges for first-time leaders. These are the challenges of changing relationships, dealing with different personalities, lack of self-efficacy and the issue of time and the subsequent tension between teaching and leading.

\subsection{Effectiveness of leadership PDL}

This section discusses the effectiveness of leadership PDL identified by the interviewees with an emerging theme of improved leadership capabilities. In the first section findings show how TLRs felt more skilled at working with teaching colleagues to improve teaching and learning. Most of the increased capabilities

${ }^{3}$ A SENCO is the Special Education Needs Coordinator. All New Zealand public schools have a teacher carrying out the SENCO role. 
identified were as a result of formal or deliberate informal PDL about specific leadership acts. Some self-realisations are described as a result of self-directed learning.

The second section firstly describes less deliberate and informal on-the-job PDL identified by principals. Then the ways in which two principals' intentional choices of leadership PDL increased the leadership capability of both new and experienced TLRs is discussed.

\subsubsection{Effectiveness of leadership PDL: TLRs}

The leadership capability related to working with and leading others, to improve teaching and student learning, emerged from TLRs' comments. PDL that involved modelling and scaffolding increased TLRs capabilities when working with colleagues. For example:

That pre-planning at leadership meeting before having a syndicate meeting; I don't go into a syndicate meeting feeling uneasy because I feel confident that I've got what I need to do the job (R).

Frances found scaffolding from an outside PDL facilitator particularly effective:

One of the...things that has most helped me...is his critical feedback...it's been really useful and helped me not to assume that things are as I think they are $(F)$.

Direct PDL had given Lisa and Diana the capabilities to redesign and refine their schools' teacher appraisal systems to evaluate teacher effectiveness. Lisa combined learning from both a formal, outside agency and non-formal PDL on coaching to assist teachers to create an action plan to achieve their learning goals. Subsequently this work was added to the appraisal cycle. The leadership inquiry requirement in NAPP enabled Diana to apply the learning that she had received, to her own work:

I ended up completely remodelling, revamping our professional management system and we had ERO (Education Review Office) this year and...they commented on how effective it was $(D)$. 
Various forms of PDL assisted some TLRs in dealing with difficult conversations. Through informal reflection Emily demonstrated a shift in how to view the nature of a difficult conversation.

I think it's been helpful to be able to distance yourself from the actual happening, step back from that and not take it as a personality dynamic between you and your colleague but more as a process that is happening there $(E)$.

While Frances found that her formally organised mentor provided the support and guidance to carry out these conversations:

It's been really helpful and kind of talking through how I can go about this and what process might work in the future and those kinds of conversations $(F)$.

Informal, self-directed, on-the-job PDL has also developed some TLRs' realisations about themselves and their efficacy as leaders. Both Frances and Mary talked about running full staff meetings for the respective areas of responsibility for the very first time in their careers with little or no support from superiors. They found that teachers had subsequently applied some of the ideas introduced in the staff meetings to their own teaching. Thus both TLRs gained some satisfaction and awareness that they could carry out these leadership tasks.

\subsubsection{Effectiveness of leadership PDL: Principals}

Principals who used a small number of organised structures in an unsystematic manner in the leadership PDL of TLRs found that TLRs have showed increased leadership competence through carrying out on-the-job tasks.

It's people taking on and running staff meetings or saying I'm confident to do that $(H)$.

One person...just organised a parent evening and she really got involved in upskilling herself to do that and she presented this amazing evening which went really, really well $(G)$. 
Regular monitoring of learning that occurs within a systematic PDL approach has not occurred in these schools therefore it is difficult to infer how the organised leadership PDL within Helen and Graham's schools may have contributed to the observed improvements. Whereas principals, who systematically mapped out the PDL of TLRs, were more clearly able to articulate the observed changes in their leaders.

Each year Sophie and her leadership team attended formal off-site PDL, followed up with on-site informal PDL combined with regular external leadership PLCs. Consequently the TLRs have displayed increased capability as leading learners through the facilitation of deeper learning conversations:

Some of the issues being dealt with that...previously wouldn't have been. So thinking about those open-to-learning conversations and those sorts of things. I think that as the leadership team we are much more seeing things addressed rather than being let go $(S)$.

Julia, in her first year as a principal at her present school, identified a real need for leadership PDL for all her TLRs as she perceived that they were task-oriented managers rather than leading learners. Julia reported that most of her TLRs shared with her that they were unsure of what was expected of them and there were some who had misconceptions about leadership. Initially she facilitated PDL that was followed by employment of an outside agent to enable coaching PDL. Alongside the formal PDL there were the purposefully planned leadership meetings to further scaffold leadership responsibilities. Julia found that leadership capabilities, selfefficacy and self-confidence increased so much that the TLRs have directed the learning and have initiated a feedback survey from their staff concerning their leadership effectiveness:

Initially...I was more focused on let's gel as a leadership team and make sure we all understand our role. I wanted a bit of the leadership theory stuff. So that's where it started and moved into coaching $(\mathrm{J})$.

Also as a result of PDL both Sophie and Julia could glean from team meeting minutes that TLRs were becoming leaders of learning and had a more strategic view: 
They're moving away from that what's on top to having deeper, richer conversations...entries...are very reflective around teacher practice or student achievement...that's quite a big shift (S).

The discussions that they're facilitating...they're talking about learning and children as opposed to talking about who's going to ring the parents for the trip on Monday $(J)$.

\subsubsection{Summary of effectiveness of leadership PDL}

In this section TLRs were able to clearly identify the improved sense of capability from specific leadership PDL they had experienced. Two TLRs spoke of increased leadership self-efficacy through on-the-job learning experiences. Some principals spoke anecdotally of leaders' increased capabilities but these were not linked directly to PDL structures. Therefore it is difficult to identify which planned PDL had the greatest impact. With intentionally planned, on-going leadership PDL principals were able to draw on anecdotal observations to describe the increase in their leaders' capabilities as a direct result of planned PDL.

\subsection{Enablers for leadership PDL within a school}

This section presents findings related to the deliberate practices within a school that enable PDL for TLRs. These practices have been grouped into three categories: allocation and structuring of work; encounters and relationships with people at work that support on-going PDL within the workplace; and lastly expectations of each person's role, performance and progress (Eraut, 2004, 2009).

\subsubsection{Allocation and structuring of work}

Strategic resourcing of time and money is something identified by both groups and will be discussed in the allocation and structuring of work.

\section{Allocation and structuring of work: TLRs}

TLRs have taken part in organised formal and informal leadership PDL suggesting that strategic resourcing was employed to have this PDL. Some TLRs mentioned that being released from classroom teaching for a designated time has helped in their PDL as it has given them an opportunity to focus on the learning or alleviate the issue of workload thus allowing for PDL at other times in their busy schedules. 


\section{Allocation and structuring of work: Principals}

In line with the TLRs, principals identified a number of strategic resourcing decisions. They all spoke of the choice to utilise formal leadership PDL requiring consideration of both monetary and time resources. Julia approached her Board of Trustees to obtain a greater monetary commitment as she felt that there was a real need to employ an outside agent who had the necessary skills to meet her leaders' learning needs. Financial limitations are a frustration expressed by all the principals as it restricts the amount of support that they can provide for the TLRs and the ability to afford appropriate PDL for TLRs.

Strategic use of time and money to provide release for key leadership roles and for TLRs to attend PDL during school time was mentioned. If TLRs required extra release it would be organised for them. Sophie and Julia sometimes found themselves in classrooms in order to secure the release.

\subsubsection{Encounters and relationships with people at work}

The encounters and relationships with people at work, to ensure ongoing PDL within the workplace, is split into relationships with the principal and relationships with other people in this section, as was done in the literature review.

\section{Encounters and relationships with people at work: TLRS}

The presence or lack of a collaborative, intentional PDL pathway for the TLR and an established mentoring relationship is explored in the TLRs' responses about relationships with the principal. Whilst in relationships with others, the deliberate action of organising the observation of, co-leadership with, and learning with leadership colleagues is discussed.

\section{a. Providing on-going PDL in the workplace: Relationships with the principal}

Most TLRs said they felt supported by some formal leadership PDL arranged for them by their principals but they did not have an intentional pathway of learning to follow. Alex felt her attendance at a useful and relevant offsite, seriated leadership course in the second half of the year would have been more worthwhile when she started her role:

If I'd had it right from the start it would have been good because it talks 
about creating that vision as a team together at the start of the year and how you're going to progress throughout the year $(A)$.

Without a structured PDL plan co-constructed between their principals and themselves Tom and Diana struggled with completing the job-embedded inquiry component of NAPP. Diana grappled with finding time to complete the work and Tom found that his inquiry did not fit with the existing professional development of the school. Consequently it was difficult to gain teachers' support for his initiative:

Me coming in and saying, "this is something really awesome, we should check this out or watch this", it was met with more, not hostility but more resistance than it otherwise would have been if it had been foreplanned and organised much more in advance $(T)$.

Diana relayed an incident with a newly appointed TLR in her school who had not received any leadership PDL and struggled with carrying out teacher appraisals. Had the TLR had some rigorous PDL from the start of his or her role the following situation may not have occurred:

A team leader who hasn't had any official professional development...found doing an appraisal with one particular teacher very upsetting, she said "I'm never going to do this again" she was very upset by it and said "Oh, I haven't been trained to do this" (D).

Conversely, Lisa, Rachel and Frances had opportunities for some ownership in creating a PDL pathway for themselves. A PDL plan was formulated as part of a collective leadership team for Lisa and Rachel. Through the school's appraisal system, Frances collaborated with her AP to create an individual leadership goal and reflected on progress through mentoring. The three leaders spoke of how this approach has enhanced their PDL.

Many TLRs spoke of valuable informal, incidental or formal mentoring relationships with their principal or another significant leader in their school. However with no formal mentoring arranged mentors were not always available and TLRs did not feel that they could disturb them: 
I know I could go to him and he would support me or help me sort it out...if you haven't got the support of your school leader it's not going to work (E).

Being able to talk to the principal, often they are busy and it's hard to catch them and you don't want to take up too much of their time so if you have a set aside where you can really talk $(F)$.

An organised mentor/coach was something identified as an ideal learning structure for new TLRs as part of a larger PDL plan. It was felt the mentor did not necessarily have to be the principal as it was more important to have someone who had similar recent experience and was suitable for the position. Clare spoke of the need to have regular support, feedback and encouragement to give the new TLR recognition, direction and motivation:

I think it does come down to relationships again so ideas can be validated and you can actually realise....that someone else can see the potential in me and you're getting the affirmation. I think that would be key as a starter to give them that time, discussion and affirmation $(C)$.

\section{b. Providing on-going PDL in the workplace: Relationships with others}

TLRs identified the use of a more experienced leader to either observe or co-lead with the new leader providing scaffolding to move the new TLR towards independence. Modeling of leadership by the more experienced leader also involved implicit and reactive learning through the experience of being led by another:

I feel that because I was...in a supporting role, I got to practice some of the tasks without having all the responsibility on me. So that I grew into the position little bit, which I thought was really helpful (A).

I guess also modelling from others and your own personal experiences of how you've been treated by a leader, the things you'd put in place in the things you wouldn't put in place $(R)$.

Lisa, Rachel and Frances found participating in planned, formal and informal leadership PDL with all the members of the leadership team, including the principal, led to a shared understanding of what leadership means and looks like. Relationships 
between the members of the leadership team in their schools have also been strengthened.

\section{Encounters and relationships with people at work: Principals}

The intentional acts of utilising encounters and relationships with others to sustain leadership PDL in the workplace reported by the principals were similar to the TLRs' responses. However different principals reported carrying out distinct, intentional acts in their relationships with their TLRs and these are discussed.

\section{a. Providing on-going PDL in the workplace: Relationships with the principal}

Findings showed that all the principals interviewed deliberately organised PDL structures for their TLRs. However for some principals there was an unsystematic approach to the leadership PDL that lacked support for consolidation and clarification of learning for the TLRs. Alternatively other principals took a systematic approach to the PDL where development of the TLR was more closely supported and monitored.

In his relationship with his leaders Graham had formally organised some PDL structures but did not have a purposeful and coherent PDL plan that ensured monitoring of learning. He utilised annual teacher appraisals as a development tool for TLRs to set themselves leadership goals with achievement reviewed at the end of the year. Throughout the year Graham had weekly scheduled, individual meetings with his team leaders. The opportunity was provided for each of the leaders to reflect on their job and were offered advice and guidance for any concerns. However learning was mostly reactive and not used to intentionally reflect on the progress of the leadership goal. Graham's practice is similar to the incidental support that the majority of the TLRs spoke of.

Each year, in a more systematic approach, both Julia and Sophie had consciously consulted, planned and facilitated leadership PDL with their senior leadership team comprising their team leaders. Furthermore, each of the TLRs appointed to a specific role in Sophie's school constructed a PDL pathway with Sophie, focusing on their specific learning needs. 
In order to maintain momentum of leadership PDL and monitor the TLRs' learning the Julia used her relationships with her leaders to maintain the:

Every fortnight we have on our agenda, coaching touch base and it's quite informal...we're doing that for a couple of reasons, one is to try and keep momentum... and the other thing is to make sure that people feel supported $(J)$.

To sustain leadership PDL impetus Sophie intentionally schedules separate meetings with both her senior leadership team and the designated TLRs to review their learning. If there are any PDL needs arising from these reflections then strategies are put in place to address these:

It's the chats that we have that provide the support and...what are other ways that we can think about this, what are the ways that we can support you $(S)$.

As with the TLRs, principals indicated scheduled mentoring/coaching sessions were an ideal PDL structure in tandem with other PDL structures. These would be in addition to being available at any time for the incidental mentoring situations that may arise. Sophie commented on the effectiveness of an organised mentor/coach:

Being able to work alongside someone in a coaching mentoring/role would be one of the most powerful...having someone who was just on call for you who you knew you could go to and they would drop everything and come and not solve your problem but help you reflect in a way that would move you forward and help you find a solution (S).

Julia acknowledged that TLRs outside of the leadership team had not received the same formalised support as her team leaders. She had incidental and reactive mentoring sessions with these TLRs rather than having scheduled chats. However, during these incidental chats she had begun to take a coaching role in order to increase the TLR's learning and ownership of an issue.

\section{b. Providing on-going PDL in the workplace: Relationships with others}

Principals in this study used relationships with others to enhance PDL by organising 
observations and co-leadership of more experienced leaders where both implicit and reactive learning occurred. Observations were arranged within their own and other schools. It was important for every principal that any leadership PDL was undertaken with at least one other person. Helen makes a deliberate choice to send at least two people to an off-site, seriated leadership course to ensure that the attendees have someone to discuss their understanding with. Both Sophie and Julia view themselves as learners with the other members of their leadership teams.

\subsubsection{Expectations of each person's role, performance and progress}

The use of job descriptions is discussed in this section in relation to both groups. Principal's assumptions about the competency of first-time leaders and the subsequent support they provide, are then presented in both. Lastly the principals' understandings of the PDL needs of TLRs are highlighted.

\section{Expectations of each person's role, performance and progress: TLRS}

Since none of the members within the first time TLR focus group had received a job description when they first began their role there was widespread agreement that this was desirable in order to clarify expectations when starting a new leadership role. Some of these same TLRs expressed an impression that their superiors assumed that they would cope in the new role and were left to do the job with little support and guidance:

I think a little bit of it is role definition as well...clarity about exactly what I'm supposed to do, I think you just pick it up by osmosis or by learning from other people but there's no clear definition $(A)$.

It would be quite nice to see an itemised list of what the role entails...sometimes when you show yourself capable of doing the role then it's just, "you can do it, look, you're doing it." It just assumed well you don't need... well we might have these chats to help but you're doing the role so what's the problem? (B).

The experienced leaders did not directly mention the use of a job description as necessary for a new leader. They acknowledged that they had not received a job 
description for their leadership positions. Janet comment on the need to define job expectations:

I think that's integral as well, having clearly defined and explained, this is what I see as your role...this is what I expect of you and having that really clear so that a first time leader doesn't go, I don't quite know what I'm doing. No actually, I know what the end games got to be.

\section{Expectations of each person's role, performance and progress: Principals}

Some of the principals ensured that there were clear guidelines and expectations of a TLR's role through the use of a job description and ensured strategies were put in place to monitor PDL. In order to provide some direction Julia provided job descriptions for leadership roles:

We have one for our AP, DP and syndicate leaders but we also have job descriptions for those key leadership positions like IT, SENCO, Literacy, Numeracy, Health and PE. So for those bigger areas of curriculum, those people have got leadership job descriptions $(J)$.

A job description provided clarity of expectations for any teacher wishing to apply for these positions. To engender a sense of being a leader of learning rather than merely a manager Julia also included a leadership component within the job description.

Alternatively at the beginning of each year a job description is negotiated between Sophie and the TLR:

We sit down and talk about where we want to go with this, what's your picture about it, what's my picture about it, okay, what would be realistic in terms of a job description ...not just coming out with a job description saying "right off you go and do it, come back to me when it's done" that kind of thing $(S)$.

In the quote above Sophie alludes to principals' assumptions that new TLRs will be able to carry out their roles with little or no support. Graham also acknowledged and commented upon the assumptions made by principals: 
A huge barrier to leadership development is when leaders are just left. "You've got that job, that's your job" and there's no support... it's like throwing someone literally into a pool having not taught them to swim at all and say, "it's okay, go". It's a terrible way to learn $(G)$.

\subsubsection{Summary of enablers for PDL within a school}

Many of the deliberate practices to enhance the PDL in the workplace reported by both TLRs and principals are the same. These include strategic resourcing and working alongside and with others.

There appeared to be two approaches to the deliberate practice of organising and supporting a PDL programme for TLRs. The first approach could be termed unsystematic. In the unsystematic approach TLRs felt supported in their work place, they received incidental, intermittent, formal and informal PDL but the PDL was irregular and incoherent. Most of the TLRs involved in the unsystematic approach had little input into what they wished to learn and no scheduled and regular monitoring of progress. The principals who provided this type of PDL found it difficult to talk specifically about the learning progress made by the TLRs as a result of purposeful PDL as there was no regular monitoring.

The second approach was systematic. A coherent PDL pathway was co-constructed between the principal and the TLR at the beginning of each year. Ongoing, scheduled mentoring meetings were part of this plan in order to provide regular reflection on progress and to maintain the momentum of the intentional PDL. The interviewed TLRs and principals who reported being involved in this process were easily able to articulate progress of learning and leadership capacity

There were some inconsistencies between schools in terms of the use of a job description for first time TLRs. The majority of principals reported providing the leaders with job descriptions. However most new TLRs and some of the experienced ones spoke of not receiving one when they started out as leaders. There was an agreement amongst the TLRs that this was a necessity for new leaders.

Most of the TLRs and principals interviewed felt that the deliberate practice of establishing an intentional mentoring/coaching relationship was seen as an ideal PDL structure for all new leaders including leaders of school-wide specific learning 
areas. All participants thought that the formal mentoring/ coaching relationship needed to be done in conjunction with other structures and used to gauge a TLR's learning progress.

\subsection{Summary of interview findings}

Some key themes have developed from the analysis of results. Firstly, participants from the different schools in the study all reported involvement in similar informal and formal PDL structures. Most of the structures mentioned increased the TLRs' ability to carry out leadership acts that overcame some of the challenges and issues they faced and consequently their leadership efficacy grew. Although all the TLRs recollected different structures of PDL many were informal and unsystematic. A number of TLRs felt that they had not received any formal support as first time TLRs.

An effective type of PDL in which a small number of TLRs felt fully informed and supported was a co-constructed, pre-planned combined PDL structure. This arrangement utilised a number of both informal and formal PDL structures to ensure learning and application of specific leadership acts to increase capability. An important structure within the combined model was the use of organised mentoring and coaching. This formal structure allowed for both TLRs and principals to more accurately articulate and monitor learning through the regularly scheduled meetings.

There were common deliberate practices between schools to enable PDL such as strategic resourcing, and working alongside and with others to sustain the PDL within the workplace. However variation occurred in the level of systematic organisation of PDL structures that individuals received. Whilst all principals strategically resourced PDL, only some utilised the relationship with their TLRs to formulate an interconnected combined PDL structure. Combined with a coherent PDL pathway is the deliberate act by a principal to provide a clear job description for all key TLRs within a school. This provides an uncertain first-time TLR a starting point for knowing what is expected of them as well as a basis for determining learning needs. Inconsistencies between schools in their provision of a job description for leaders were evident in this study. 
Finally it is interesting to note that all the principals understood almost all the issues and challenges new teachers faced. However the two principals, who felt that firsttime TLRs lacked self-efficacy through uncertainty of their roles, delivered a job description and a carefully thought-out, consistently supported and monitored PDL structure for their TLRs. 


\section{Chapter Six: Discussion}

\subsection{Introduction}

This chapter draws on findings and uses literature to support these findings to propose a possible PDL framework that could help to ensure that TLRs are provided with appropriate and effective guidance and support to help them maximise their leadership capability.

Firstly the background reasoning for the creation of the framework is explained. Then, to provide sufficient justification, the framework has been divided into two parts. Firstly, three contextual factors that enable effective PDL within a workplace (Eraut, 2004, 2009) are discussed. In the second part, an annual cycle of PDL for TLRs is explained. Finally the entire framework is displayed showing how the two parts come together to create a potential PDL approach for TLRs that is systematic, ongoing, active, and relevant and likely to increase leadership capability.

\subsection{Justification for framework}

The study findings show that the amount of PDL for TLRs varies greatly between Wellington schools. A third of new TLRs in the questionnaire reported that they had not received any PDL for their present leadership position. It may be that the TLRs viewed PDL as the very specific structure of formal leadership PDL rather than seeing the broader view of PDL as being both formal and informal. However the study findings are supported by Cameron and Dingle's (2006) research that New Zealand TLRs felt that they had received inadequate guidance and support for their leadership roles.

Most of the new TLRs in the focus group had experienced unsystematic PDL that was either incidental, as a part of another school activity such as a leadership meeting, or formal PDL, organised for them to attend with little or no consultation. Although the vast majority of experienced TLRs in the questionnaire felt that they had received PDL in their present role, almost all the interviewees who were experienced leaders stated that they had not received PDL as first-time leaders.

Conversely there were a number of questionnaire participants who spoke of purposefully organised, formal, PDL targeted for TLRs such as NAPP, or PDL for a 
specific leadership competency such as coaching. Study findings showed that these PDL structures assisted TLRs in developing leadership theories, beliefs and practices that enhanced their leadership capability and addressed some of the issues and challenges they faced as leaders.

Some examples of systematic PDL were identified in the findings. An experienced team leader reported in the questionnaire being part of a cluster of schools in which a large investment was put into specific PDL for TLRs over three years. The course content was adapted to meet the needs of the attendees. Three of the interviewed TLRs spoke about ongoing and relevant leadership PDL within their schools as part of a leadership team. Principals of two of these teachers were able to clearly articulate the PDL pathways and the observed benefits supported this finding.

The majority of experienced TLRs felt that PDL had increased their leadership capability but only a third of new TLRs agreed or strongly agreed that it had. Almost half of new TLRs neither agreed nor disagreed that PDL had impacted upon their leadership capabilities. One TLR mentioned:

The PD I have undertaken is related to the curriculum area and not specifically leadership itself (FTL, CL)

This comment and other findings in the study support the view that although there is a lot of professional development taking place in schools, it is often focused on improving teaching and learning rather than targeted at improving leadership capabilities (Briggs, 2012b).

TLR's lack of understanding of what PDL is may also contribute to the neutral opinion by the majority of new TLRs regarding the effectiveness of the PDL they are receiving. Deece (2003) described TLRs as unaware of what they did not know about leadership due to insufficient PDL and this view was echoed during focus group interviews. With prompting, some of the first time TLRs were able to articulate the effectiveness of their leadership as a result of carrying out leadership tasks; a form of informal, self-directed, inside-out learning. Yet the deliberative learning opportunity of sharing and reflecting on the task and the learning that took place had not occurred. Therefore they did not know or view this as a learning situation and could not appreciate the benefits. 
The study findings suggest that principals in some schools lack an understanding of the developmental needs of TLRs and this is supported by the literature (ChildsBowen et al., 2000). Many TLRs expressed their perceptions of assumptions that their principals have in regards to the PDL needs of a first-time TLR or TLR new to a school

You don't do it by osmosis...you wouldn't do it to the kids so why do we do it to adults? We wouldn't expect children to go in and do something without some sort of scaffolding so surely we have that process for the adults as well. It's not just, oh well, hit and miss (C).

All the interviewed principals could articulate formal and informal PDL structures that they were using for TLRs. The principals who could clearly describe the impact of those structures on the TLRs' capabilities were the ones who had planned and implemented consistent, ongoing, leadership PDL programmes that specifically addressed their TLRs' needs. These were also the same principals who identified self-efficacy as a challenge for new leaders. This would suggest that a well planned and executed, systematic PDL programme enables principals to obtain an understanding of the developmental needs of TLRs.

The variation in, and the apparent inadequacy of the PDL, assumptions made by both principals and TLRs, and a lack of understanding of appropriate leadership PDL in the findings infers that a PDL framework for TLRs that schools could adapt to their own contexts, to meet identified learning needs, would be useful. The actions that a principal takes strongly influence the effectiveness of TLRs (Mangin, 2007). The deliberate act of establishing a purposeful, systematic and continual PDL framework can provide support and motivation for the TLR. The framework can also assist principals in obtaining a better understanding of leadership PDL and provide adequate support and guidance to ensure that their TLRs become capable leaders.

The suggested framework described over the following pages is derived from the findings of this study and relevant literature. The main aim of this study was to find out how teachers, who are new to having leadership responsibility in New Zealand schools, are supported in the role. This framework is a reflection of the effective practices that were identified in the PDL of all TLRs. Therefore this proposed 
framework is not exclusively for first-time TLRs, it could be used for any teacher leader within a school with a key responsibility.

The explanation for the framework will be presented in two parts. The first will illustrate how the three contextual factors identified as effective in the study might pervade the annual cycle of PDL to maximise PDL for TLRs. The three contextual factors explored are: allocation and structuring of work; encounters and relationships with people at work; and finally expectations of each person's role, performance and progress (Eraut, 2004, 2009).

The second part of the suggested framework discussed is the annual cycle of PDL. The description of the suggested yearly cycle depicts the assembly of the effective PDL structures, conditions and deliberate practices identified in this study. In order to provide sound justification for the cycle it has been broken down into the three components. These are the co-construction or review of a job description and a PDL pathway, PDL structures and finally the necessary elements that permeate the entire cycle. 


\subsection{Part one: Contextual factors that enable leadership PDL}

The three contextual factors, allocation and structuring of work, encounters and relationships with people at work and expectations of each person's role, performance and progress that enable PDL within a workplace (Eraut, 2004, 2009) surround and infiltrate the annual PDL cycle through the deliberate practices (Fullan, 2011) actioned by the principal. Findings showed that PDL is less likely to be coherent, active and relevant to TLRs without these deliberate practices. Consequently a TLR's competence to carry out their job is affected. Figure 6.1 shows how the three contextual factors surround the PDL cycle.

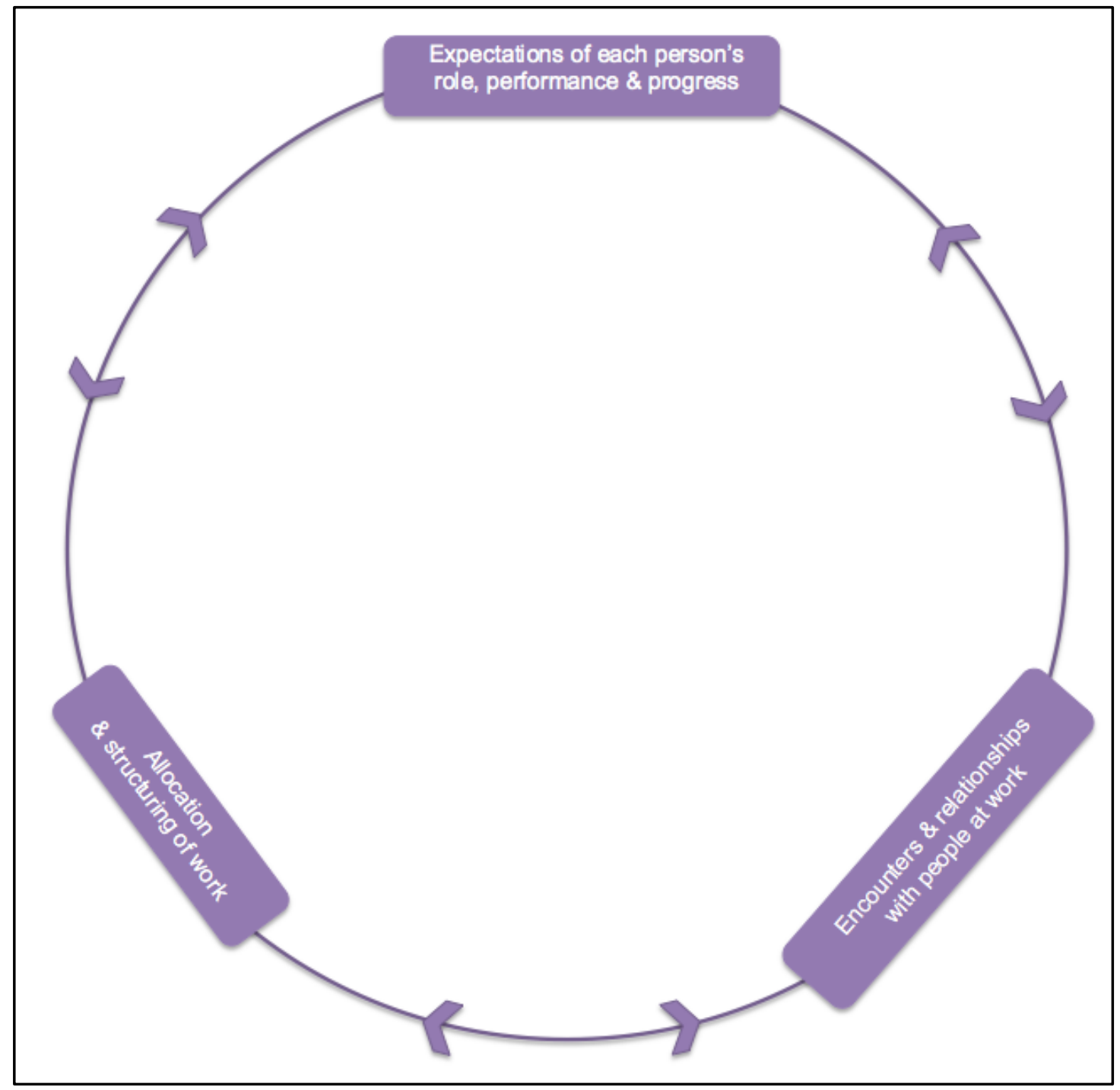

Figure 6.1: Contextual factors

The deliberate practices carried out by the principals are categorised into the contextual factors allocation and structuring of work, encounters and relationships 
with people at work, and expectations of each person's role, performance and progress that enable PDL within a workplace (Eraut, 2004, 2009) and occur throughout the different components within the suggested PDL framework. The deliberate acts need to be undertaken in order for each component to operate effectively. Table 6.1 demonstrates how the deliberate practices identified in the study findings and literature surround and woven into the PDL framework.

Table 6.1: Where contextual factors fit in the PDL framework

\begin{tabular}{|c|c|c|}
\hline $\begin{array}{l}\text { Contextual } \\
\text { Factor }\end{array}$ & Deliberate practice & Place in the framework \\
\hline \multirow{2}{*}{$\begin{array}{l}\text { Allocation \& } \\
\text { structuring of } \\
\text { work }\end{array}$} & $\begin{array}{l}\text { Strategic resourcing for PDL \& } \\
\text { release }\end{array}$ & $\begin{array}{l}\text { Co-construction or review of } \\
\text { job description and PDL } \\
\text { pathway }\end{array}$ \\
\hline & $\begin{array}{l}\text { Provision of intentional \& } \\
\text { appropriate PDL }\end{array}$ & - The whole framework \\
\hline \multirow{4}{*}{$\begin{array}{l}\text { Encounters } \\
\text { and } \\
\text { relationships } \\
\text { with people } \\
\text { at work }\end{array}$} & $\begin{array}{l}\text { Organising targeted, job embedded } \\
\text { PDL with the TLR }\end{array}$ & $\begin{array}{l}\text { - Co-construction or review of } \\
\text { job description and PDL } \\
\text { pathway } \\
\text { - PDL structures }\end{array}$ \\
\hline & $\begin{array}{l}\text { Providing systematic, on-going } \\
\text { support of PDL }\end{array}$ & $\begin{array}{ll}\text { - } & \text { Coaching/mentoring } \\
\text { - } & \text { Provision of intentional } \\
\text { critical reflection time }\end{array}$ \\
\hline & Provision of role models & $\begin{array}{l}\text { - Observation/co-leadership } \\
\text { PDL structure } \\
\text { - Intentional use of sharing and } \\
\text { collaboration of learning with } \\
\text { colleagues }\end{array}$ \\
\hline & $\begin{array}{l}\text { More than one TLR participating in } \\
\text { PDL }\end{array}$ & $\begin{array}{l}\text { - Choice of PDL structures } \\
\text { - Sharing \& collaboration } \\
\end{array}$ \\
\hline \multirow{2}{*}{$\begin{array}{l}\text { Expectations } \\
\text { of each } \\
\text { person's role, } \\
\text { performance } \\
\text { and progress }\end{array}$} & $\begin{array}{l}\text { Provision of a job description to } \\
\text { support a TLR when beginning a } \\
\text { new role }\end{array}$ & $\begin{array}{l}\text { - Co-construction or review of } \\
\text { job description and PDL }\end{array}$ \\
\hline & Understanding PDL needs & $\begin{array}{l}\text { Co-construction or review of } \\
\text { job description and PDL } \\
\text { pathway } \\
\text { - } \\
\text { Mentoring/Coaching }\end{array}$ \\
\hline
\end{tabular}

On the left-hand side of the table are the three contextual factors that enable PDL. The middle column shows the deliberate acts identified in the study that principals carried out that enhanced PDL and are mentioned throughout the second component of the PDL framework. The third column demonstrates where the deliberate practices take place in the framework. The provision of intentional and appropriate PDL is the one exception as this deliberate practice is an essential practice that 
drives the entire framework.

\subsection{Part two: Annual cycle of PDL for TLRs}

The annual cycle of PDL for TLRs is a process that combines all of the effective PDL structures, conditions and deliberate practices identified in this study. The process consists of three components, the initial step is the co-construction or review of a job description and PDL pathway and it is evaluated at end of the cycle. This step provides direction for the rest of the cycle. The second component is the PDL structures selected and completed throughout the year and the third component shows the essential elements for successful PDL. The presence of each component within the annual cycle of leadership PDL will be explained separately using the study findings and literature.

\subsubsection{Component one: Co-construction or review of job description and PDL pathway}

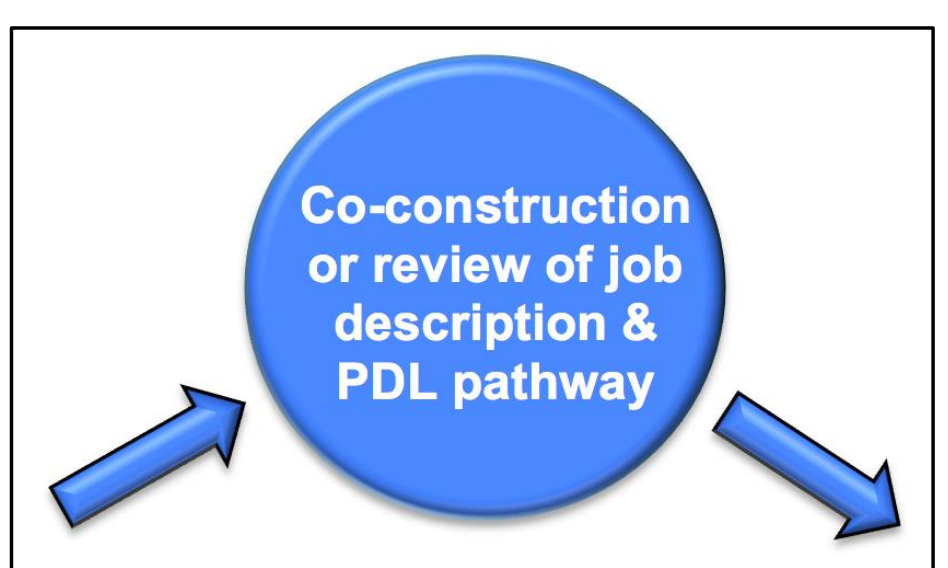

Figure 6.2: Component one
The PDL cycle begins with the co-creation or review of a job description and consequent co-construction of a PDL pathway between the principal and the TLR. This practice was seen in the study to influence direction, coherence and provide a joint

understanding of the reasons for the learning undertaken. Co-construction or review of a job description and PDL pathway could be done at the beginning of each PDL annual cycle and reviewed at completion of the cycle. The study showed that the joint creation of a job description and PDL direction increases the effectiveness of PDL by: enhancing the relationship and understanding between the principal and TLR; eliciting self-directed learning with the consequent positive psychological effects; and creating a strategically viable PDL programme. 


\section{Principal and TLR relationship}

The joint creation (or review) of a job description and PDL plan between a principal and a first-time TLR or a TLR new to a school initiates a specific working and nurturing relationship that is pivotal for effective PDL (Mangin, 2007). This relationship is valuable to the TLR as it provides a clear indication of principal support for them in their role, motivation to learn (Cyboran, 2005; Vardi, 2000) and develops leadership theory, beliefs and practice (Duignan \& Cannon, 2011; Mangin, 2007). Frances, Rachel and Lisa all experienced this type of relationship with their principal or a designated proxy. All were extremely motivated by, and appreciative of, the support they had received. Meanwhile the relationship was beneficial for the principal as they gain a better understanding of and empathy for the TLR starting a new role as illustrated by the two principals in the study who carried out the deliberate practice of co-construction or review of a job description and PDL pathway with their TLRs.

\section{Principal understanding}

Both findings and literature showed that there was a perceived assumption by some principals that new TLRs could carry out their leadership role with little or no support (Baecher, 2012; Briggs, 2012a; Patti et al., 2012). Often employers forget that when an experienced worker in one area begins an unfamiliar role, they become novices in that position and they require support and guidelines to get started (Dreyfus, 2004; Edwards et al., 1997).

Principals in the study spoke of identifying and appointing new leaders through their actions and attitudes as classroom teachers. Principals followed that identification with mostly incidental and informal PDL that did not effectively meet the learning needs of the TLR. Many first-time TLRs spoke of the feelings of uncertainty and frustration stemming from not getting a job description at the onset of their job and not knowing what was expected of them. TLRs stated that leadership of other teachers is quite a different role and requires support both through providing a job description and regular on-going formal and informal PDL. In the questionnaire TLRs expressed their thoughts on the transition to leadership and the support that is needed: 
Currently teachers who may be excellent teachers become managers of adults and there is no transition or guidance for that changing role (EL, $A P / D P)$.

Leadership is not something most people have naturally and it is important to build capability in order to help and enhance others' capability (EL, CL).

One way to avoid those assumptions on behalf of the principals is the deliberate act of recognising and supporting a first time TLR as carried out by Sophie and Julia. This can be done by the inclusion or creation of a job description at this planning stage. A job description gives clear structures and expectations (Armstrong, 2012; Belling et al., 2004; Edwards et al., 1997) and provides a clear framework from which PDL needs can be ascertained. It also alleviates some of the anxiety a novice leader has.

The level of co-construction of the job description is dependent upon environmental factors. As seen in this study, some schools may already have a written job description before a TLR takes up the role. In this situation, as part of the PDL cycle, it would be necessary for the principal and the first time TLR or TLR new to a school to review the job description to ensure that expectations were clearly understood.

A principal's deliberate act of creating a PDL plan with the TLR provides an avenue for the principal to better understand what the TLR's learning needs are rather than assumptions being made. While only one principal in the study used the process of co-construction of both job description and PDL programme another talked of how the provision of a job description initiated discussions with TLRs about their learning needs. Notably these were the principals who identified the lack of selfefficacy of first-time leaders also identified in the literature (Armstrong, 2012; Clemans et al., 2010). This suggests a better understanding of the PDL needs of new TLRs through purposefully established relationships.

There were some syndicate leaders...that ... said to me, "I don't know what I'm doing, I don't know what the role is, I don't know what I have to do, I know I'm not doing my job properly but I'm not sure why" (J). 
The annual review of the job description and co-construction of a PDL plan for a TLR who has been in the role for at least a year provides the principal a chance to better understand the specific learning needs of the TLR subsequently aiding increased efficacy of the PDL (Eraut, 2004).

\section{Self-directed learning}

The joint construction of the job description and/or the PDL pathway allows for the deliberative, informal learning structure of self-directed learning for the TLR. TLRs are able to make some informed decisions about the PDL focus with guidance from a principal or facilitator. Both Diana's and Lisa's recollections reflected the effectiveness of self-directed learning by improving the quality of their respective school appraisal systems. Self-directed learning is a PDL structure that elicits critical thinking and meaningful learning (Garrison, 1997). This is because the learner becomes the active initiator and owner of the knowledge rather than a submissive receptacle (Boyer, 2004; Taylor et al., 2011).

This self-determination also provides a new TLR, whose efficacy is affected by both emotional and social destabilisation (Bandura, 1997), some sense of control and empowerment thus increasing motivation (Cyboran, 2005; Garrison, 1997; Vardi, 2000). A motivated, novice TLR, adapts more positively to a role they are unfamiliar with (Cyboran, 2005; Vardi, 2000) and feels increased competence to carry out agreed tasks. For a large number of new TLRs in this study there was a sense of a lack of control, empowerment and ultimately diminished self-efficacy as there was no job description provided, little or no consultation with the principal on what was expected of them and PDL was randomly chosen rather than determined from an identified learning need.

\section{Strategic viability}

This study showed that creating a PDL plan gives the principal a clearer direction about the strategic resourcing that needs to take place for effective PDL to occur. When Sophie co-constructed the job description and determined the learning needs of TLRs she was able to plan the PDL and the subsequent strategic resourcing that was required to support the PDL. Choices about PDL will be affected by the deliberate practice of strategic resourcing and the framing of the annual school 
budget that is carried out towards the end of the previous year. Nevertheless creating a PDL pathway provides an indication of what resources are required and whether the annual budget is adequate. From the co-construction of learning needs with her TLRs Julia recognised that the PDL required would necessitate a larger amount of monetary support than was budgeted for. Therefore she approached her Board of Trustees for the additional funding and was successful in doing so as she could easily justify the need for it.

\section{Summary of component one: Co-construction or review of job description and PDL pathway}

The first component of the annual cycle of PDL for TLRs is the co-construction between a principal and a TLR of a job description and a coherent and meaningful PDL pathway. This establishes an organised professional and supportive relationship between the principal and the TLR. A TLR new to the position would gain clarity about expectations of what they need to do and the self-determination that would enable them to feel more empowered and competent in taking on new tasks. Sharing the formation of the PDL pathway initiates the effective PDL structure of self-directed learning and finally ensures the establishment of a PDL direction that is efficacious and sustainable.

\subsubsection{Component two: PDL structures}

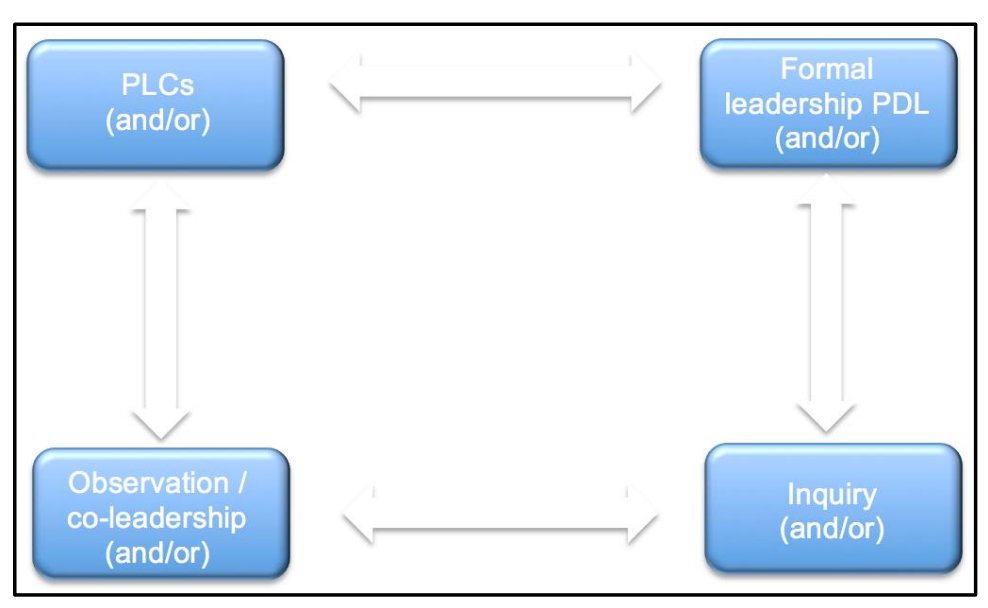

Figure 6.3: Component two

The second component of the annual cycle is the use of different structures of PDL. The four structures as seen in Figure 6.4 are formal PDL, inquiry, PLCs, and observation/coleadership. The research findings showed that each of these structures facilitated effective learning and participation, and a combination of these structures would increase that effectiveness. 


\section{Seriated formal leadership PDL}

Seriated, formal PDL is one structure that was shown to be effective in this study. It allows for the potent combination of inside-out and outside-in learning (Turbill, 2002). Seriated, formal PDL involves the use of a designated facilitator (Eraut, 2000) from an outside agency, working with TLRs to develop specific leadership capabilities either in off-site environments or within a school. The questionnaire and interview findings showed effective formal PDL, facilitated by an outside agent, encouraged leaders to create new ideas about leadership theories, beliefs and practices by combining their thinking with others through sharing, collaboration and reflection then applying the new thoughts to their leadership role. An experienced leader in the questionnaire commented:

Working with outside agencies...has been huge and has had a huge impact on my ability to lead - as I used to slip into role of nurturer and enabler instead of a coacher to support the development of others (EL, AP/DP).

The literature showed that outside PDL agents who employed continuous, active and reflexive learning, problem solving and utilised already established leadership capabilities (Duignan, 2004) increased the TLRs' ability to lead and their efficacy grew (Bush, 2008; Cotter, 2007; Taylor et al., 2011; Turbill, 2002).

\section{Professional learning communities}

The next informal PDL structure that could be used is regular participation in PLCs. PLCs are another ideal forum for inside-out and outside-in learning to be combined with sharing, collaboration and reflection (Clemans et al., 2010; Earley \& Jones, 2011; Gilpin-Jackson \& Bushe, 2007). They provide, a more intimate and safe forum for the sharing of learning and, social support for participants who are having similar leadership experiences.

Many TLRs spoke of enjoying the opportunity to share their learning and realities with others in a PLC setting. All three interviewed TLRs who participated in NAPP found hearing from other leaders and sharing ideas increased their leadership capabilities. Rachel spoke of a Mathematics PLC she attends in which members had initiated and carried out collaborative inquiries on mathematics teaching and leadership. Lisa expressed her appreciation of the effectiveness of a more structured 
PLC in which a coaching approach is taken to elicit more critical thinking.

The leadership PLC meetings have made me realise that I have learned a lot... and I've had some really tough questions asked of me about leadership issues $(L)$.

\section{Inquiry}

The final informal PDL structure is leadership inquiry and could be seen as subsidiary of self-directed learning where inside-out learning takes place. The structure allows and motivates TLRs to investigate leadership practices they have identified as learning needs in Component One of the PDL cycle (Garrison, 1997; Taylor et al., 2011). Through deliberative learning episodes (Eraut, 2004) embedded in relevant contexts, TLRs could obtain a better understanding of the complexities of leadership. Accompanying this growth in knowledge comes increased leadership capacity (Hunzicker, 2012; Taylor et al., 2011). Diana found inquiry was the most effective PDL component of NAPP.

It is notable that few TLRs in this study identified the use of inquiry as a form of PDL, however many spoke of experiences that involved capacity building through experimenting with application of leadership capabilities and subsequent reflection. It appears therefore that they were carrying out an inquiry, and reinforces Reid's (2004) belief that inquiry is "a way of professional being" (p. 3).

Many TLRs displayed single loop learning by articulating the reactive learning that had occurred through trying things out, but there was no mention of sufficiently robust reflection of the inquiry leading to transformative change. The use of a premeditated and structured reflection with others would increase the likelihood of the recognition of double loop learning, as there is someone to challenge the TLR's thinking (Brockbank \& McGill, 2006; Garrison, 1997; Robertson, 2005).

\section{Observation / co-leadership}

The observation of a more experienced TLR or co-leadership of an area of responsibility is another PDL structure that could be used. Alex spoke of how coleading with a more experienced leader assisted her in developing her capabilities as a team leader before taking the role on independently. Rachel has found the co- 
leadership of the mathematics curriculum with the deputy principal provided her with the necessary scaffolding to become the sole leader in the future. A number of principals also spoke of using this practice to enhance the capabilities of their leaders using more experienced leaders within their own and other schools.

In this study, thus far, the deliberate practice of using observation or working with a more experienced TLR to develop a less experienced one has been classified as a contextual factor of encounters and relationships with people at work to enhance professional development (Bush, 2008; Earley \& Jones, 2011; Eraut, 2004). Yet this deliberate practice can also be viewed as an informal PDL structure where outside-in learning would be predominant. Observation of and co-leading with good role models provides TLRs with opportunities for implicit and reactive learning (Eraut, 2004) of new leadership perspectives and practices (Anderson \& Cawsey, 2008; Breakspear, 2010; Rhodes \& Brundrett, 2009). The level of learning is dependent on the amount of sharing, collaboration and reflection that takes place. Learning obtained from observing another leader requires sharing and reflection after the observation. Co-leading with a more experienced leader must result in sharing and collaboration since they are working together. Deliberate discussions and reflection need to take place in both structures to increase learning (Cheetham \& Sandberg, 2005; Dall'Alba \& Sandberg, 2006).

\section{Combination of structures}

Many participants in the study spoke of having experienced a combination of leadership PDL structures over a year, each structure addressing a slightly different learning need. To grow capacity, TLRs need to be offered a variety of appropriate PDL to meet different needs and address the complexities of leadership (Belling et al., 2004; Pont et al., 2008). Therefore a combination of the PDL structures within Component Two need to occur within the annual PDL cycle. Using one structure in isolation is not sufficient to meet the multifaceted learning needs that a new leader has. This is shown in Sophie's utilisation of a range of PDL structures to address the identified learning needs of her leadership team, to good effect. Rachel spoke of feeling very supported in her learning needs through the mixture of different leadership PDL structures she had experienced in her first year at a new school as a team leader. One TLR from the questionnaire remarked: 
All the PD I have had has contributed in some way. You take different things from different places. Reflection on what is working and what is needed helps too $(E L, A P / D P)$.

\section{Summary of component two: PDL structures}

The accessing of a variety of PDL structures as a component of a TLR's annual PDL pathway is important as the combined structures provide ongoing, active and relevant learning programmes that empower TLRs to grow stronger in their leadership capabilities. Formal PDL, informal PLCs, inquiry and observation of or co-leading with a more experienced leader are all structures that can be chosen and combined to ensure holistic PDL.

\subsubsection{Component three: Essential elements}

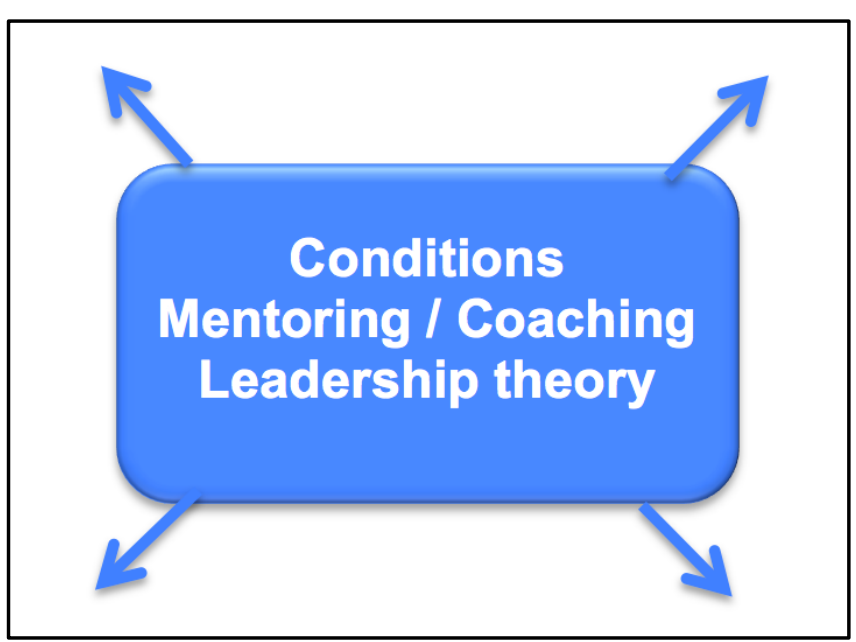

Figure 6.4: Component three

The third component of the annual cycle is the intentional, periodic use of a mixture of essential conditions, structures and leadership theory to support PDL throughout the cycle (Figure 6.5). The study's findings showed that each of these elements had some impact on the TLRs' PDL. However for many of the TLRs who experienced unsystematic PDL not all of these elements were combined to optimise learning. In order to achieve effective PDL where inside-out learning, outside-in learning and the conditions of sharing, collaboration and reflection are combined to create greater understanding, cognitive dissonance and transformational learning (Turbill, 2002) it is suggested that the three conditions should infiltrate all the PDL structures in the cycle. The PDL structure of mentoring and/or coaching should be used regularly throughout the PDL cycle, and finally, leadership theory should underpin all structures and conditions. 


\section{Conditions}

The conditions of sharing, collaboration and reflection are the processes through which knowledge can be developed, questioned and changed. All three conditions need to occur as part of any one PDL structure for it to be truly effective (Turbill, 2002) and can take place in both formal and informal PDL structures. Turbill (2002) believes that if structures are well planned and executed, all three conditions should happen naturally. The findings showed that sharing, collaboration and reflection took place in the formal PDL, PLCs and the schools where an ongoing, systematic PDL plan occurred.

Sharing and collaboration facilitates outside-in learning, the sharing of one's own and the hearing of others theories, beliefs and practice (Turbill, 2002). With sharing and collaboration comes increased trust, respect and collective understanding (Gilpin-Jackson \& Bushe, 2007). Subsequently this increased motivation for increased risk-taking in sharing and synthesizing information and taking action. Sharing and collaboration can be implicit or incidental particularly in the informal PDL that many of the TLRs spoke of such as leadership meetings and incidental chats with colleagues. For many of the TLRs sharing and collaboration often happened within the incidental and informal mentoring that transpired between principals and leadership colleagues.

Principals in this study created deliberative learning situations in which purposeful sharing and collaboration of leadership theories, beliefs and practice took place. All the principals interviewed deliberately practised this to varying degrees. Both Julia and Sophie have made the conscious decision to do the same PDL as their leadership teams. Not only did their participation lead to the shared understandings and increased collaboration that both Rachel and Lisa mentioned, but also gave Sophie and Julia another chance to monitor the TLRs' learning needs.

Other opportunities for sharing and collaboration could occur as part of the PDL structures mentioned in Component Two. There might also be intentional use of these two conditions in informal PDL structures such as leadership meetings for example Julia scheduled time in leadership team meetings for sharing of and collaboration on how the practice of coaching was progressing with each TLR. 
For many TLRs the condition of reflection did not occur. TLRs in this study reported that learning often occurred through sharing and collaboration with leadership colleagues. However, very few TLRs spoke of purposeful reflection that elicited the vital recognition and articulation of one's own theory, beliefs and practices in order to compare and assimilate them with others' that is required for effective PDL. This was corroborated with findings from principal interviews.

Reflection is required to consolidate understanding and transformation of theory, beliefs and practices (Brockbank \& McGill, 2006; Clemans et al., 2010, 2012; Robertson, 2005; Turbill, 2002). Deliberate reflection provides the opportunity to consciously consider how inside-out learning aligns with the outside-in learning happening during sharing and collaboration (LaBoskey, 2010; Mezirow, 2003; Robinson, 2011; Timperley et al., 2007). This study's findings and literature showed that reflection prompted TLRs to articulate and clarify learning and provided a forum to expose cognitive dissonance (Clemans et al., 2010, 2012; Mezirow, 2003; Timperley et al., 2007). This was demonstrated in Emily's understanding of leadership after attendance at formal PDL that incorporated intentional reflection time:

It shifted my perspective of what leadership means because initially I was quite ambiguous about the idea of being a leader because I associated it with someone who was bossy, tell it all, I didn't really identify with that and it really helped me to think, a leader doesn't mean that at all. Everyone can be a leader and it's just doing the job that's there $(E)$.

\section{Formal mentoring and/or coaching}

Formally scheduled mentoring and coaching are structures that could be used as part of the PDL cycle as they are useful for monitoring progress and understanding of theory, beliefs and practice and any misconceptions can be addressed (Garrison, 1997; Robertson, 2005; Schulz, 2010). Mentoring might be more appropriate for a first time TLR or experienced TLR commencing a leadership position at a new school. Coaching is a subset of mentoring and could be used as part of the mentoring process but also used as a stand-alone structure once new TLRs felt comfortable in their environment. 
Mentoring for an individual new to a role or environment provides security, enhances self-efficacy and assists in the development and understanding of the role and culture of the institution (Clutterbuck, 2008; McManus \& Russell, 1997). Both TLR and principal interviewees saw formalised mentoring as an ideal PDL structure for first-time leaders and it was proved to be appropriate for TLRs beginning a different leadership role in a new school. This was illustrated by the formalised mentoring that Rachel and Frances received at the start of their new jobs. Both these TLRs mentioned how their mentor's guidance and support assisted them in becoming more familiar and comfortable with their roles, similar to the findings of Duncan and Stock (2010) and Cotter (2007).

Establishing a formal mentoring relationship between the principal and a new TLR is an important part of the deliberate practice of providing ongoing PDL in the workplace and also provides the principal with a greater insight into understanding of the TLR's PDL needs. However to alleviate some of the workload for the principal, a mentoring relationship could be organised using a designated experienced leader as the mentor. Rachel and Frances both had formal mentors who were not their principals. Alex's suggestion of who a first-time TLR's mentor could be, can be directly related back to Edwards et al.'s (1997) theory that competent leaders make the most suitable mentors:

I quite like the idea of having a mentor that's in a similar position or has been in a similar position before so that they've still got their finger on the pulse about what you're trying to do (A).

Coaching can either be an element of a mentoring relationship for a first-time TLR or a leader transitioning to a new school or it can be a stand-alone PDL structure, particularly for competent to expert leaders (Dreyfus, 2004) who are wishing to achieve specific leadership goals established in Component One. Coaching facilitates ownership of the learning and consequent actions by strategic questioning (Duncan \& Stock, 2010; Pask \& Joy, 2007). Coaching also provides an excellent forum for the necessary critical reflection required in an inquiry to, verify the accuracy of learning and transform learning (Mezirow, 2003; Robertson, 2005; Timperley et al., 2007). 
Findings showed very little use of formal coaching with the majority of TLRs. However the schools that have utilised coaching as a PDL structure have found it powerful. Sophie and Lisa spoke highly of the effectiveness of the coaching format of their leadership PLCs in order to empower the participants. Julia and Rachel also spoke of the value of coaching in enabling TLRs to become problem solvers. This evidence and the literature support the effectiveness of coaching and the necessity to have it as a mandatory component of the PDL cycle.

As part of coaching and mentoring it is important to make a commitment to regularly schedule time throughout the PDL cycle (Eraut, 2004). Julia and Sophie illustrated the usefulness of doing this as they found that the dedicated time for sharing, collaboration and reflection continued the momentum of the PDL. It also contributed to both principals obtaining a stronger understanding of their TLRs' PDL progress and needs. Having a scheduled time also reassures TLRs that there is a time where they can share their concerns with their mentor without feeling that they are disturbing the otherwise busy person; a concern expressed in the findings.

\section{Leadership theory}

The inclusion of leadership theory throughout all of the structures and conditions mentioned in the PDL cycle would be useful as it provides another valuable avenue for outside-in learning (Turbill, 2002). Theory gives a variety of analytical perspectives regarding leadership theory, beliefs and practice that affirm, open up and challenge an individual (Simkins, 2005). Theory also provides a sound basis for substantiating established theory, beliefs and practices or transformational change (Robertson, 2005):

Reading research has given me different ideas of how to respond to various situations $(E L, A P / D P)$.

Probably most helpful has been ongoing reading...that has challenged my thinking, helped me clarify my vision (EL, CL).

Interviewees spoke of the value of using theory to initiate discussion, learning and change in leadership practice. Julia used theory to begin discussions about the concept of leadership and what it looked like when she began PDL with her TLRs 
and helped transform their thinking:

Through the leadership theory stuff we raised the problem of being problem solvers $(J)$.

Lisa talked about the value of reading theory about coaching, discussing the ideas suggested with her leadership colleagues and then applying it to her work. First time TLRs saw the inclusion of leadership theory as an important element of ideal PDL for first-time leaders.

\section{Summary of component three: Essential elements}

The conditions of sharing, collaboration and reflection, the PDL structure of mentoring and/or coaching and the inclusion of leadership theory are essential elements that need to occur throughout the PDL framework to augment the PDL. In doing so TLRs are provided with the chance to recognise, talk about and practise their leadership learning in order to build capability. 


\subsection{Framework of PDL for TLRs}

Figure 6.6 shows how the two parts, contextual factors enabling effective PDL in the workplace and annual PDL cycle fit together to create a possible framework of PDL for TLRs.

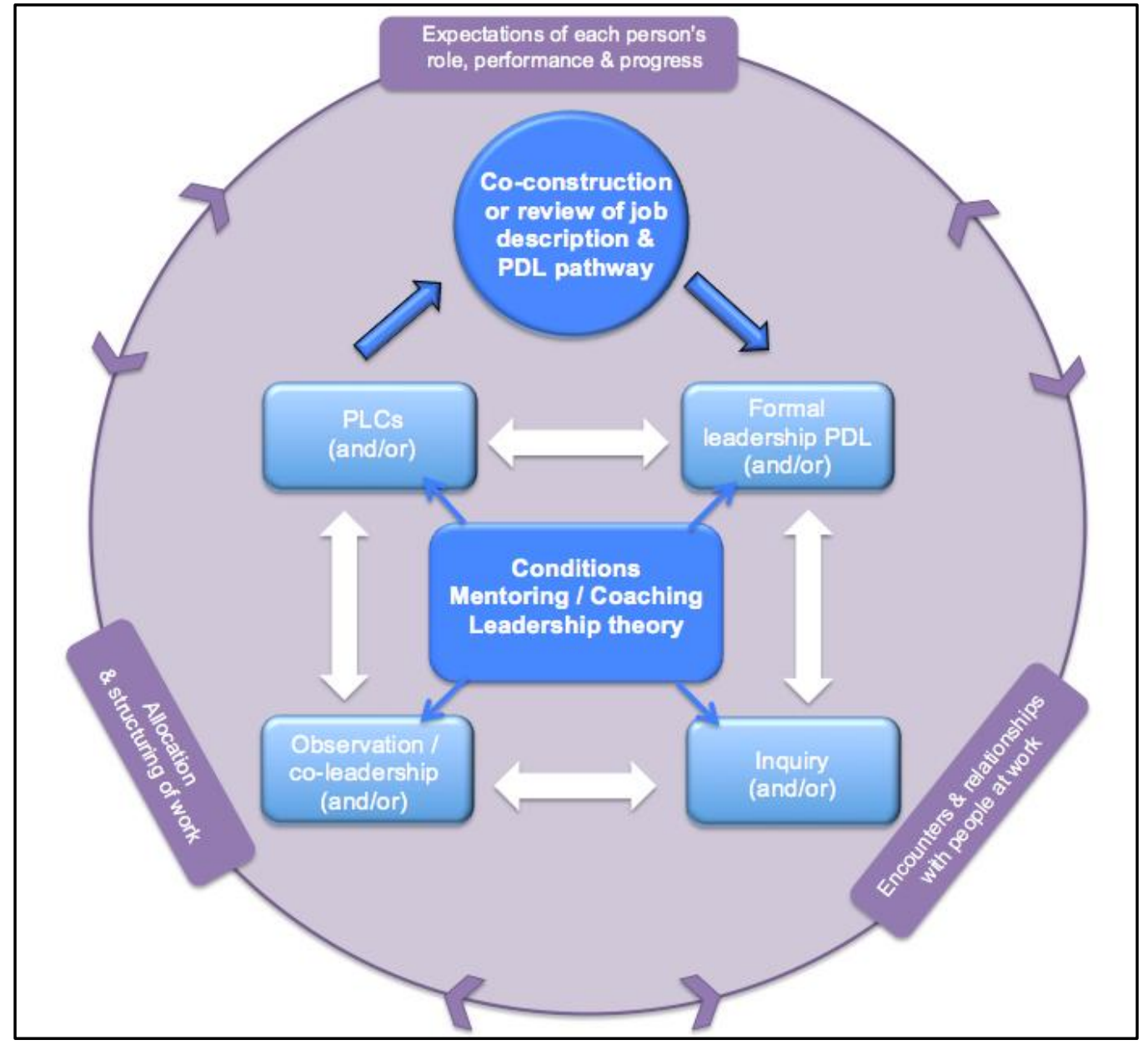

Figure 6.5: Framework pf PDL for TLRs

The possible contextual factors surround and filter through the annual cycle as the deliberate acts taken within each of these contextual factors are required in order for the annual cycle to take place. The annual PDL cycle is in the centre of the framework as the enacted deliberate practices in the outer circle could provide the direction and coherence of ongoing and appropriate PDL that may affect the level of TLR leadership capability.

\subsection{Summary of discussion}

The inconsistencies in the findings of the types and effectiveness of PDL and the deliberate acts taken to enable PDL for TLRs between schools suggests that there is 
a possibility that there is a lack of understanding about the PDL needs of a TLR, in particular, a first time TLR or one who is new to a school. The PDL offered varied from well thought out, systematic and on-going, through unsystematic and reactive, to no PDL at all.

The framework of PDL for TLRs described in this chapter is based on the effective deliberative and systematic practice identified in the findings. It is centered on the philosophy of co-ownership of the PDL by both the principal and the TLR. This enables increased understanding for both parties. The framework contains two parts, the first part being the three contextual factors of allocation and structuring of work, encounters and relationships with people at work and expectations of each person's role, performance and progress that enhance PDL in the workplace. The advocated PDL cycle will only operate if principals carry out deliberate acts, which fall under the three factors and permeate the PDL cycle.

The second part of the proposed framework is the annual PDL cycle that consists of the components, the co-construction or review of job description in PDL pathway, PDL structures and necessary elements. The two parts combined constitute a possible option for a PDL framework for all TLRs. Using this pre-meditated approach is more likely to ensure that PDL is relevant and motivating for the TLR. Use of the framework involves the allocation of time for fundamental critical reflection with a formal mentor or coach during which learning can be monitored for accuracy and progress. The use of a PDL framework such as this could increase leadership capability at a more effective rate than the use of an unsystematic approach. 


\section{Chapter Seven: Conclusion}

\subsection{Introduction}

This final chapter firstly revisits the aim and research question. Then it offers recommendations for policy and practice related to supporting TLRs new to a position in New Zealand primary schools derived from the findings in this study and the literature reviewed. The limitations of the study and directions for future research are then discussed.

\subsection{Summary of research aim}

The purpose of this study was to find out how teachers, who are new to having leadership responsibility in New Zealand primary schools, are supported in their role. It appears from the results that whilst there are some first-time TLRs who have not received any form of PDL the majority receive some PDL. The type and effectiveness they receive depends very much upon the leadership of the principal.

The type of PDL structures identified in the study can be classified into informal and formal learning. The main formal learning structure identified was the seriated use of an outside agent to facilitate leadership PDL. Leaders either attended a series of offsite, day courses or the agent came into school regularly to work with the leadership team. Often the agent would assume the role of mentor or coach to empower the learners. This structure proved effective, as a number of participants were able to articulate growing leadership competence.

The structures of informal learning ranged from events where implicit learning occurred such as observation of another leader or organising a staff meeting, through to situations causing deliberative learning for example planned segments of leadership meetings to review progress of learning. A large number of participants spoke of the benefits of the incidental talks that took place with colleagues and/or principals, either in passing or as part of a leadership team meeting. While participants could see the benefits of these chats, learning was mostly reactive and often implicit, inside-out learning. These means, that whilst learning was happening TLRs struggled to recognise the learning and were unsure about whether they were doing the right thing, in addition, principals were unsure of the TLRs learning needs. 
The PDL that was provided for TLRs by schools seemed to fall under two categories of organisation. The first category of organisation was premeditated and systematic PDL. Learning needs were identified by the use of either an already established job description or a co-constructed one. A variety of both formal and informal PDL structures were utilised to combine inside-out and outside-in learning with sharing, collaboration and reflection and was continued throughout the year. As a result TLRs involved in this system could readily articulate the progress they had made in becoming more competent leaders. Meanwhile principals who carried out this deliberate practice were able to easily identify learning that had occurred and used the system well to pinpoint further learning needs. Although the main focus of this study has been on the level of support first-time TLRs receive, this PDL framework as seen in Figure 6.6 could be used for any TLR regardless of experience and time within a particular role.

The second category of organisation was unsystematic. TLRs and principals spoke of utilising formal PDL combined with mostly informal situations that provoked implicit and reactive learning. There was little consistency or direction in PDL decisions and a vague comprehension of specific learning needs.

\subsection{Recommendations}

The findings of this study highlight the importance of the actions taken by the principal in influencing a TLRs ability to be the most effective leader they can possibly be. These recommendations in this section are linked to the deliberate acts that principals carry out as the primary facilitators of learning for TLRs within a school. Practice and police foreshadow all the recommendations.

\subsubsection{On-going leadership PDL in the workplace}

The primary recommendation of this study is for a PDL framework similar to the one that is described in Chapter Six to be adopted by New Zealand primary schools. This could lead to greater consistency and higher quality PDL being offered to TLRs throughout New Zealand. This would have the consequence of increasing the numbers of TLRs with the capacity to lead other teachers effectively in raising student achievement. 


\subsubsection{Strategic resourcing of principal's time and expertise}

Principals may wish to reflect on the strategic resourcing time needed to administer a PDL framework similar to the one mentioned in this study. An investment of time in developing the leadership capabilities of a school's TLRs will lead to a more empowered and capable educational leadership team, who in turn, can expertly lead to ensure a higher quality of teaching and learning.

\subsubsection{Principal capability}

A review of the development of mentoring and coaching skills for principals is another recommendation. As mentoring and coaching are seen as an important structure within the PDL framework there may be a need to review the support that principals receive in programmes such as the First-Time Principals' Programme (University of Auckland, 2012) in order to develop the specific skills required for mentoring and coaching. The benefit of learning these skills is that they can be applied to many different situations within and outside of a school to empower individuals.

\subsubsection{Strategic resourcing}

The main implication for policy is strategic resourcing from the Ministry of Education earmarked specifically for PDL of TLRs. The Ministry of Education (2012) has recognised the importance of TLRs within schools and the need to provide ongoing PDL. However the Ministry of Education has provided little or no information on how to carry out this PDL and expectations are that schools must fund any PDL that they provide. This study recommends that additional, specific funding for the PDL of TLRs be provided for in a school's operations' grant. In doing so, principals will be compelled to invest time and money into establishing a PDL framework for TLRs such as the one suggested in this study.

\subsection{Limitations of the research}

There are a number of research limitations that need to be taken into consideration when contemplating the trustworthiness of this study. Firstly the small number of participants may not be a representative sample of all TLRs. TLRs are very busy people and may have simply chosen not to complete the online survey or participate in the focus group interviews. It is a possibility that TLRs who felt less supported and more overwhelmed with the job did not have the time to participate. 
Additionally, individual invitations for TLRs to participate in the questionnaire reached just over a third of the schools within the Wellington region. Meanwhile the majority of invitations were sent to principals with a request to pass them on. Using this system does not guarantee that TLRs will receive the emails as principals, cognisant of a TLR's workload, will not necessarily forward the email to the TLR.

Whilst there were a number of participants in the focus group interviews from a range of schools, only four principals out of a possible nine schools volunteered to participate in individual interviews. This not only provided a less representative sample but also restricted the amount of triangulation that could occur.

The study was restricted to primary schools in the greater Wellington region, which adds to the issue of a representative sample. The participants in the interviews came from a wide geographical area but were all from urban schools. This raises questions about whether findings may have been different from rural schools or primary schools in other regions.

\subsection{Opportunities for future research}

During this research certain issues arose that could create possibilities for future research. These include:

- An issue that some principals mentioned was the apparent lack of appropriate formal PDL structures for TLRs. Research into exactly what formal PDL is offered in New Zealand and the effectiveness of this would assist in gaining a more accurate picture for both the Ministry Of Education and schools of what quality formal PDL for TLRs is available.

- The principals of schools in which PDL of TLRs was premeditated and systematic also talked about creating a culture of learning and leading. They mentioned some deliberate practices they carried out to enhance the culture of learning and leading and research on the deliberate practices that are undertaken to create a culture of learning and leading could be of interest.

- In this study there was very little mention of the specific use of feedback to enhance leadership performance. Feedback is recognised as an essential teaching and learning tool. Eraut (2004) found that in a longitudinal study of secondary school teachers in England feedback on performance was less than 
optimal. Without forward-thinking, constructive feedback the teachers were left feeling uncertain about their role and less committed. Further research on the frequency and type of feedback given and the impact it has on TLRs would provide insight into how the quality of feedback used by principals improves leadership capabilities.

\subsection{Summary}

This study has shown that teachers who are new to having leadership responsibility in New Zealand primary schools are provided with varying levels of effective support in order to carry out their leadership roles capably. The levels of PDL to support TLRs ranged from little or no PDL, to sporadic and inconsistent, through to co-constructed, organized and on-going. This study has shown that effective PDL for first-time TLRs is not just a one off event. The PDL needs to be a combination of formal and informal structures supported with opportunities to share, collaborate and reflect on the learning that is taking place.

A PDL framework has been suggested that ensures a balanced programme of PDL that explores the knowledge domains of leadership theory, beliefs and practice and provides active and meaningful learning for the TLRs. Although a job description is neither a PDL structure nor condition this study has shown that it is an essential component in the framework. The provision or co-construction of a job description provides initial guidance that a novice TLR, who is lacking self-efficacy requires, as well as a starting point for identifying and driving a TLRs learning needs.

Findings showed that the established and sustained partnership between the principal and the TLR as part of the PDL cycle has benefits for both parties. Initially the review or co-construction of the job description and PDL pathway gives the TLR some self-determination in their learning. Consequently more efficacious PDL occurs, learning is more purposeful and relevant to the TLR's needs and motivation to learn increases. In addition, having a job description and a self-directed PDL pathway alleviates some of the concerns and issues that a first-time TLR has.

The study also explained how a possible PDL cycle allows TLRs to regularly share and reflect on their learning with their principals or delegated mentor/coach. This enables more effective learning for the TLR and principals gain an understanding of, 
and can continually monitor, the PDL needs of the TLR. This practice also helps to avoid the assumptions mentioned in the study.

Finally, the study showed how the actions of the principal can determine the success of this PDL cycle and the leadership capabilities of their TLRs. The PDL cycle requires forward thinking and commitment by all who are involved. When the principal demonstrates commitment the TLR will certainly follow.

With a clear direction and a carefully implemented and monitored plan a school will reap the benefits of developing capable educational leaders who will help to ensure quality education for their students. 


\section{Reference List}

Ahlgren, L., \& Tett, L. (2010). Work-based learning, identity and organisational culture. Studies in Continuing Education, 32(1), 17-27.

Anderson, A., \& Cawsey, C. (2008). Learning for leadership: Building a school of professional practice. Camberwell: ACER.

Anderson, K., Clarke, S., \& Vidovich, L. (2009). Taking up the reins: The first year for deputy principals. Leading \& Managing, 15(2), 31- 43.

Argyris, C., \& Schon, D. (1996). Organisational learning II: Theory, method and practice. Wokingham: Addison-Wesley.

Armstrong, D. E. (2012). Connecting personal change and organizational passage in the transition from teacher to vice principal. Journal of School Leadership, $22(3), 398-424$.

Avolio, B. J. (2005). Leadership development in balance: Made/born. London: Lawrence Erlbaum Associates.

Baecher, L. (2012). Pathways to teacher leadership among English-as-a-secondlanguage teachers: professional development by and for emerging teacher leaders. Professional Development in Education, 38(2), 317-330.

Bandura, A. (1997). Self-efficacy: The exercise of control (10th ed.). New York: W. H. Freeman and Company.

Barnett, B. G., Shoho, A. R., \& Oleszewski, A. M. (2012). The job realities of beginning and experienced assistant principals. Leadership and Policy in Schools, 11(1), 92 - 128.

Basit, T. N. (2010). Conducting research in educational contexts. London: Continuum

Belling, R., James, K., \& Ladkin, D. (2004). Back to the workplace: How organisations can improve their support for management learning and development. Journal of Management and Development, 23(3), 235 - 255.

Blanchard, P. N., \& Thacker, J. W. . (2007). Training Design. In P. P. Hill (Ed.), Effective training: Systems, strategies and practices (pp. 159 - 214). New Jersey.

Blase, J., \& Blase, J. (1999). Implementation of shared governance for insructional improvement: Principals' perspectives. Journal of Educational Administration, 37(5), 476 - 500.

Bolden, R. (2007). Trends and perspectives in management and leadership development. Business Leadership Review(April), 1 - 13.

Boyer, N. R. (2004). Using Social, self-directed learning frameworks to engage and transform aspiring school leaders. Scholar-Practitioner Quarterly, 2(4), 7788.

Breakspear, S. (2010). Upgrading your 'in-house' leadership development. Australian Educational Leader, 32(3), 29-30.

Breen, R. L. (2006). A practical guide to focus-group research. Journal of Geography in Higher Education, 30(3), 463-475.

Briggs, A. R. (2012a). Growing our leaders. Leading Lights, 4, 5 - 6.

Briggs, A. R. (2012b). Growing our leaders NZEALS visiting scholar tour 2012.

Brockbank, A., \& McGill, I. (2006). Facilitating reflective learning through mentoring and coaching. London and Philadelphia: Kogan Page.

Bryman, A. (2006). Integrating quantitative and qualitative research: How is it done? Qualitative Research, 6(1), 97-113. 
Burnett, G. (2012). Research paradigm choices made by postgraduate students with Pacific education research interests in New Zealand. Higher Education Research \& Development, 31(4), 479 - 492.

Bush, T. (2007). Authenticity in research - reliability, validity and triangulation. In A. R. Briggs \& M. Coleman (Eds.), Research methods in educational leadership and management (2nd ed.). London: Sage.

Bush, T. (2008). Leadership and management development in education. London: Sage.

Cameron, M., \& Dingle, R. (2006). Career paths in the New Zealand primary school sector. Retrieved from National Digital Heritage Archive website: http://ndhadeliver.natlib.govt.nz/delivery/DeliveryManagerServlet?dps_pid=I E758481\&dps_custom_att_1=ilsdb

Cardno, C. (2005). Leadership and professional development: The quiet revolution The International Journal of Educational Management, 19(4), 292-306.

Cardno, C., \& Piggott-Irvine, E. (1996). Incorporating action research in school senior management training. International Journal of Educational Management, 10(5), 19 - 24.

Cheetham, G., \& Sandberg, J. (2005). Making the best of it: Maximising informal learning within professional development programmes Professionals, competence and informal learning (pp. 210 - 224). Cheltenham, UK: Edward Elgar.

Childs-Bowen, D., Moller, G., \& Scrivner, J. (2000). Principals: Leaders of leaders. National Association of Secondary School Principals. NASSP Bulletin, 84(616), 27 - 34.

Clarke, S. (2008). Australia's recent attempts to forge a national agenda for quality school leadership. In M. Brundrett, \& Crawford, M. (Ed.), Developing school leaders: An international perspective (pp. 138 - 154). Abingdon, Oxon: Routledge.

Clemans, A., Berry, A., \& Loughran, J. (2010). Lost and found in transition: The professional journey of teacher educators. Professional Development in Education, 36(1-2), 211-228.

Clemans, A., Berry, A., \& Loughran, J. (2012). Public anticipation yet private realisation: The effects of using cases as an approach to developing teacher leaders. Australian Journal of Education, 56(3), 287-302.

Clutterbuck, D. . (2008). What's happening in coaching and mentoring? And what is the difference between them? Development and Learning In Organizations, 22(4), $8-10$.

Confessore, S. J., \& Kops, W. J. (1998). Self-directed learning and the learning organization: Examining the connection between the individual and the learning environment. Human Resource Development Quarterly, 9(4), 365375.

Conger, J. A. (1998). Qualitative research as the cornerstone methodology for understanding leadership. Leadership Quarterly, 9(1), 107 - 121.

Cotter, M. (2007). Building the capacity of middle leaders. Learning Matters, 12(2), $63-64$.

Creswell, J. W. (2012). Educational research: Planning, conducting, and evaluating quantitative and qualitative research (4th ed.). Boston: Pearson.

Creswell, J. W., \& Clark Plano, V. L. (2011). Designing and conducting mixed methods research (Second ed.). Thousand Oaks, California: Sage Publications. 
Creswell, J. W., Hanson, W. E., Clark Plano, V. L., \& Morales, A. (2007). Qualitative research designs: Selection and implementation The Counselling Psychologist, 35(2), $236-264$.

Cyboran, V. L. (2005). The influence of reflection on employee psychological empowerment: Report of an exploratory workplace field study. Performance Improvement Quarterly, 18(4), 37-49.

D'Abate, C. P., Eddy, E. R., \& Tannenbaum, S. I. (2003). What's in a name? A literature-based approach to understanding mentoring, coaching and other constructs that describe developmental interactions. Human Resource Developmental Review, 2, 360 - 384.

Dall'Alba, G., \& Sandberg, J. (2006). Unveiling professional development: A critical review of stage models. Review of Educational Research, 76(3), 383 - 412.

Dalton, J. (2010). Learning talk: Build understandings. Maldon, Victoria, Australia: Hands On Educational Consultancy Pty Ltd.

Day, D. V. (2001). Leadership development: A review in context. Leadership Quarterly, 11(4), 581 - 613.

Deece, A. . (2003). The leadership capabilities and decision making of the secondary head of department. Leading \& Managing, 9(1), 38 -51.

Dellinger, A.B., \& Leech, N. L. (2007). Toward a unified validation framework in mixed methods research. Journal of Mixed Methods Research, 1(4), 309-332.

Dreyfus, S. E. (2004). The five-stage model of adult skill acquisition. Bulletin of Science, Technology \& Society, 24(3), 177-181.

Duignan, P. (2004). Forming capable leaders: From competencies to capabilities. New Zealand Journal of Educational Leadership, 19(2), 5 - 13.

Duignan, P., \& Cannon, H. (2011). The power of many: Building sustainable collective leadership in schools. Victoria: ACER.

Duncan, H. E., \& Stock, M. J. (2010). Mentoring and coaching rural school leaders: What do they need? Mentoring \& Tutoring: Partnership in Learning, 18(3), $293-311$.

Earley, P., \& Jones, J. (2011). Accelerating potential school leaders. Principal Matters(89), 12,14-16.

Edwards, J., Butler, J., Hill, B., \& Russell, S. (1997). People rules for rocket scientists. Samford, Queensland: Samford Research Associates.

Elmuti, D. (2004). Can management be taught?: If so, what should management education curricula include and how should the process be approached? Management Decision, 42(3/4), 439 - 453.

Eraut, M. (2000). Non-formal learning and tacit knowledge in professional work. British Journal of Educational Psychology, 70(1), 113-136.

Eraut, M. (2004). Informal learning in the workplace. Studies in Continuing Education, 26(2), 247-273.

Eraut, M. (2009). How professionals learn through workLearning to be professional through a higher education E-Book (pp. 1 - 28). Retrieved from http://learningtobeprofessional.pbworks.com/f/CHAPTER+A2+MICHAEL+ ERAUT.pdf.

Fenwick, T., \& Tennant, M. . (2004). Teaching adults. In G. Foley (Ed.), Dimensions of adult learning: Adult education and training in a global era. Maidenhead, UK: Open University Press.

Foster, B. (2010). From administrators to leaders : Developing middle managers who make a difference. Australian Educational Leader, 32(3), 18-21. 
Fransson, G., Lakerveld, J., \& Rohtma, V. (2008). To be a facilitator of in-service learning: Challenges, roles and professional development. In A. Swennen \& M. Klink (Eds.), Becoming a Teacher Educator (pp. 75-88): Springer Netherlands.

Fullan, M. (2011). Change leader: Learning to do what matters most. San Francisco, CA: Jossey-Bass.

Fullan, M. . (2002). Leadership and Sustainibility. Retrieved from Michael Fullan website: http://www.michaelfullan.ca/Articles_02/12_02.htm

Fullan, M., \& Ballew, A. C. (2004). Leading in a culture of change personal action guide and workbook. San Francisco: Jossey-Bass.

Garrison, D. R. (1997). Self-directed learning: Toward a comprehensive model. Adult Education Quarterly, 48(1), 18.

Gilpin-Jackson, Y., \& Bushe, G. R. (2007). Leadership development training transfer: A case study of post-training determinants. Journal of Management Development, 26(10), 980-1004.

Greene, J.C., Caracelli, V. J., \& Graham, W. F. (1989). Toward a conceptual framework for mixed-method evaluation designs. Educational Evaluation and Policy Analysis, 11(3), 255-274.

Gronn, P. . (2002). Distributed leadership as a unit of analysis The Leadership Quarterly, 13, 423-451.

Hager, P., \& Hodkinson, P. . (2009). Moving beyond the metaphor of transfer. British Educational Research Journal, 35(4), 619 - 638.

Harris, A. (2008). Disributed leadership: According to the evidence. Journal of Educational Administration, 46(2), 172 - 188.

Harris, A., Busher, H., \& Wise, C. (2001). Effective training for subject leaders. Journal of In-Service Education, 21(1), 83-94.

Harvie, L. . (2009). Leadership identification and development of primary school teachers: Exploring the complexities Unitec Institute of Technology, Auckland. Retrieved from http://unitec.researchbank.ac.nz/bitstream/handle/10652/1392/Linda Harvie MEdL\%26M.pdf?sequence $=1$

Haverkamp, B. E., \& Young, R. A. (2007). Paradigms, purpose, and the role of the literature: Formulating a rationale for qualitative investigations. The Counseling Psychologist, 35(2), 265-294.

Henning, D., \& McIver, C. (2008). The emergent leadership program. Principal Matters (75), 35-38.

Hiemstra, R. (1999). Self-directed learning. In W. J. Rothwell \& K. J. Sensenig (Eds.), The sourcebook for self-directed learning (pp. 9 - 19). Amherst, MA: HRD Press. Retrieved from http://books.google.co.nz/books?hl=en\&lr=\&id=yWes2NRKQroC\&oi=fnd\& pg=PA9\&dq=Facilitating+self-

directed+learning+as+a+staff+development+option\&ots=x49Nq2oJBD\&sig $=$ I0izUT-7gJfzI-9ckKNPn6LvKjk - v=onepage \&q\&f=false.

Hipp, K., \& Huffman, J. . (2010). Demystifying the concept of professional learning communities. In J. H. K. Hipp (Ed.), Demystifying professional learning communities (pp. 11 - 21). Plymouth, UK: Rowan \& Littlefield Education.

Hunzicker, J. (2012). Professional development and job-embedded collaboration: how teachers learn to exercise leadership. Professional Development in Education, 38(2), 267-289. 
Johnson, B., \& Christensen, L. (2012a). Educational research: Quantitative, qualitative, and mixed approaches (4th ed.). Thousand Oak, CA: Sage Publications Inc.

Johnson, B., \& Christensen, L. . (2012b). Chapter 8: Methods of data collection: Lecture notes Retrieved from Sage: Student study site for educational research, fourth edition website: http://www.uk.sagepub.com/bjohnson4e/study/intro.htm

Kiss, K. L., \& Townsend, J. S. (2012, 2012 Fall). Teacher inquiry: From knowledge to knowledges. Issues in Teacher Education, 21, 23+.

Krueger, R. A. (1994). Focus groups: A practical guide for applied research (2nd ed.). Thousand Oaks, CA: Sage.

Kvale, S. (2007). Doing interviews. London: Sage Publications.

LaBoskey, V. K. (2010). Teacher education and models of teacher reflection. In P. Peterson, E. Baker \& B. McGaw (Eds.), International Encyclopedia of Education (Third Edition) (pp. 629-634). Oxford: Elsevier.

Leblanc, P. R., \& Shelton, M. M. (1997). Teacher leadership: The needs of teachers. Action in Teacher Education, 19(3), 32-48.

Leech, N. L., \& Onwuegbuzie, A. J. (2008). Qualitative data analysis: A compendium of techniques and a framework for selection for school psychology research and beyond. School Psychology Quarterly, 23(4), 587604.

Leithwood, K. (2003). Teacher leadership: Its nature, development, and impact on schools and students. In M. Brundrett, N. Burton \& R. Smith (Eds.), Leadership in education (pp. 103 - 117). London: SAGE.

Lieberman, A., \& Friedrich, L. D. (2010). How teachers become leaders: Learning from practice and research. New York, NY: Teachers College Press.

London, M., \& Noe, R. A. (1997). London's Career Motivation Theory: An Update on Measurement and Research. Journal of Career Assessment, 5(1), 61-80.

Mack, L. (2010). The philosophical underpinnings of educational research. Polyglossia, 19(October), 5 - 11. Retrieved from Ritsumeikan Asia Pacific University website: http://www.apu.ac.jp/rcaps/uploads/fckeditor/publications/polyglossia/Polygl ossia_V19_Lindsay.pdf

Mangin, M. M. (2007). Facilitating elementary principals' support for instructional teacher leadership. Educational Administration Quarterly, 43(3), 319-357.

McCulla, N. (2011). Crossing the line. Professional Educator, 10(4), 29-31.

McDonald, L., \& Flint, A. (2011). Effective educative mentoring skills: A collaborative effort. New Zealand Journal of Teachers' Work, 8(1), 33 - 46.

McManus, S. E., \& Russell, J. E. . (1997). New directions for mentoring research: An examination of related constructs. Journal of Vocational Behavior, 51, $145-161$.

Merriam, S. B. (1988). Case study research in education: A qualitative approach. San Francisco, California: Jossey-Bass Inc.

Merriam, S. B., \& Associates. (2002). Qualitative research in practice. San Francisco, CA: Jossey-Bass.

Mezirow, J. (2003). Transformative learning as discourse Journal of Transformative Education, 1(1), 58 - 63.

Ministry of Education. (2007). The New Zealand curriculum. Wellington: Ministry of Education. 
Ministry of Education. (2010). Education workforce advisory group: Discussion document.

http://www.minedu.govt.nz/ /media/MinEdu/Files/TheMinistry/Consultation /WorkforceAdvisoryGroup/DiscussionDocumentPDF.pdf

Ministry of Education. (2012). Leading from the middle: Educational leadership for middle and senior leaders. Wellington: Learning Media Limited.

Ministry of Education. (2013a). Five year agreement (5YA) funding. 2013, from http://www.minedu.govt.nz/NZEducation/EducationPolicies/Schools/Propert yToolBox/StateSchools/Funding/5YAFunding.aspx

Ministry of Education. (2013b). How schools are run. 2013, from http://www.minedu.govt.nz/Parents/AllAges/EducationInNZ/SchoolsInNew Zealand/HowSchoolsAreRun.aspx

Ministry of Education. (2013c). National aspiring principals programme 2013 Retrieved March, 2013, from http://www.educationalleaders.govt.nz/Leadership-development/Leadershipprogrammes/NAPP-2013

Ministry of Education. (2013d). School directory. 2013, from http://www.minedu.govt.nz/parents/allages/schoolsearch.aspx

New Zealand Teachers Council. (2010). Registered teacher criteria handbook Wellington: New Zealand Teachers Council.

Onwuegbuzie, A. J., Dickinson, W. B., Leech, N. L., \& Zoran, A. G. (2009). A qualitative framework for collecting and analyzing data in focus group research. International Journal of Qualitative Methods, 8(3), 1 - 21.

Pask, R., \& Joy, B. (2007). Mentoring-coaching: A guide for education professionals. Maidenhead, England: Open University Press.

Patterson, J., \& Patterson, J. . (2004). Sharing the lead. Educational Leadership, April, 74-78.

Patterson, S. (2013). Educative mentoring: Challenges and enablers of implementation in an intermediate school context. Victoria University of Wellington, Wellington.

Patti, J., Holzer, A. A., Stern, R., \& Brackett, M. A. (2012). Personal, professional coaching: Transforming professional development for teacher and administrative leaders. Journal of Leadership Education, 11(1), 263 - 274.

Pont, B., Nusche, D., \& Moorman, H. (2008). Improving school leadership, Volume 1: Policy and practice Retrieved from http://www.oecdilibrary.org.helicon.vuw.ac.nz/docserver/download/9108051e.pdf?expires=13 79043533\&id=id\&accname $=$ oid006392 $\&$ checksum $=00 C F F 81 C 622 \mathrm{E} 640 \mathrm{~F} 04$ D4269DE47C932C

Reid, A. R. (2004). Towards a culture of inquiry in DECS. 3 - 19. Retrieved from South Australian Department for Education and Child Development Website: http://www.earlyyearsliteracy.sa.edu.au/files/links/20120305_RST_Towards _a_cul.pdf

Rhodes, C., \& Brundrett, M. (2009). Growing the leadership talent pool: perceptions of heads, middle leaders and classrom teachers about professional development and leadership succession planning within their own schools. Professional Development in Education, 35(3), 381-398.

Robertson, J. (2005). Coaching leadership: Building educational leadership capacity through coaching partnerships. Wellington: NZCER Press. 
Robinson, V. (2011). Building relational trust through open to learning conversations [PowerPoint presentation]. Auckland, New Zealand: Centre for Educational Leadership.

Robinson, V., Hohepa, M., \& Lloyd, C. (2009). School leadership and student outcomes: Identifying what works and why BES. Wellington: Ministry of Education.

Ross, D., Adams, A., Bondy, E., Dana, N., Dodman, S., \& Swain, C. (2011). Preparing teacher leaders: Perceptions of the impact of a cohort-based, job embedded, blended teacher leadership program. Teaching and Teacher Education, 27(8), 1213-1222. doi: http://dx.doi.org/10.1016/j.tate.2011.06.005

Rubin, H. J., \& Rubin, I. S. (2005). Qualitative interviewing: The art of hearing data (Second ed.). Thousand Oaks, California: Sage Publications.

Schein, E. H. (2004). Organizational culture and leadership (3rd ed.). San Francisco, CA: Jossy-Bass.

Schulz, R. (2010). Inquiry-oriented teacher education. In P. Peterson, E. Baker \& B. McGaw (Eds.), International Encyclopedia of Education (Third Edition) (pp. 604-609). Oxford: Elsevier.

Servage, L. . (2008). Critical and transformative practices in professional learning communities Teacher Education Quarterly, Winter, 63 - 77.

Silverman, D. (2006). Interpreting qualitative data (Third ed.). London: Sage Publications.

Simkins, T. (2005). Leadership in education: 'What works' or 'what makes sense'? Educational Management Administration \& Leadership, 33(1), 9 - 26.

Tashakkori, A., \& Creswell, J. W. (2007). Editorial: The new era of mixed methods. Journal of Mixed Methods Research, 1(1), 3-7.

Tashakkori, A., \& Teddlie, C. (2008). Quality of inferences in mixed methods research: Calling for an integrative framework. In M. M. Bergman (Ed.), Advances in mixed methods research: Theories and applications (pp. 101 119). London: SAGE Publications Ltd.

Taylor, M., Goeke, J., Klein, E., Onore, C., \& Geist, K. (2011). Changing leadership: Teachers lead the way for schools that learn. Teaching and Teacher Education, 27(5), 920-929. doi: http://dx.doi.org/10.1016/j.tate.2011.03.003

Teddlie, C., \& Tashakkori, A. (2009). Foundations of mixed methods research: Integrating quantitative and qualitative approaches in the social and behavioral sciences. Thousand Oaks, California: Sage.

Thomas, D. R. (2006). A general inductive approach for analyzing qualitative evaluation data. American Journal of Evaluation, 27(2), 237-246.

Timperley, H., Wilson, A., Barrar, H., \& Fung, I. (2007). Teacher professional learning and development: Best evidence iteration. Wellington, New Zealand: Ministry of Education.

Turbill, J. (2002). The role of a facilitatior in a professional learning system: the Frameworks project. In G. F. Hoban (Ed.), Teacher learning for educational change (pp. 94 - 114). Buckingham: Open University Press.

University of Auckland. (2012). First-time principals Retrieved May, 2012, from http://www.education.auckland.ac.nz/uoa/first-time-principals-programme

Vardi, Y. (2000). Psychological empowerment as a criterion for adjustment to a new job. Psychological Reports, 87(3f), 1083-1093.

Vaughn, S., Schumm, J. S., \& Sinagub, J. (1996). Focus group interviews in education and psychology. Thousand Oaks, California: Sage Publications. 
Victoria University of Wellington. (2007). Human ethics policy. Retrieved from Victoria University of Wellington website: http://www.victoria.ac.nz/documents/policy/research-policy/human-ethicspolicy.pdf

Wikipedia. (2013). List of schools in the Wellington region. 2013, from http://en.wikipedia.org/wiki/List_of_schools_in_the_Wellington_Region cite_note-years-

Wlodkowski, R. J. (2008). Enhancing adult motivation to learn: A comprehensive guide for teaching all adults What motivates adults to learn (pp. 95 - 123). San Francisco: Jossey-Bass.

Yin, R. K. (2003). Case study research: Design and methods (3rd ed. Vol. 5). Thousand Oak, California: Sage Publicationd Inc.

York-Barr, J., \& Duke, K. (2004). What do we know about teacher leadership? Findings from two decades of scholarship. Review of Educational Research, 74(3), 255-316. 
Appendices 


\section{Appendix A}

TLR Questionnaire

Q1 How many years have you been teaching as a fully registered teacher?

Under 1 year (1)

O 1 - 4 years $(2)$

O 5 - 10 years (3)

O 11 - 15 years $(4)$

O 15 - 20 years $(5)$

O $20+$ years $(6)$

Q2 How many years have you been teaching at your present school?

Under 1 year (1)

O 1 - 4 years $(2)$

O 5 - 10 years (3)

O $11-15$ years $(4)$

O 15 - 20 years $(5)$

O $20+$ years $(6)$

Q3 Is this the first time you have been a teacher with leadership responsibilities?

O Yes (1)

O No (2)

If Yes Is Selected, Then Skip To How many years have you been in ..

Q4 How many other roles have you had?
1- $2(1)$
O $3-4(2)$
O $5-6(3)$
O $7-8(4)$
○ $9-10(5)$
O $11+(6)$

Q5 What were the other roles you had as a teacher with leadership responsibilities? Please indicate the categories that apply to you.

Syndicate / Team Leader (1)

口 Associate / Assistant / Deputy Principal (2)

口 Pedagogical leader of a curriculum area - please specify (3)

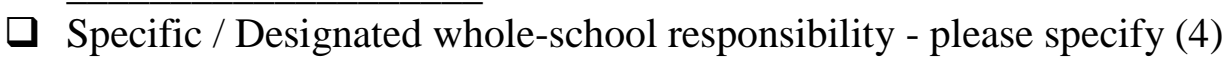

$\square \overline{\text { Other - please specify (5) }}$ 
Q6 How many years have you been in your present role of a teacher with leadership responsibilities?

Under 1 year (1)

O 1 - 2 years $(2)$

O 3 - 4 years $(3)$

O $5+$ years $(4)$

Q7 What is your main leadership responsibility? Please indicate the designated role you have.

O Syndicate / Team Leader (1)

O Associate / Assistant / Deputy Principal (2)

Pedagogical leader of a curriculum area - please specify (3)

Specific / Designated whole-school responsibility - please specify (4)

Other - please specify (5)

Q8 Are you also a teacher with a classroom responsibility?

Y Yes (1)

No (2)

If No Is Selected, Then Skip To How many staff do you regularly work ...

Q9 What year level/s do you presently teach? Please indicate the categories that apply to you.

$\square$ Year $1(1)$

Y Year $2(2)$

口 Year $3(3)$

- Year $4(4)$

$\square$ Year $5(5)$

Year $6(6)$

$\square$ Year $7(7)$

$\square$ Year $8(8)$

Q10 How many staff do you regularly work / interact with as their leader?
O 1 - $2(1)$
O $3-4(2)$
O $5-6(3)$
O $7-8(4)$
○ $9-10(5)$
O $10+(6)$ 
Q13 Using a scale of 1 to 5 where 1 is strongly disagree please rank how true you believe these statements to be.

\begin{tabular}{|c|c|c|c|c|c|}
\hline & $\begin{array}{c}\text { Strongly } \\
\text { Disagree } \\
\text { (1) }\end{array}$ & $\begin{array}{c}\text { Disagree } \\
\text { (2) }\end{array}$ & $\begin{array}{l}\text { Neither } \\
\text { Agree nor } \\
\text { Disagree } \\
\text { (3) }\end{array}$ & Agree (4) & $\begin{array}{l}\text { Strongly } \\
\text { Agree (5) }\end{array}$ \\
\hline $\begin{array}{l}\text { I have had } \\
\text { professional } \\
\text { development and } \\
\text { learning in my } \\
\text { present role as a } \\
\text { teacher with } \\
\text { leadership } \\
\text { responsibilities. } \\
\text { Please comment. } \\
\text { (1) }\end{array}$ & 0 & $\mathrm{O}$ & 0 & 0 & 0 \\
\hline $\begin{array}{l}\text { I have found that } \\
\text { this professional } \\
\text { development and } \\
\text { learning has } \\
\text { increased my } \\
\text { leadership } \\
\text { capabilities. } \\
\text { Please comment. } \\
\text { (2) }\end{array}$ & 0 & 0 & 0 & 0 & 0 \\
\hline $\begin{array}{l}\text { The professional } \\
\text { development and } \\
\text { learning of } \\
\text { teachers with } \\
\text { leadership } \\
\text { responsibilities is } \\
\text { very important. } \\
\text { Please comment. } \\
\text { (3) }\end{array}$ & 0 & 0 & 0 & 0 & 0 \\
\hline $\begin{array}{l}\text { The professional } \\
\text { development and } \\
\text { learning of } \\
\text { teachers with } \\
\text { leadership } \\
\text { responsibilities, in } \\
\text { my present } \\
\text { school, has a high } \\
\text { priority. Please } \\
\text { comment. (4) }\end{array}$ & 0 & 0 & 0 & 0 & 0 \\
\hline
\end{tabular}


Q14 What professional development and learning modes for leadership and management have you participated in, in your present role? Please indicate all categories that apply to you.

A one off, off site, leadership course (1)

A seriated, off site, leadership course (2)

$\square$ Mentoring (3)

$\square$ Coaching (4)

As part of an in-school curriculum development run by an outside agency (5)

$\square$ Action / Inquiry research (6)

P Post - graduate study (7)

Shadowing another leader (8)

$\square$ Leadership conference (9)

$\square$ Leadership cluster groups - please specify (10)

$\square$ Other - please specify (11)

Q16 The following questions will give you an opportunity to talk more about your experiences of professional development and learning for your role as a teacher with leadership responsibilities. The space for entering the answer will expand as you type.

Q17 What issues and challenges have you faced in becoming a teacher with leadership responsibilities?

Q18 What professional development and learning, if any, has helped you overcome those issues and challenges and how have they helped?

Q19 What other successes, if any, have you had when involved in your leadership development and learning?

Q20 If you are in your first role as a teacher with leadership responsibilities and are willing to participate in: 1. An individual interview with me OR 2. A focus group interview with leadership responsibilities and me OR 3. Either type of interview; Please e-mail me at hesketmarg1@ myvuw.ac.nz letting me know which of the three options you would prefer. Also please let me know in the e-mail how many years you have been in this, your first role as a teacher with leadership responsibilities. Please e-mail me by Wednesday 22 May 2013. 


\section{Appendix B}

TLR individual or focus group interview questions

1. Are you also a teacher with a classroom responsibility?

2. How many staff do you regularly work/interact with as their leader?

3. What planned professional development and learning have you had in your present role as a teacher with leadership responsibilities? What was the content of the PD? Was the PDL something you chose or were encouraged to do?

4. Have there been any other types of informal professional development and learning you have undertaken? (Such as coaching, mentoring or any other support within/outside of your school?) In the questionnaire many people indicated that they had had some form of mentoring, if you have had it was it formally organised or not?

5. Who and/or what has helped you with the successes you have had in leadership development and learning? Why?

6. What issues and challenges have you faced when involved in leadership development and learning? How have these been addressed?

7. What were some of the feelings you experienced when you started this leadership role? What PDL, if any, helped you overcome it?

8. If you were planning leadership development and learning for a first time teacher with leadership responsibilities in a primary school what would it look like and why are you suggesting these strategies?

9. What do you see as possible barriers to successfully implementing this programme?

10. Is there anything else you wish to say? 


\section{Appendix C}

1. Are you also a teacher with a classroom responsibility?

2. How many staff do you regularly work/interact with as their leader?

3. What planned professional development and learning have you had in your present role as a teacher with leadership responsibilities? What was the content of the PD? Was the PDL

What professional development and learning are new TLRs offered and/or encouraged to participate in?

What are the enablers \& barriers to effective professional development?

How effective do principals and TLRs consider the current professional development and learning of TLRs to be?

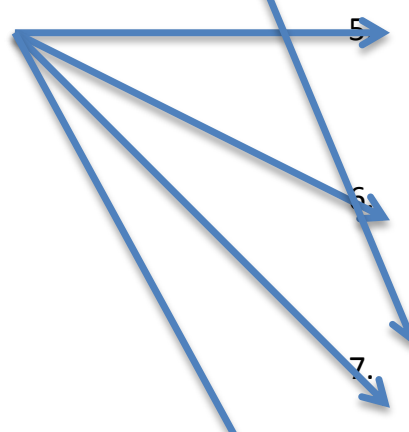

Who and/or what has helped you with the successes you have had in leadership development and learning? Why?

What issues and challenges have you faced when involved in leadership development and learning? How have these been addressed?

What were some of the feelings you experienced when you started this leadership role? What PDL, if any, helped you overcome it?

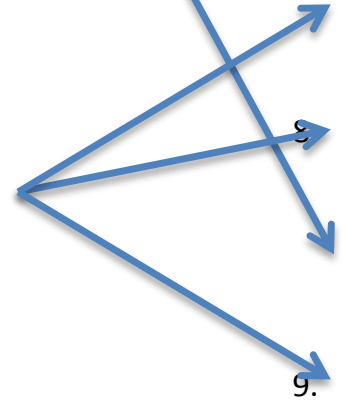

What do you see as possible barriers to successfully implementing this programme?

Probing:

- Could you say something more about that?

- Can you give a more detailed description?

- Can you give me some further examples of this?

Interpreting:

- You then mean that....?

- Is it correct that you feel.....?

- Does the expression.....cover what you have just expressed? 


\section{Appendix D}

Principal Interview Questions

1. What processes do you use select a particular individual for a TLR position?

2. What are the expectations you have of your teachers with leadership responsibilities?

3. What do you consider the challenges are for these teachers in these roles?

4. What strategies have you implemented to further develop teachers with leadership responsibilities' expertise? Why did you select these particular strategies?

5. What do you use to measure the effectiveness of the PLD you have implemented?

6. What of those outcomes have you experienced with your leaders? What things do you consider have helped the PDL to be successful?

7. What are the issues and barriers you have experienced in further developing the capacity of teachers with leadership responsibilities? Have you been able to address the issues and barriers you identified? If so how? / If not why not?

8. How have your experiences in supporting the development of teachers with leadership responsibilities changed what you would do in the future?

9. Which strategies would be ideal to develop teachers with leadership responsibilities expertise, in your school? What do you think the barriers might be in implementing these ideal leadership development and learning strategies?

10. Is there anything else you wish to say? 


\section{Appendix E}

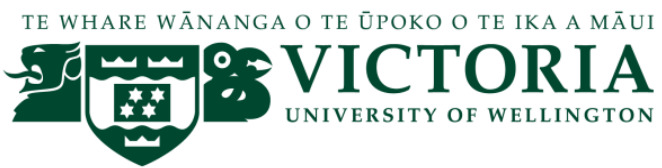

The professional development and learning of teachers with new leadership responsibilities within New Zealand primary schools

Hello! I am Margaret Hesketh and I am currently a Masters student enrolled in the Master of Education degree at Victoria University of Wellington. As part of this degree I am undertaking a research project leading to a thesis. The project I am doing is to examine how New Zealand primary schools are currently supporting new middle and senior leaders to develop their leadership capacity. This project has arisen out of my own interests as a teacher of 23 years, eight of those as a senior teacher and nine as a deputy principal.

You are invited to participate in an online anonymous questionnaire focusing on the professional development and learning (PDL) you have experienced as a teacher with leadership responsibilities. There are questions that address your school context and the type of PDL you have participated in. The survey also asks about your thoughts on the efficiency of the PDL and your opinions on the place of PDL for new middle and senior leaders.

The survey will take between five to ten minutes. Results of the survey will be analysed and will contribute towards the findings of this project. By completing this survey you are consenting to participate in the research. Participation in this survey is optional.

At the end of the questionnaire you will be asked if you would be willing to participate in a one-off, individual or focus group interview. For these I am hoping to talk with leaders who are in their first leadership position, you may or may not have a classroom responsibility and are working with other staff on a permanent, regular basis, in a leadership capacity. The purpose of the interview would be to gain a deeper understanding of the responses I have already obtained and discuss what an ideal PDL programme for leaders like you would look like.

The focus group interview will be held with other teachers with leadership responsibilities from other schools. The interview will take place after school at a time that is most convenient for the majority of you. The individual interview will last between 30-40 minutes and the focus-group interview between 60 to 90 minutes. If there are enough of you indicating that you are willing to be part of a focus group interview then I will not be interviewing individuals.

You will be asked to e-mail me if you wish to participate, in this e-mail please indicate which preference for an interview you have. I will contact you letting you know which type of interview it will be. If you specified that you would like an 
individual interview and it eventuates that I have enough people for a focus-group interview I shall e-mail you to let you know and give you the option of choosing to participate or not.

I will be recording the contributions in all interviews and will provide a transcript for you to check before data analysis is undertaken. Should you feel the need to withdraw from the project, you may do so without question at any time before the commencement of data analysis Monday 2 August 2013. Please let me know at the time.

If you are a new leader and opt to participate in an interview I will be contacting your principal and inviting them to participate in an individual interview with me. The focus of this interview would be on your school's approach to PDL for teachers with leadership responsibilities, the enablers and barriers and I will also ask your principal to articulate his/her ideal PDL.

If you wish to complete the survey please click on the link below. Survey responses must be received by Saturday 10 May 2013 to be included in the research study.

All data collected will be kept confidential and secure. No other person besides my supervisor, Dr Kate Thornton, and I will see the responses. The data will be destroyed five years after the conclusion of the project.

The research has been approved by the Faculty of Education Human Ethics Subcommittee under delegated authority from the Victoria University Human Ethics Committee. The approval number is SEPI/2013/30 RM 19803.

If you have any questions or would like to receive further information about the project, please contact me at hesketmarg1@myvuw.ac.nz or my supervisor, Dr Kate Thornton, at the Education Faculty at Victoria University, phone 4639976 or by email, kate.thornton@vuw.ac.nz. If you have any questions about the ethical issues associated wit this research you may contact Dr Allison Kirkman, chair of the Victoria University of Wellington Human Ethics Committee by emailing allison.kirkman@vuw.ac.nz

Yours sincerely Margaret Hesketh 


\section{Appendix F}

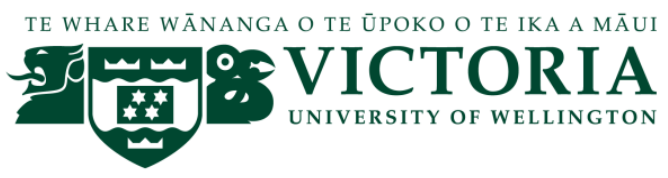

Dear

My name is Margaret Hesketh and I am currently a Masters student enrolled in the Master of Education degree at Victoria University of Wellington. As part of this degree I am undertaking a research project leading to a thesis. The project I am doing is to examine how New Zealand primary schools are currently supporting new middle and senior leaders to develop their leadership capacity. This project has arisen out of my own interests as a teacher of 23 years, eight of those as a senior teacher and nine as a deputy principal.

At present I am trying to locate and contact all teachers who have a leadership responsibility within schools in the larger Wellington area, as I would like to invite them to participate in this project. I wish to invite them to participate in an online, anonymous questionnaire that explores the professional development of teachers with new leadership responsibilities within New Zealand primary and intermediate schools.

Could you please forward this e-mail with the attached information sheet to all teachers in your school who have designated leadership roles?

If you have any questions or would like to receive further information about the project, please contact me at hesketmarg1@myvuw.ac.nz or my supervisor, Dr Kate Thornton, at the Education Faculty at Victoria University, phone 4639976 or by email, kate.thornton@vuw.ac.nz. If you have any questions about the ethical issues associated with this research you may contact Dr Allison Kirkman, chair of the Victoria University of Wellington Human Ethics Committee by emailing allison.kirkman@vuw.ac.nz

The research has been approved by the Faculty of Education Human Ethics Subcommittee under delegated authority from the Victoria University Human Ethics Committee. The approval number is SEPI/2013/30 RM 19803.

Kind regards

Margaret Hesketh 


\section{Appendix G}

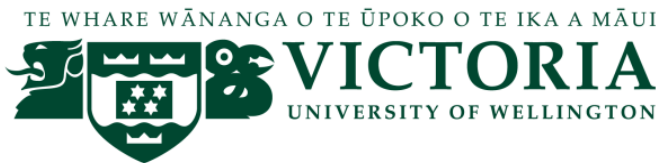

Dear

Thank you for completing the online questionnaire for me about the professional development and learning of teachers with leadership responsibilities in New Zealand primary schools and for volunteering to participate in an individual interview. I appreciate it knowing how precious your time is.

As I mentioned in the information letter, I would be holding only focus group interviews if I had enough teachers happy to be part of them. It has eventuated that I do have enough people so I have made the decision not to have individual interviews.

Since you expressed the desire to have an individual interview I am now inviting you to participate in the focus group interview if you wish. However if you would prefer not to then I completely understand.

If you do not want to participate in a group interview then do not reply to this e-mail. However if you are happy to participate in the focus group interview then do reply to this e-mail. Please reply by Tuesday 28 May 2013.

Once again, thank you for your time and willingness to participate.

Kind regards

Margaret Hesketh

hesketmarg1@myvuw.ac.nz 


\section{Appendix H}

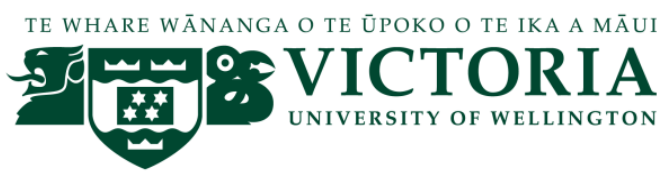

Dear

Thank you for completing the online questionnaire for me about the professional development and learning of teachers with leadership responsibilities in New Zealand primary schools and for volunteering to participate in a focus group interview with teachers from other schools and me. I appreciate it knowing how precious your time is.

As I mentioned in the information letter, I would be holding only focus group interviews if I had enough teachers happy to be part of them. It has eventuated that I do have enough people.

Please fill in the attached consent form and return it me by Tuesday 28 May 2013. I will then be in contact to organise a date, time and venue.

Should you feel the need to withdraw from the project, you may do so without question at any time before the commencement of data analysis Monday 2 August 2013. Please let me know at the time.

Once again, thank you for your time and willingness to participate.

Kind regards

Margaret Hesketh

hesketmarg1@myvuw.ac.nz 


\section{Appendix I}

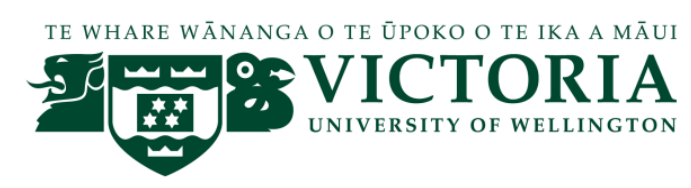

The professional development and learning of teachers with new leadership responsibilities within New Zealand primary schools

I have been given and have understood an explanation of this research project. I have had an opportunity to ask questions and have had them answered to my satisfaction. I understand that I may withdraw myself (or any information I have provided) from this project (before data collection and analysis is complete) without having to give reasons or without penalty of any sort.

- I understand that the focus group interview will be between 60 to 90 minutes long and that I will be interviewed in a group, with other teachers with leadership responsibilities. (OR I understand that the interview will be between 30 to 40 minutes long.)

- I understand that any information I provide will be kept confidential to the researcher and the supervisor; the published results will not use my name or my organisation.

- I understand that no opinions will be attributed to me in any way that will identify me.

- I also understand that I will be provided with a transcript (or summary of findings if appropriate) for checking before data analysis is started.

I would like to receive an electronic copy of the results of this research when it is completed.

I agree to take part in this research.

Signed:

Name of participant:

(Please print clearly)

Date:

Please return to

Margaret Hesketh

hesketmarg1@myvuw.ac.nz 


\section{Appendix J}

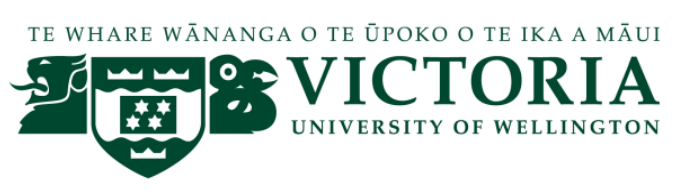

Dear

Recently you completed an online questionnaire for me about the professional development and learning of teachers with leadership responsibilities in New Zealand primary schools and you indicated that you are willing to have an individual interview with me.

Firstly thank you for completing the questionnaire and for volunteering to be interviewed. I appreciate it knowing how precious your time is.

As I mentioned in the information letter, I would be holding only focus group interviews if I had enough teachers happy to be part of them. It has eventuated that I do not have enough people. Therefore I will be carrying out individual interviews

Please fill in the attached consent form and return it me by Tuesday 28 May 2013. I will then be in contact to organise a date, time and venue.

Should you feel the need to withdraw from the project, you may do so without question at any time before the commencement of data analysis Monday 2 August 2013. Please let me know at the time.

Once again, thank you for your time and willingness to participate.

Kind regards

Margaret Hesketh

hesketmarg1@myvuw.ac.nz 


\section{Appendix K}

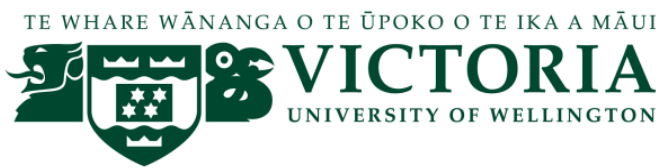

The professional development and learning of teachers with new leadership responsibilities within New Zealand primary schools

Hello! I am Margaret Hesketh and I am currently a Masters student enrolled in the Master of Education degree at Victoria University of Wellington. As part of this degree I am undertaking a research project leading to a thesis. The project I am doing is to examine how New Zealand primary schools are currently supporting new middle and senior leaders to develop their leadership capacity. This project has arisen out of my own interests as a teacher of 23 years, eight of those as a senior teacher and nine as a deputy principal.

I invited any teacher who has leadership responsibilities in schools, who may or may not have classroom duties and are working with other staff on a permanent, regular basis, in a leadership capacity to complete an online questionnaire that explores their school context, the type of professional development and learning (PDL) they have participated in in their capacity as a teacher with leadership responsibilities and their thoughts and opinions on the place of PDL for new middle and senior leaders.

At the end of the survey I gave the teachers the option of participating in a one-off follow-up interview either as an individual or with a focus group. volunteered to participate.

As his/her principal I would also appreciate an opportunity to carry out an individual, 30 to 40 minute interview with you. The interview would focus on your school's approach to PDL for teachers with leadership responsibilities, the enablers and barriers and what an ideal professional development and learning for these leaders would look like. The interview would be at a time that is suitable for you.

I will be recording the contributions in all interviews and will provide a transcript for you to check before data analysis is undertaken. Should you feel the need to withdraw from the project, you may do so without question at any time before the commencement of data analysis Monday 2 August 2013. Please let me know at the time.

The responses I collect in all data gathering exercises will form the basis of my research project. Neither you nor your school will be identified in the thesis. All material collected will be kept confidential. No other person besides my supervisor, Dr Kate Thornton, and I will see the questionnaires and transcripts. The thesis will be submitted for marking to the School of Education and deposited in the University Library. Questionnaires and transcripts will be destroyed five years after the end of the project. 
The research has been approved by the Faculty of Education Human Ethics Subcommittee under delegated authority from the Victoria University Human Ethics Committee. The approval number is SEPI/2013/30 RM 19803.

If you have any questions or would like to receive further information about the project, please contact me at hesketmarg1@myvuw.ac.nz or my supervisor, Dr Kate Thornton, at the Education Faculty at Victoria University, phone 4639976 or by email, kate.thornton@vuw.ac.nz. If you have any questions about the ethical issues associated wit this research you may contact Dr Allison Kirkman, chair of the Victoria University of Wellington Human Ethics Committee by emailing allison.kirkman@vuw.ac.nz.

Finally if you are willing to be interviewed please fill in the attached consent form.

Yours sincerely

Margaret Hesketh 


\section{Appendix L}

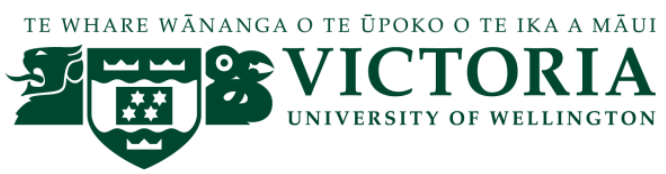

The professional development and learning of teachers with new leadership responsibilities within New Zealand primary schools

I have been given and have understood an explanation of this research project. I have had an opportunity to ask questions and have had them answered to my satisfaction. I understand that I may withdraw myself (or any information I have provided) from this project (before data collection and analysis is complete) without having to give reasons or without penalty of any sort.

- I understand that the interview will be between 30 to 40 minutes long.

- I understand that any information I provide will be kept confidential to the researcher and the supervisor; the published results will not use my name or my organisation.

- I understand that no opinions will be attributed to me in any way that will identify me.

- I also understand that I will be provided with a transcript (or summary of findings if appropriate) for checking before data analysis.

I would like to receive an electronic copy of the results of this research when it is completed.

I agree to take part in this research.

Signed:

Name of participant:

(Please print clearly)

Date:

Margaret Hesketh

hesketmarg1@myvuw.ac.nz 